\title{
A guide towards safe, functional and renewable BPA alternatives by rational molecular design: structure-property and structure-toxicity relationships $\uparrow$
}

\author{
L. Trullemans, a S.-F. Koelewijn, a I. Scodeller, ${ }^{a}$ T. Hendrickx, a \\ P. Van Puyvelde ${ }^{b}$ and B. F. Sels $\quad *^{a}$
}

Over the last few decades extensive research gave unambiguous evidence for the endocrine disrupting nature of bisphenol A (BPA), which has been an indispensable precursor in polymer chemistry since 1946. Unfortunately, current alternatives (e.g., bisphenol F and bisphenol S), are as endocrine active as BPA, emphasizing the need for a more multidisciplinary approach to design BPA alternatives, including a preliminary toxicity screening of the endocrine disrupting character in addition to performance screening. Moreover, the current topical transition towards a circular- and bio-economy stresses to adopt renewable resources to produce future chemicals and materials. To enable, inspire and stimulate the design of safer, functional and renewable BPA alternatives, this review gathered all research concerning bio-based bisphenol structures, their performance and in vitro oestrogenic activity. As a key structural feature providing high-performance polymer properties, only bio-based bisphenols with a diphenylmethane core scaffold, published in peer-reviewed papers, were included in this study. This focus revealed valuable structure-property and structure-toxicity relationships, providing the fundament for rational design of safe bisphenols.

\section{Introduction}

Bisphenol A (BPA) is a notorious but indispensable building block for the polymer industry. Its unique rigid molecular structure, characterised by a diphenylmethane (DPM) scaffold, provides good thermomechanical properties, chemical resistance and thermal stability to numerous polymers. In particular, it is the predominant precursor to synthesize high-performance polycarbonates and epoxy resins. ${ }^{1-3}$ Considering the impact of the COVID-19 pandemic, the global BPA market is estimated at 6.2 million metric tons in 2020 and expected to reach 7.1 million metric tons by $2027 .{ }^{4}$

Unfortunately, it has been shown that free monomeric BPA can leach out of consumer plastics (e.g., due to incomplete polymerization, (bio)chemical degradation and thermomechanical stress $)^{5-7}$ contaminating the environment (e.g., surface

${ }^{a}$ Dept. of Microbial and Molecular Systems $\left(M^{2} S\right)$, Centre for Sustainable Catalysis and Engineering (CSCE), KU Leuven, Celestijnenlaan 200F, 3001 Leuven, Belgium. E-mail: bert.sels@kuleuven.be

${ }^{b}$ Dept. of Chemical Engineering, Soft Matter, Rheology and Technology (SMaRT), KU Leuven, Celestijnenlaan 200F, 3001 Leuven, Belgium waters, soils, air $)^{8}$ and resulting in human exposure. ${ }^{8}$ BPA has been detected in body fluids (e.g., human blood, urine) and tissues of children and adults. ${ }^{9}$ Over the last decades, extensive research associated multiple adverse health effects to human BPA exposure ${ }^{10}$ (e.g., cancer, ${ }^{11,12}$ reproductive issues, ${ }^{13,14}$ obesity $^{15}$ ). In 2018, the European Chemicals Agency (ECHA) added BPA to the list of substances of very high concern (SVHCs), recognizing its endocrine disrupting activity and toxicity to reproduction. ${ }^{16}$ In addition, recent publications on the CLARITY-BPA study (i.e., a collaboration between the US Food and Drug Administration (FDA) and academic scientists) showed effects of BPA on a variety of health-predictive or apical endpoints at the lowest dose tested of $2.5 \mu \mathrm{g}$ per $\mathrm{kg}$ per day. ${ }^{17}$ Thereby highlighting the urgency to lower the current tolerated daily intake (TDI) by government agencies. ${ }^{18}$ This aspect, alongside the rising restrictions on BPA usage for certain applications (e.g., food packaging, baby bottles, thermal paper), emphasizes the need for safer BPA alternatives. BPA is currently being replaced by other, as endocrine active, bisphenols (i.e., BPF, BPS) ${ }^{19,20}$ so-called 'regrettable substitutions, ${ }^{21,22}$

Another challenge our society faces today is climate change. The current strategy endorsed by academic, ${ }^{23}$ governmental ${ }^{24}$ and industrial partners ${ }^{25,26}$ to lower the human footprint is 
the transition from a linear fossil-based economy to a circular bio-based economy. Herein, the use of renewable resources for sustainable, bio-based materials is key. ${ }^{23,27}$ Replacing BPA with not only a safer but also a renewable alternative that preserves its core structural feature (i.e., DPM scaffold), would therefore lead to safer high-performance bio-based materials. In this regard, Liao et al. showed for instance that via the holistic biorefining of sustainable wood, profitable, renewable and low carbon footprint chemicals can be attained. ${ }^{28}$ More particularly, through the valorisation of lignin, the largest natural source of sustainable aromatics, via biorefinery processes (e.g., reductive catalytic fractionation (RCF)) numerous phenolic monomers suitable for the synthesis of renewable bisphenols can be obtained. ${ }^{29-35}$

Hence, the quest for safe, renewable and functional BPA alternatives is truly multidisciplinary in nature. As aptly stated by Paul T. Anastas: "The knowledge of the functional performance of a molecule is a minimal requirement. However, we must also understand the potential hazards of the molecule. Ideally, we would know what properties or structures dictate the functional performance and potential hazards."36 Accordingly, this review renders a systematic overview on biobased bisphenols, their functional polymer performance (i.e., characteristic polymer properties) and their potential hazards (i.e., oestrogenic activity). Thereby, extracting valuable information on the structure-property and structure-toxicity relations to guide the rational design of non-regrettable BPA alternatives.

\section{Bio-based monomers: bio- bisphenols}

Fossil-based bisphenols are typically synthesized by reacting one mole of ketone/aldehyde with two moles of phenol in the presence a Brønsted acid catalyst. This condensation reaction consists of two consecutive electrophilic aromatic substitutions, i.e., an hydroxyalkylation/alkylation reaction. In the latter water is released to form the hallmark bisphenol structure. This rigid molecular structure is characterised by a onecarbon bridge connecting two phenyl groups, the DPM core structure. ${ }^{1,2,37}$ The favoured alkylation position [i.e., ortho- $(o-)$ or para- $(p-)]$ during the reaction determines the orientation of the carbon bridge to the hydroxyl groups, resulting in three different bisphenol regioisomers: the $p, p^{\prime}-, o, p^{\prime}-$ and $o, o^{\prime}-$ isomer (Fig. S1, ESI $\dagger$ ). In the synthesis of BPA-based polymers, only the $p, p^{\prime}$-isomer is considered as a suitable building block for polymer chemistry. Hence, a high $p, p^{\prime}$-bisphenol purity is required for the production of polycarbonates $(>99 \%)$ and epoxy resins $(>95 \%))^{2,38}$ It has been shown that the reactivity of the aldehyde influences the final isomer distribution. For instance, in the synthesis of bisphenol F (BPF) and BPA, where formaldehyde and acetone are used as carbonyl reagents respectively, the selectivity towards the $p, p^{\prime}$-isomer is shown to be higher for BPA (88-95\% $p, p^{\prime}, 5-13 \% o, p^{\prime}$ - and negligible $\left.o, o^{\prime}\right)^{39}$ than for BPF $\left(30-38 \% p, p^{\prime}, 47-49 \% o, p^{\prime}\right.$ and $19-23 \%$ $\left.o, o^{\prime}\right) .{ }^{40-42}$ Varying the carbonyl reagent not only influences the isomer distribution of the final bisphenol, but also gave rise to nowadays diverse bisphenol platform. In this review (synthetically pure) BPA, BPF and bisphenol E (BPE) were selected as reference bisphenols, characterised by a melting point (m.p.) of $158-159{ }^{\circ} \mathrm{C}, 162-164{ }^{\circ} \mathrm{C}$ and $123-127{ }^{\circ} \mathrm{C}$, respectively (Table 1, Fig. 1 and 2).

Currently, the only bisphenol that is commercially available and (partially) bio-based, is $p, p^{\prime}$-diphenolic acid, $p, p^{\prime}$-DPA (5), which is produced on large scale from levulinic acid and phenol. ${ }^{43-45}$ Through esterification with different primary alcohols (e.g., methanol, ethanol, ...), a series of $p, p^{\prime}$-DPA esters is obtained (i.e., DPA-Me (6), DPA-Et (7), DPA- $n$ Pr (8), DPA- $n$ Bu (9), DPA- $n$ Pent (10)), their molecular structures are presented in Fig. 1. The ester series has a lower m.p. compared to that of $p, p^{\prime}$-DPA $\left(168-171^{\circ} \mathrm{C}\right)$, decreasing with the alkyl chain length from $135{ }^{\circ} \mathrm{C}$ for $p, p^{\prime}$-DPA-Me (6) to $100{ }^{\circ} \mathrm{C}$ for $p, p^{\prime}$-DPA- $n \operatorname{Pr}(8)$ (Table 1, Fig. 2). ${ }^{46-49}$

During the last decade, the substitution of reagents (i.e., aldehyde, ketone and/or phenol) with bio-derivable alternatives gained research interest in the quest for a sustainable BPA alternative. This resulted in a plethora of new (partially) bio-based bisphenols (hereafter referred to as 'bio-bisphenols'). All bio-bisphenols are summarized in Fig. 1 and in Table 1. To facilitate the comparison between compounds, a new nomenclature is introduced to associate the bio-bisphenol's name with its molecular structure. Accordingly, the regioisomer orientation of the bisphenol (e.g., $\left.o, p^{\prime}, p, p^{\prime}\right)$ is followed by three capital characters. The first two are related to the phenolic structures (i.e., phenol (P), catechol (C), guaiacol (G) and syringol (S)). The character B, referring to 'bis', is used if the two phenol structures are the same. The third character refers to the carbon bridge of the bisphenols (i.e., isopropylidene (A), methylidene (F), ethylidene (E), n-propylidene (P)). The three capital characters might be followed by information about substituent(s) on the aromatic ring (e.g., -4M, indicating a methyl substituent in position 4). An exception is made for wellknown abbreviations, for instance, the commercial bio-bisphenol diphenolic acid and its derivatives (5-10).

Featuring the $p, p^{\prime}$-isomer orientation, Harvey et al. $(2016)^{50}$ presented $p, p^{\prime}$-BPF-3iP-6M (16), a bio-bisphenol synthesized by the acid-catalysed condensation of carvacrol and 1,3,5-trioxane. This bio-bisphenol was obtained as a white powder and it contains a DPM scaffold with alkyl substituents in position 3 and 6 relative to the hydroxyl group. ${ }^{50}$ More recently, Yang et al. $(2020)^{51}$ presented $p, p^{\prime}-\mathrm{BGF}_{\mathrm{UR}}$ (11), a DPM core structure with two ortho (o)-methoxy groups and a 2 -furyl substituent on the carbon bridge, obtained by a base-catalysed coupling reaction of guaiacol and furfural. $p, p^{\prime}-\mathrm{BGF}_{\mathrm{UR}}$ was obtained as a white solid with $145^{\circ} \mathrm{C}$ m.p. ${ }^{51}$ If catecholic reagents are used, a $p, p^{\prime}$-orientated bio-bisphenol with four functional hydroxyl groups is acquired. This is shown by Jiang et al. (2018), ${ }^{52}$ using 4-methylcatechol and furfural or 5-hydroxymethylfurfural (HMF) in a base-catalysed condensation reaction $p, p^{\prime}-\mathrm{BCF}_{\mathrm{UR}^{-}}$ $3 \mathrm{M}(12)$ and $p, p^{\prime}-\mathrm{BCH}_{\mathrm{MF}}-3 \mathrm{M}(\mathbf{1 3})$, respectively, were obtained as solids. $^{52}$ 


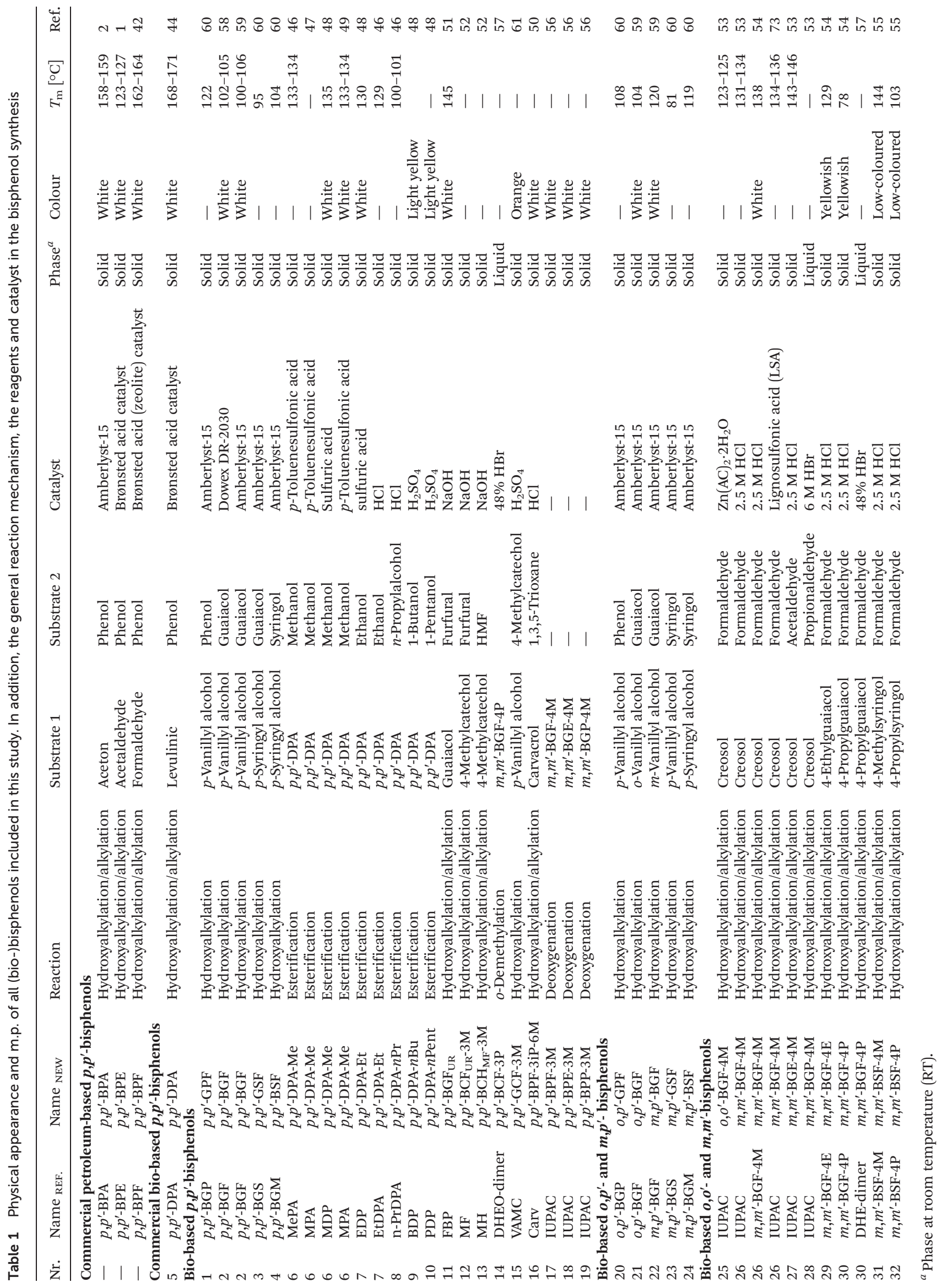



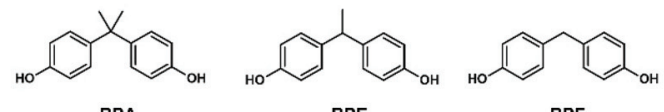

\begin{tabular}{l}
$p, p$ BPA \\
\hline$p, p$ BPE
\end{tabular}

bio-based $\rho, p^{\prime}$-bisphenols

(1)
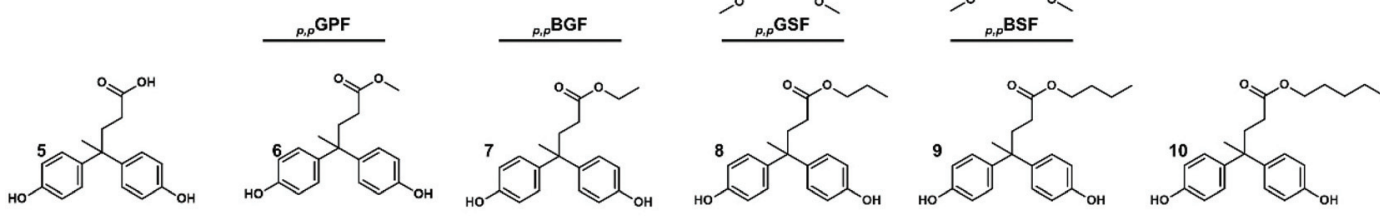

p,pDA

p,pDA-Me

p,pDA-Et

${ }_{p, p \text { DPA-nPr }}$

$\underline{p, p \text { DPA-nBu }}$
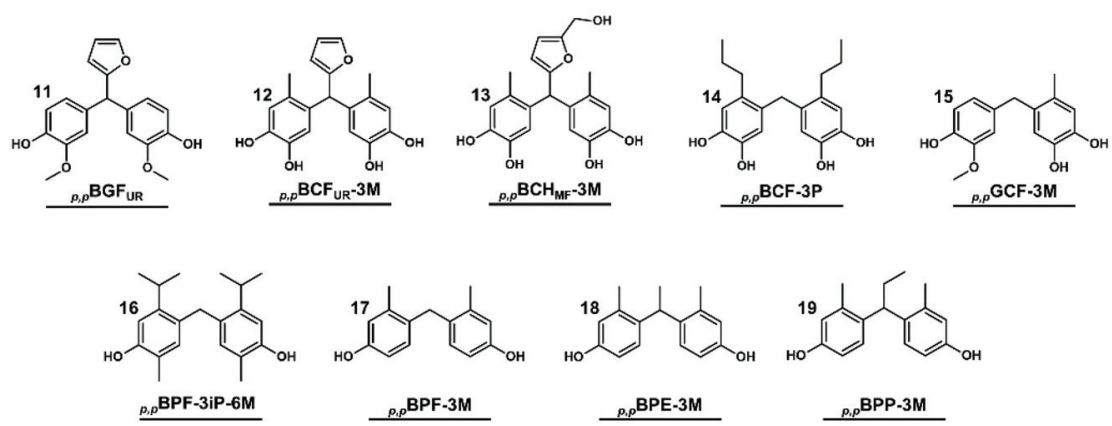

\section{bio-based o,p's and $m, p^{\prime}$-bisphenols}

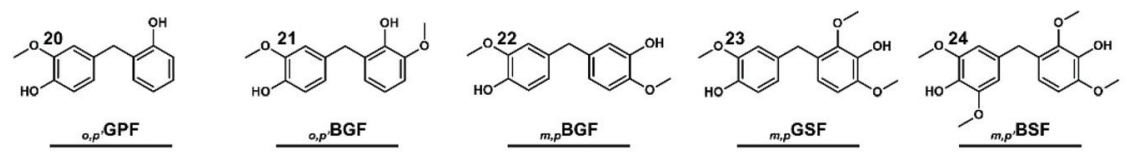

\section{bio-based $0,0^{\prime}$ - and $m, m^{\prime}$-bisphenols}
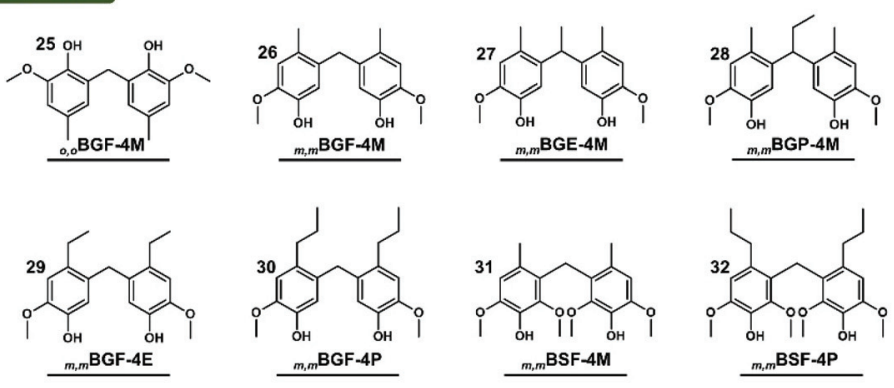

Fig. 1 Overview of all (bio-)bisphenols included in this study. Representation of reported (bio-)bisphenols, their molecular structure and corresponding abbreviation according to the suggested nomenclature (vide infra).

If para-alkylated phenols are used in the aromatic substitution reaction, alkylation in ortho- and meta-position is observed. In Brønsted acidic conditions, the meta-alkylation is favoured by the presence of mesomeric and inductive electrondonating groups (e.g., hydroxyl, methoxy) in ortho-position to the hydroxyl group. Given that bio-derived phenolic com- pounds are often characterised by the presence of $p$-alkyl groups (e.g., 4-n-propyl), o-methoxy groups (e.g., guaiacol, syringol) and $o$-hydroxyls (e.g., catechol, pyrogallol), this meta-alkylation (relative to the hydroxyl group) is a unique feature of bio-based substrates in aromatic substitution reactions. 


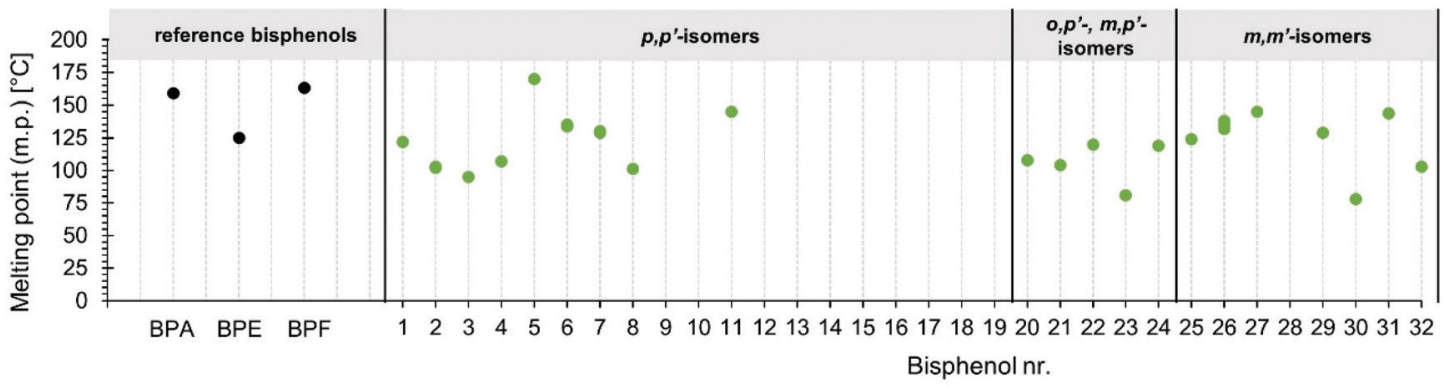

Fig. 2 Melting point $\left[{ }^{\circ} \mathrm{C}\right]$ of all (bio-)bisphenols included in this study.

In this regard, Meylemans et al. $(2012)^{53}$ synthesized $m, m^{\prime}$ and $o, o^{\prime}$-bio-bisphenols by coupling 4-methylguaiacol (i.e, creosol) with different aldehydes (i.e., formaldehyde, acetaldehyde and propionaldehyde). Using a Brønsted acid catalyst, a high selectivity towards the $m, m^{\prime}$-isomer was obtained (i.e., $>96 \% m, m^{\prime} ;<4 \% o, m^{\prime}$ ), resulting in $m, m^{\prime}$-BGF-4M (26), $m, m^{\prime}$-BGE-4M (27) and $m, m^{\prime}$-BGP-4M (28). The use of a Lewis acid catalyst $\left(\mathrm{Zn}(\mathrm{Ac})_{2} \cdot 2 \mathrm{H}_{2} \mathrm{O}\right)$ favoured the alkylation in orthoposition, yielding $o, o^{\prime}$-BGF-4M (25). The $o, o^{\prime}$-isomer of BGF-4M showed a lower m.p. than the $m, m^{\prime}$-isomer, being $123-125{ }^{\circ} \mathrm{C}$ and $131-134{ }^{\circ} \mathrm{C}$, respectively. A higher m.p. (143-146 ${ }^{\circ} \mathrm{C}$ ) was observed for $m, m^{\prime}$-BGE-4M (27), showing that a methyl substituent on the carbon bridge increases the melting point. In contrast, this trend is not shown by the bisphenol references BPF and BPE, where a methyl substituent on the carbon bridge lowers the melting point. However, further elongation of the bridging alkyl chain lowered the m.p. significantly, as $m, m^{\prime}$ BGP-4M (28) was obtained as a viscous oil.

Koelewijn et al. (2017), ${ }^{54}(2018)^{55}$ extended the $m, m^{\prime}$-bisphenol platform by coupling lignin-derived 4- $n$-propylguaiacol and 4- $n$-propylsyringol with formaldehyde under acidic conditions. Furthermore, the phenolic compounds 4-methylguaiacol, 4-ethylguaiacol and 4-methylsyringol were used to obtain a series of structurally related bio-bisphenols: $m, m^{\prime}$-BGF-4M (26), $m, m^{\prime}$-BGF-4E (29), $m, m^{\prime}$-BGF-4P (30), $m, m^{\prime}$-BSF-4M (31) and $m, m^{\prime}$-BSF-4P (32). Looking into the melting point and thermal stability of these bio-bisphenols, Koelewijn et al. showed that (i) elongation of the 4-alkyl chain decreases the melting point, m.p. $138^{\circ} \mathrm{C}>129^{\circ} \mathrm{C}>78^{\circ} \mathrm{C}$ (for 4-Me, -Et, - $n$ Pr $m, m^{\prime}$-bisguaiacols) and $144^{\circ} \mathrm{C}>103{ }^{\circ} \mathrm{C}$ (for 4-Me and $-n \operatorname{Pr} m, m^{\prime}$-bissyringols) (Fig. 2), (ii) the presence of an additional $o$-methoxy group increases the melting point with about $25^{\circ} \mathrm{C}$ and (iii) the biobisphenols show similar, or even higher for $m, m^{\prime}$-BGF-4P (30), thermal stability compared to BPA. Note that the combination of a lower melting point and similar thermal stability ( $c f$. BPA) results in a broader liquid-state processing window of these bisphenols. $^{54,55}$

As a key characteristic of BPA, the $p, p^{\prime}$-isomer orientation is still preferred in the design of a sustainable BPA alternative. Harvey et al. $(2015)^{56}$ converted $m, m^{\prime}$-BGF-4M (26), $m, m^{\prime}$ BGE-4M (27) and $m, m^{\prime}$-BGP-4M (28) to $p, p^{\prime}$-isomers by deoxygenation and hydrolysis, resulting in $p, p^{\prime}$-BPF-3M (17), $p, p^{\prime}$ -
BPE-3M (18) and $p, p^{\prime}$-BPP-3M (19). ${ }^{56}$ Another conversion of a $m, m^{\prime}$-isomer is presented by Zhao et al. (2016), ${ }^{57}$ through an $o$-demethylation of $m, m^{\prime}$-BGF-4P (30), $p, p^{\prime}$-BCF-3P (14), a compound containing four hydroxyl groups, was obtained. ${ }^{57}$

A more (carbon-)efficient way to synthesize $p, p^{\prime}$-bio-bisphenols was presented by Hernandez et al. (2016). ${ }^{58}$ Through the use of a phenolic compound featuring an intrinsic reactivity towards alkylation in para-position (i.e., p-vanillyl alcohol), a 'short-cut' reaction mechanism with only one alkylation step is attained, resulting in a higher selectivity towards the $p, p^{\prime}$ isomer. When $p$-vanillyl alcohol was coupled with guaiacol in the presence of a heterogeneous ion-exchanging catalyst (i.e., Amberlyst-15), only three different regioisomers of BGF were obtained: the $p, p^{\prime}-(\mathbf{2}), m, p^{\prime}-(\mathbf{2 2})$ and $o, p^{\prime}$-isomer (21), with an isomer distribution of $82 \%, 15 \%$ and $3 \%$, respectively. To investigate the physical appearance and properties of the $m, p^{\prime}-$ and $o, p^{\prime}$-isomer, Koelewijn et al. (2019) ${ }^{59}$ selectively synthesized these isomers using vanillyl alcohol isomers (e.g., $m$ and $o$-vanillyl alcohol), thereby shifting the isomer distribution. Interestingly, the $m, p^{\prime}$-isomer showed a significantly higher melting point $\left(119-120{ }^{\circ} \mathrm{C}\right)$ than the $p, p^{\prime}-\left(99-100{ }^{\circ} \mathrm{C}\right)$ and $o, p^{\prime}$-isomer $\left(103-105^{\circ} \mathrm{C}\right)$.

Nicastro et al. $(2018)^{60}$ extended the substrate scope for this short-cut reaction using other phenolic compounds, like phenol and syringol. Because of the substrates varying amount of $o$-methoxy group(s), bisphenols with different isomer orientations and distributions were obtained. For example, coupling of $p$-vanillyl alcohol with phenol yielded $81 \%$ of $p, p^{\prime}$-GPF (1) and $19 \% o, p^{\prime}$-GPF (20), whereas coupling with syringol gave $79 \%$ of $m, p^{\prime}$-GSF (23) $21 \%$ of $p, p^{\prime}$-GSF (3). Hence, the presence of a second $o$-methoxy group in syringol, compared to guaiacol, promoted the alkylation in meta to the hydroxyl group. In addition, $p$-syringyl alcohol was coupled with syringol to obtain $76 \%$ of $m, p^{\prime}$-BSF (24) and $24 \%$ of $p, p^{\prime}$-BSF (4). After isolation, the melting points of all bio-bisphenols were determined. Despite a variation in m.p. ranging from $81^{\circ} \mathrm{C}$ to $122^{\circ} \mathrm{C}$, there is no clear correlation between the melting point and isomer orientation or amount of $o$-methoxy groups of the bio-bisphenols. ${ }^{60}$

In 2019, Zhao et al. ${ }^{61}$ reported the synthesis of a bio-bisphenol characterised by three hydroxyl groups. Coupling $p$-vanillyl alcohol with 4-methylcatechol in the presence of an acid catalyst, $p, p^{\prime}$-GCF-3M (15) was obtained as an orange solid. ${ }^{61}$ 
The current bio-bisphenol platform counts, to the best of our knowledge, 32 bio-bisphenols, from which 22 were directly derived from phenolic lignin monomers (e.g, 4-methylcatechol, guaiacol, syringol) and 4 were indirectly obtained from some of the previous ones (e.g., deoxygenation, demethylation). The use of lignin-derived phenols brought out new bisphenol isomer orientations (i.e., $m, p^{\prime}$ and $m, m^{\prime}$ ) in addition to the conventional isomer orientations (i.e., $o, o^{\prime}, o, p^{\prime}$ and $p, p^{\prime}$ ). Moreover, sugar-derived aldehydes and ketones (e.g., furfural, HMF, levulinic acid) proved to be efficient coupling agents, introducing interesting functional groups on the bisphenol carbon bridge. Except for $p, p^{\prime}$-BCF-3P (14) and $m, m^{\prime}$-BGP-4M (28), all bio-bisphenols were obtained as solids with m.p. ranging from $78^{\circ} \mathrm{C}$ for $m, m^{\prime}$-BGF-4P (30) to $171^{\circ} \mathrm{C}$ for $p, p^{\prime}$-DPA (5) and colours varying from white to light yellow and orange.

\section{Bio-based polymers: structure- property}

As previously mentioned, BPA is used for the synthesis of numerous polymers, including thermoplastic (e.g., polycarbonates, polyesters) and thermosetting (e.g., epoxy resins, cyanate ester resins and benzoxazine resins) polymers. The polycarbonate and epoxy resins industry are the main sales markets for BPA, demanding $66 \%$ and $30 \%$ of the global production capacity, respectively. ${ }^{2}$ In addition, BPA is an important precursor for more specialized high-performance thermosets, like cyanate ester and benzoxazine resins. Depending on the author's interest, different polymers were synthesized from the presented bio-bisphenols (Fig. 1), an underlined number (e.g., (1)) is used to refer to the polymer or resin from the corresponding bio-bisphenol (e.g., (1)). Hence, the following section is subdivided in five polymer sections: polycarbonates, polyesters, epoxy resins, cyanate ester resins and benzoxazine resins, to reveal valuable structure-property relations.

The two polymer properties, that are discussed for all polymers, are (i) the thermal stability and (ii) the glass transition temperature $\left(T_{\mathrm{g}}\right)$. In general, thermogravimetric analysis (TGA) is used to assess the polymer's thermal stability. Unless stated otherwise, the experiment was performed under a nitrogen atmosphere. The thermal stability is defined by several parameters being (i) the onset degradation temperature $\left(T_{\mathrm{d} 5 \%}\right)$, (ii) the $10 \%$ weight loss temperature $\left(T_{\mathrm{d} 10 \%}\right)$, (iii) the $50 \%$ weight loss temperature $\left(T_{\mathrm{d} 50 \%}\right)$, (iv) the maximal degradation temperature $\left(T_{\max }\right)$, and $(v)$ the char yield at a specified temperature (e.g., $600{ }^{\circ} \mathrm{C}, 800{ }^{\circ} \mathrm{C}$ ). In what follows, mostly, $T_{\mathrm{d} 5 \%}$ and $T_{\max }$ will be used to discuss the polymer thermal stability, if $T_{\max }$ is not given, $T_{\mathrm{d} 50 \%}$ is given instead. The glass transition temperature $\left(T_{\mathrm{g}}\right)$ is determined using differential scanning calorimetry (DSC) for the thermoplastic polymers, and through dynamic mechanical analysis (DMA) for the thermosetting polymers. Although different parameters are used in literature to define $T_{\mathrm{g}}$ in a DMA experiment, the $T_{\mathrm{g}}$ reported in the following is, unless stated otherwise, the temperature where $\tan (\delta)$ reaches a maximum (i.e., $\max \tan (\delta)$ ).
In addition to the general thermomechanical properties, more specific polymer properties characterising each polymer type will be introduced and discussed, including for the thermoplastic polymers: the amorphous/crystalline phase and the solubility, and for the thermosetting polymers: the melting point of the uncured resins, the cure kinetics, processing window and more specifically water uptake and the LOI index (i.e., an index parameter of the flame resistance, that should be higher than $26^{62}$ ).

\subsection{Polycarbonates}

Since 1957, an interfacial polymerization reaction of BPA and phosgene (i.e., the phosgene process $)^{63}$ is used to produce polycarbonates (PCs) on a large scale (Fig. S2a, ESI $\dagger$ ). ${ }^{46}$ Today BPA is still the leading precursor for the polycarbonate (PC) synthesis. The rigid molecular structure of BPA provides a PC with unique physical and chemical properties. ${ }^{64,65}$ BPA-Polycarbonate (BPA-PC) is a resilient polymer from which objects with high toughness and impact strength can be manufactured. Induced by its amorphous nature, BPA.PC shows excellent transparency, making it suitable for glass applications. Furthermore, BPA.PC is characterised by a high glass transition temperature $\left(T_{\mathrm{g}}\right)$ of $145{ }^{\circ} \mathrm{C}$ abiding high process temperatures, for instance, steam sterilization. However, it has been reported that long-term effects of hot water and steam might cause stress cracks and BPA leachates. ${ }^{66-68}$ Lastly, commercial BPA.PC show a high thermal stability, with $T_{\mathrm{d} 5 \%}$ above $445{ }^{\circ} \mathrm{C}$, a $T_{\max }$ and $T_{\mathrm{d} 50 \%}$ above $500{ }^{\circ} \mathrm{C}$ and char yield $>25 \%$ at $600{ }^{\circ} \mathrm{C}$. This indicates an intrinsic flame retardant behaviour, through its ability to form polyaromatic char. ${ }^{64,65}$

The development of a bio-based BPA.PC alternative reaching the same excellent polymer properties is challenging. To evaluate the performance of today's bio-bisphenol alternatives in PCs, three characteristic properties were selected: (i) the amorphous nature (i.e. inducing optical transparency ${ }^{69}$ ), (ii) the glass transition temperature $\left(T_{\mathrm{g}}\right)$ and (iii) the thermal stability. Noteworthy, it has been shown that the mass-average molecular weight $\left(\bar{M}_{w}\right)$ and dispersity $(\nexists)$ influence $T_{\mathrm{g}}$ and thermal stability of PCs. In general, a higher $\bar{M}_{w}$ (same $\boxplus$ ), results in a higher $T_{\mathrm{g}}{ }^{70}$ and thermal stability. ${ }^{71}$ Hence, parameters such as $\bar{M}_{w}$ and $Ð$ should be considered when comparing the different polymer properties. The bio-bisphenols used in PC chemistry and their mutual structural relations are shown in Fig. 3. All collected data concerning the PCs and their polymer properties are summarized in Table 2 and Fig. 4.

In 2019, Koelewijn et al. ${ }^{59}$ determined the influence of the lignin-characterising $o$-methoxy groups on the PC synthesis and final polymer properties, comparing the PCs synthesized from $p, p^{\prime}$-BGF (2) and $p, p^{\prime}-\mathrm{BPF}{ }^{59} \mathrm{~A}$ first observation concerns the solubility of the monomers and their corresponding PCs. Compared to $p, p^{\prime}$-BPF, $p, p^{\prime}$-BGF (2) was found to be more soluble in dichloromethane (DCM), the solvent of choice for the interfacial polymerization reaction of $\mathrm{PC}$, resulting in a higher polymer yield for the bio-based PC. In contrast to the quasi-insoluble $p, p^{\prime}$-BPF-PC, the final $p, p^{\prime}$-BGF-PC (2) was found moderately soluble in DCM. The presence of the 

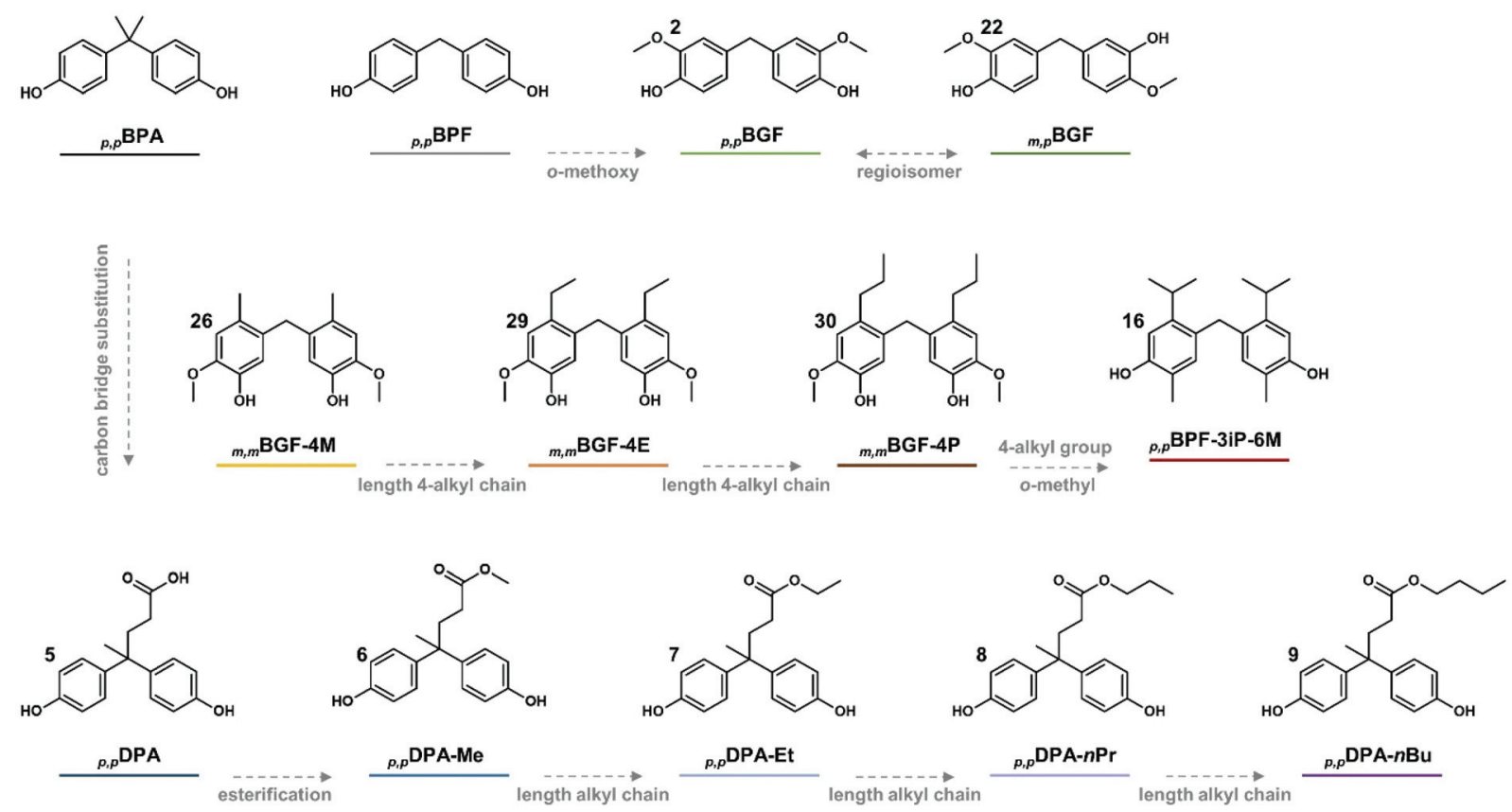

Fig. 3 Bio-bisphenols used for the synthesis of polycarbonates. The representation of all so far reported bio-bisphenols, in addition to the petroleum-based references, used for the synthesis of (partially) bio-based polycarbonates and their structural relations.

$o$-methoxy groups lowered $T_{\mathrm{g}}$ of the PCs by $8{ }^{\circ} \mathrm{C}$, from $114{ }^{\circ} \mathrm{C}$ for $p, p^{\prime}$-BPF.PC to $106{ }^{\circ} \mathrm{C}$ for $p, p^{\prime}$-BGF.PC (2). The authors attributed this decrease in $T_{\mathrm{g}}$ to the loss of segmental symmetry in the mono-substituted phenyl ring (i.e., guaiacol), resulting in a less efficient packing, thus, more free volume..$^{59,72}$ Accordingly, restoring the segmental symmetry by the introduction of a second aromatic substituent might increase $T_{\mathrm{g}}{ }^{72}$ emphasizing the potential of bio-bisphenols derived of di-substituted phenols (e.g., syringol). Moreover, the presence of the $o$-methoxy groups decreased the PC's thermal stability, showing a $29^{\circ} \mathrm{C}$ lower maximal degradation temperature $\left(T_{\max }\right)$ and $15 \%$ lower char yield at $600{ }^{\circ} \mathrm{C}$ (Table 2, Fig. 4). ${ }^{59}$

Looking into the functionality of the $m, p^{\prime}$-isomer, Koelewijn et al. $(2019)^{59}$ showed that (i) the reactivity of the $m, p^{\prime}$-isomer of BGF (22) was similar to $p, p^{\prime}$-BGF (2) in the PC synthesis and (ii) the polymer properties (i.e., amorphous phase, $T_{\mathrm{g}}$ and thermals stability) of $m, p^{\prime}$-BGF.PC (22) and $p, p^{\prime}$-BGF.PC (2) were similar (Table 2, Fig. 4). ${ }^{59}$

Comparing the fossil-based $p, p^{\prime}$-BPA.PC and $p, p^{\prime}$-BPF.PC, the influence of the carbon bridge substituent, methylidene bridge $v s$. isopropylidene bridge, could be determined showing a decrease in thermal stability $\left(T_{\max }\right.$ and $T_{\mathrm{g}}$ by $27^{\circ} \mathrm{C}$ and $20{ }^{\circ} \mathrm{C}$, respectively, for $p, p^{\prime}$-BPF.PC (Table 2). ${ }^{59}$ This decrease in $T_{\mathrm{g}}$ is related to the higher level of rational freedom of the methylidene bridged bisphenol. Accordingly, it is known that the (steric) isopropylidene bridge impart rigidity to the polymer chains, restricting the level of rotational freedom..$^{59,72}$

To evaluate the functionality of $m, m^{\prime}$-isomers, Chen et al. $(2015)^{73}$ synthesized $m, m^{\prime}$-BGF-4M·PC (26). Reaching a high molecular weight and polymer yield, a PC with poor solubility in common organic solvents was obtained. Compared to BPA.PC with similar $\bar{M}_{w}$ this PC showed a $26^{\circ} \mathrm{C}$ lower, but still remarkably high, $T_{\mathrm{g}}$ of $122^{\circ} \mathrm{C}$ and good thermal stability with $T_{\mathrm{d} 5 \%}$ of $382{ }^{\circ} \mathrm{C}$ and $T_{\max }$ of $420{ }^{\circ} \mathrm{C}$ (Table 2). Unfortunately, this polymer was obtained as a white crystalline polymer, lacking the desired PC transparency, with m.p. of $314{ }^{\circ} \mathrm{C} .{ }^{73}$ To combat the tendency for crystallisation Koelewijn et al. $(2017)^{54}$ synthesized PCs of $m, m^{\prime}$-BGF molecular structures with longer 4-n-alkyl chains, viz. $m, m^{\prime}$-BGF-4E·PC (29) and $m, m^{\prime}$-BGF-4P.PC (30). Using GPC/SEC to analyse $\bar{M}_{w}$ and $D$, bimodal curves were observed for all PCs. Since $p, p^{\prime}$-BPA.PC didn't display a shoulder under identical polymerisation conditions, this effect was attributed to macro-cyclization and associated to the $m, m^{\prime}$-isomer orientation. ${ }^{55}$ Even though white crystalline polymers were obtained, they observed a higher amorphous character, lower $T_{\mathrm{m}}$ (determined by X-ray diffraction and DSC, respectively), lower $T_{\mathrm{g}}$ and higher solubility in $\mathrm{CHCl}_{3}$, DCM and THF upon elongating the 4- $n$-alkyl chain (Table 2, Fig. 4). In conclusion, a 4-n-propyl chain substituent (i) lowers the tendency to crystallise, and (ii) improves the solubility in common solvents, facilitating downstream processing. ${ }^{54}$

Another interesting PC was synthesized by Harvey et al. $(2016)^{50}$ using $p, p^{\prime}$-BPF-3iP-6M (16) as a precursor. This amorphous PC showed a high $T_{\mathrm{g}}$ of $119^{\circ} \mathrm{C}$ and thermal stability close to the commercial BPA.PC references, with $T_{\mathrm{d} 5 \%}$ of $421{ }^{\circ} \mathrm{C}, T_{\mathrm{d} 50 \%}$ of $490{ }^{\circ} \mathrm{C}$ and char yield of $21 \%$ at $600{ }^{\circ} \mathrm{C}$ (Table 2, Fig. 4). ${ }^{50}$

The use of $p, p^{\prime}$-DPA (5) as PC precursor introduces a free acid functionality in the polymer chain. This resulted in a PC 


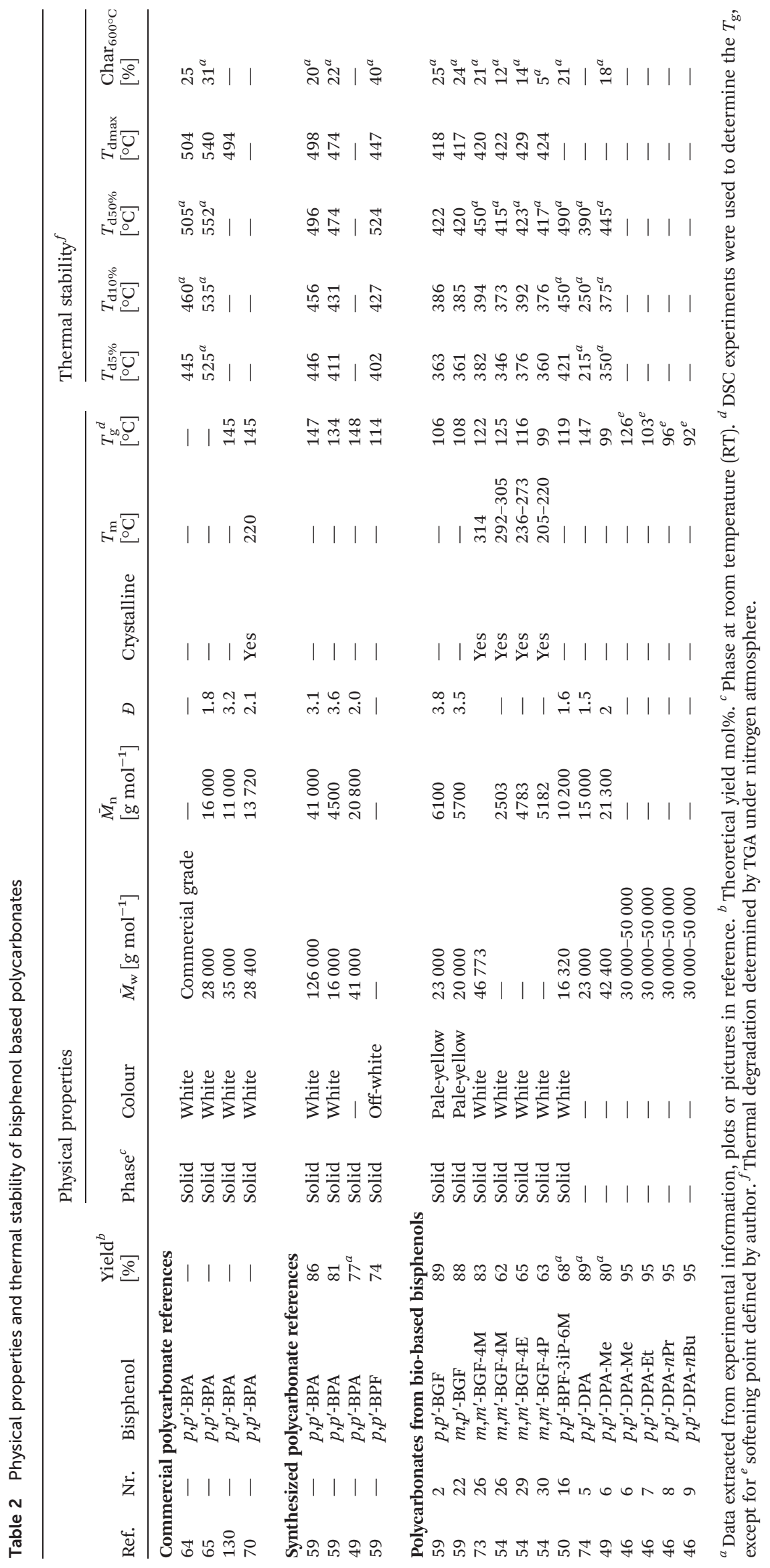



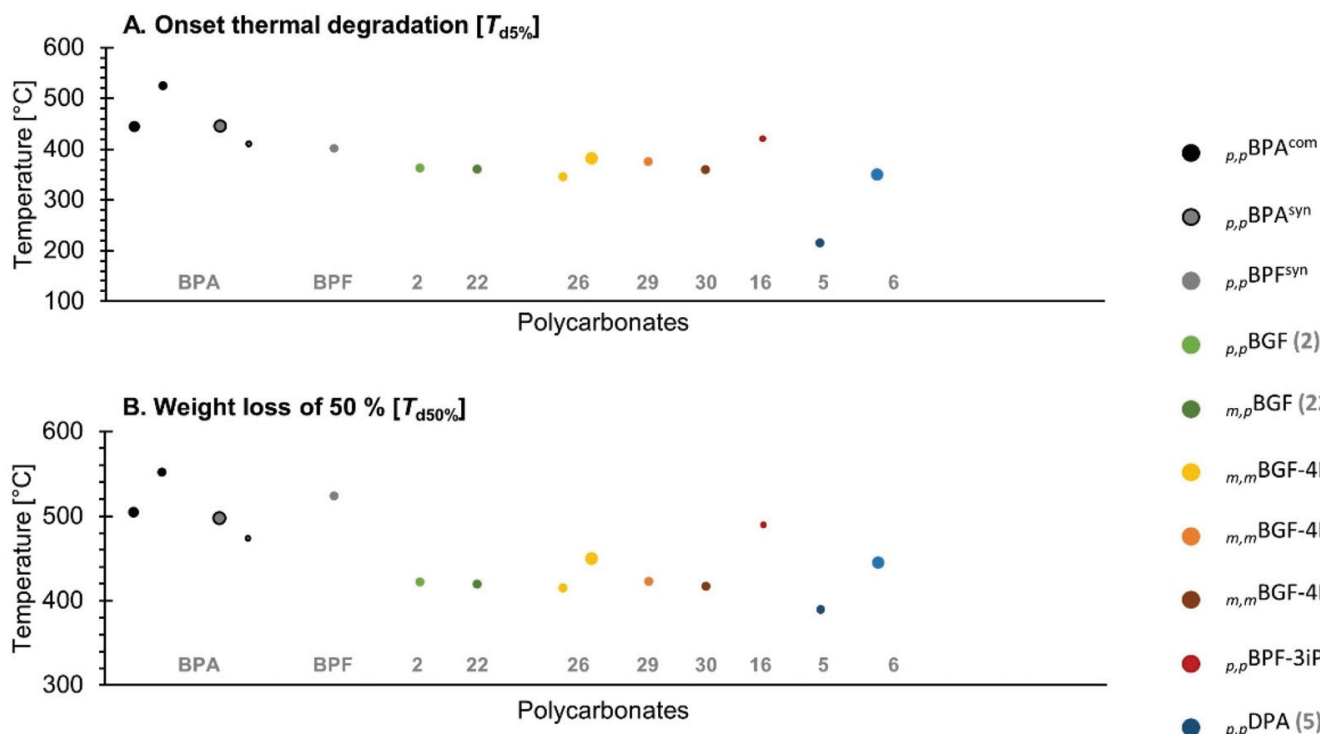

- $m, p$ BGF (22)

- $m, m$ BGF-4M (26)

- ${ }_{m, m}$ BGF-4E (29)

- ${ }_{m, m} \mathrm{BGF}-4 \mathrm{P}(30)$

- ${ }_{p, p} \mathrm{BPF}-3 \mathrm{P}$ - $6 \mathrm{M}$ (16)

- $p, p \mathrm{DPA}(5)$

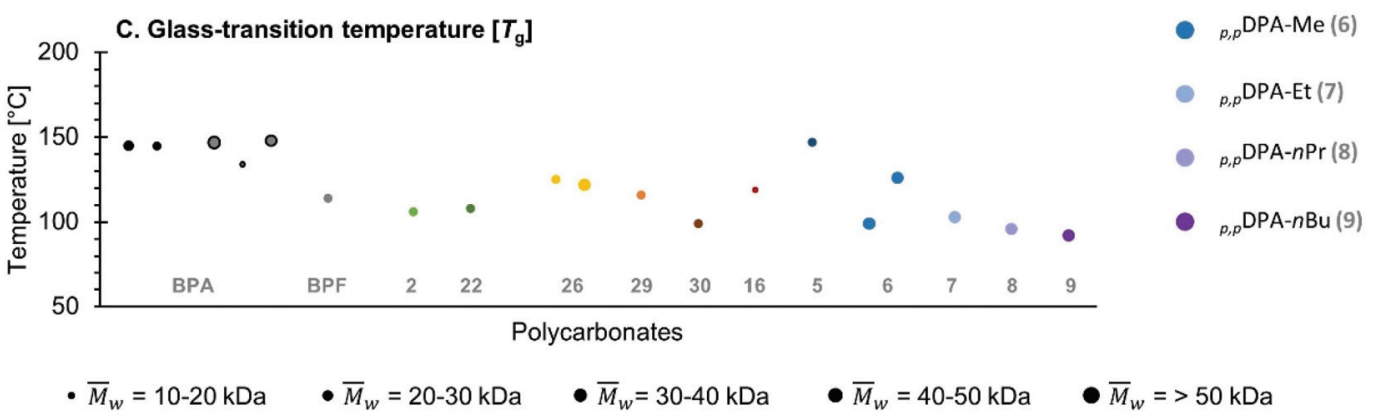

Fig. 4 Polymer properties of the bio-based and reference polycarbonates. Representation of (A) the onset thermal degradation temperature, $5 \%$ weight loss temperature ( $\left.T_{\mathrm{d} 5 \%}\right)$ under nitrogen atmosphere (B) the temperature of 50\% weight loss or $T_{\mathrm{d} 50 \%}$ under nitrogen atmosphere and (C) the glass transition temperature $\left(T_{\mathrm{g}}\right)$ of the polycarbonates. The area of the datapoints in the bubble charts are associated to the polymers average $\bar{M}_{w}$ as indicated in the legend underneath.

with (i) high $T_{\mathrm{g}}$ of $147{ }^{\circ} \mathrm{C}$, induced by hydrogen bonding retarding the local chain motion, but (ii) a relatively low thermal stability, with $T_{\mathrm{d} 5 \%}$ of $215{ }^{\circ} \mathrm{C}$ and $T_{\mathrm{d} 50 \%}$ of $390{ }^{\circ} \mathrm{C}$ being, respectively, $310^{\circ} \mathrm{C}$ and $162{ }^{\circ} \mathrm{C}$ lower than commercial BPA.PC with similar $\bar{M}_{w}$ and $\doteq$ (Table 2). ${ }^{74}$ To enhance compatibility with plasticizers, increase the solubility of the PC and lower $T_{\mathrm{g}}$, alkyl esters were synthesized from $p, p^{\prime}$-DPA (6-9) and used for PC synthesis. Fischer et al. $(1966)^{46}$ showed that (i) all DPA-ester PCs were more soluble in organic solvents compared to BPA.PC, and (ii) a decreasing softening point $\left(\approx T_{\mathrm{g}}\right)$ with increasing alkyl ester (Fig. 4). ${ }^{46}$ In addition Moore and Tannahill $(2001)^{49}$ examined the thermal stability of a $p, p^{\prime}$ DPA-Me.PC (6), reporting $T_{\mathrm{d} 5 \%}$ of $350{ }^{\circ} \mathrm{C}$ and $T_{\mathrm{d} 50 \%}$ of $445{ }^{\circ} \mathrm{C}$. This PC showed a significantly higher thermal stability than $p, p^{\prime}$-DPA-PC (5), hence, the thermal stability increased by esterification of the carboxyl group in $p, p^{\prime}$-DPA.PC (5). ${ }^{49}$

Up to $90 \%$ of all PCs are produced today by the phosgene process. Unfortunately, this process has some major drawbacks: (i) the high toxicity of phosgene, (ii) the use of large amounts of chlorinated, volatile solvents (i.e., DCM) and (iii) the large quantity of (waste) water. ${ }^{63}$ Therefore it is worth men- tioning that Fukuoka et al. $(2003)^{75}$ presented a more environmental friendly non-phosgene process to produce PC: the Asahi Kasei process. This new technology uses ethylene oxide, $\mathrm{CO}_{2}$ and BPA to yield BPA.PC and monoethyleneglycol. ${ }^{75}$

In general, all PCs were found to be amorphous except for the PCs synthesized from the $m, m^{\prime}$-isomers. However, it was shown that introduction of 4-alkyl chains in these $m, m^{\prime}$-biobisphenols lowered the polymer crystallinity. The $p, p^{\prime}$-DPA.PC (5) could reach $T_{\mathrm{g}}$ similar to that of $p, p^{\prime}$-BPA.PC. This high $T_{\mathrm{g}}$ was induced by hydrogen bonding of the free acid functional groups, limiting the polymer chain's rotational freedom. Furthermore, it was shown that (i) the presence of $o$-methoxy moieties lowers $T_{\mathrm{g}}$ moderately about $8{ }^{\circ} \mathrm{C}$, (ii) the use of $m, p^{\prime}$ isomers does not impact PC's $T_{g}$, and (iii) the substitution of the isopropylidene bridge with a methylidene bridge lowers $T_{\mathrm{g}}$ about $20^{\circ} \mathrm{C}$. The latter shows the beneficial impact of steric substituents on the carbon bridge which impart rigidity to the polymer chains, restricting the level of rotational freedom. Like for $T_{\mathrm{g}}$, the thermal stability lowered (i) in the presence of $o$-methoxy groups and (ii) by substitution of the isopropylidene bridge with a methylidene bridge. The thermal stability of the 
bio-based PCs was the lowest for $p, p^{\prime}$-DPA-PC (5) with $T_{\mathrm{d} 5 \%}$ of $215{ }^{\circ} \mathrm{C}$ and $T_{\mathrm{d} 50 \%}$ of $390{ }^{\circ} \mathrm{C}$ and the highest for $p, p^{\prime}-$ BPF-3iP-6M.PC (16) with $T_{\mathrm{d} 5 \%}$ of $421{ }^{\circ} \mathrm{C}$ and $T_{\mathrm{d} 50 \%}$ of $490{ }^{\circ} \mathrm{C}$.

Even though the current bio-based PCs do not show $T_{\mathrm{g}}$ and thermal stability as high as the BPA.PC references, the PCs show excellent thermomechanical properties suitable for diverse polymer applications. Hence, it is strongly believed that by adopting and expanding the presented structure-property relationships, future molecular bisphenol designs might lead to bio-based PCs reaching or even surpassing the performance of current BPA-based PCs.

\subsection{Polyesters}

Since 1979, BPA-based polyesters were commercially produced using an interfacial polymerization reaction of BPA and the acid chloride of terephtalic and/or isophtalic acid, being terephthaloyl chloride (TPC) and isophthaloyl chloride (IPC), respectively (Fig. S2b, ESI†). Because of their fully aromatic nature, these polyesters are called polyarylates (PARs). ${ }^{76,77}$ The incorporation of aromatic groups into the polymer chain results in polyesters with (i) high heat resistance, (ii) hydrophobicity (i.e., resistance to hydrolysis ${ }^{66}$ ), and (iii) high glass transition temperatures $\left(T_{\mathrm{g}}\right.$ 's), suitable for high-performance applications and widely used as engineering plastics. However, the extremely elevated $T_{\mathrm{g}}$ 's, high melting viscosity and poor solubility hamper polymer processing. ${ }^{78-80}$ Another characteristic of PARs is the polymer gas permeability and selectivity; this is mostly discussed in older research papers concerning PARs. ${ }^{81,82}$

To assess the polymer properties of the bio-based PARs, two characteristic parameters were selected to be discussed: (i) the glass transition temperature $\left(T_{\mathrm{g}}\right)$, and (ii) the thermal stability. Similar to the PCs, the mass-average molecular weight $\left(\bar{M}_{w}\right)$ and dispersity $(\boxplus)$ impact PARs polymer properties, unfortunately these parameters were not always provided by the authors (Table 3). Besides, it should be mentioned that the molecular structure of the carboxylic acid influences polymer properties. It has been shown that the polymer solubility decreased but the polymer rigidity, and so $T_{\mathrm{g}}$, increased using TPC instead of IPC. ${ }^{81}$ Accordingly, $T_{\mathrm{g}}$ of a PAR from BPA and TPC, $p, p^{\prime}$-BPA.PAR ${ }_{\mathrm{TPC}}$, ranges from $190{ }^{\circ} \mathrm{C}$ to $230{ }^{\circ} \mathrm{C},{ }^{55,76,81-83}$ whereas for a PAR from BPA and IPC, $p, p^{\prime}$-BPA.PAR ${ }_{\mathrm{IPC}}, T_{\mathrm{g}}$ of $180{ }^{\circ} \mathrm{C}$ is reported. ${ }^{81,82}$ In addition, both PARs show similar thermal stability, with $T_{\mathrm{d} 5 \%}$ above $450{ }^{\circ} \mathrm{C}, T_{\mathrm{d} 50 \%}$ above $500{ }^{\circ} \mathrm{C}$ and char yield at $600{ }^{\circ} \mathrm{C}$ of $30 \%$. Moreover, Korshak et al. $(1965)^{84}$ reported a similar thermal stability and softening point $\left(\approx T_{\mathrm{g}}\right.$ ) for $p, p^{\prime}$-BPA and $p, p^{\prime}$-BPF based PARs. ${ }^{84}$ The biobisphenols used for the syntheses of PARs and their mutual structural relations are shown in Fig. 5. All collected data concerning the polyesters and their polymer properties are summarized in Table 3 and Fig. 6.

Curia et al. $(2018)^{78}$ used a mixture of BGF regioisomers (221-22) and TPC to synthesize a (partially) bio-based PAR, mix'BGF.PAR ${ }_{\text {TPC }}$. The PAR of mix'-BGF showed high molecular weight, high $T_{\mathrm{g}}$ of $164{ }^{\circ} \mathrm{C}$ and good thermal stability with $T_{\mathrm{d} 5 \%}$ of $387{ }^{\circ} \mathrm{C}$ and $T_{\mathrm{d} 50 \%}$ of $500{ }^{\circ} \mathrm{C}$. Although lower than $p, p^{\prime}-$

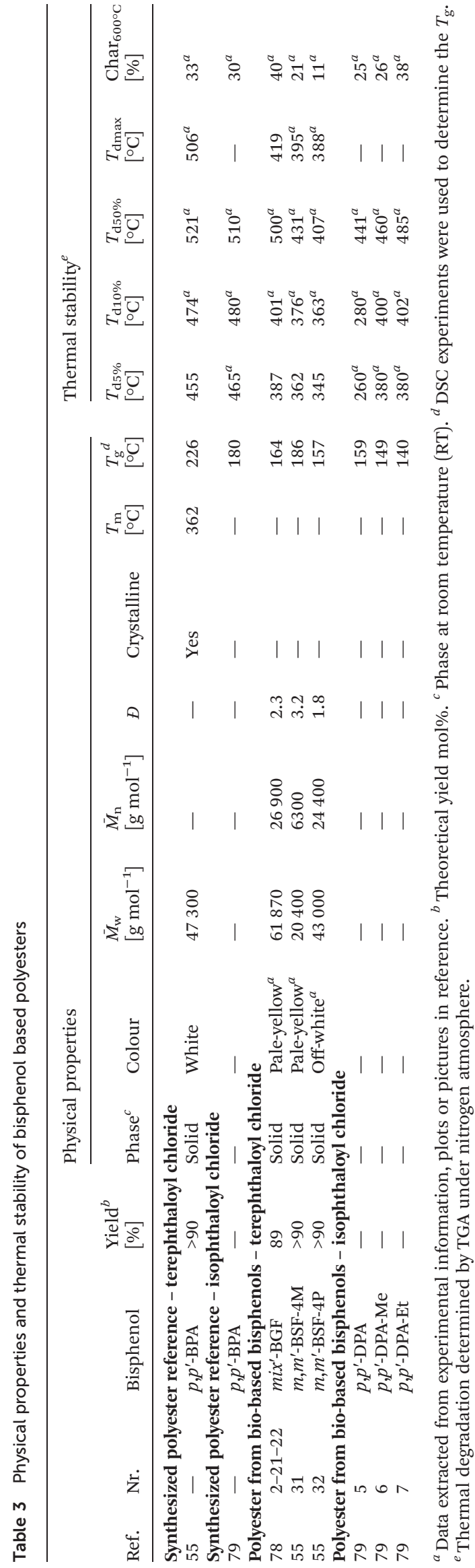




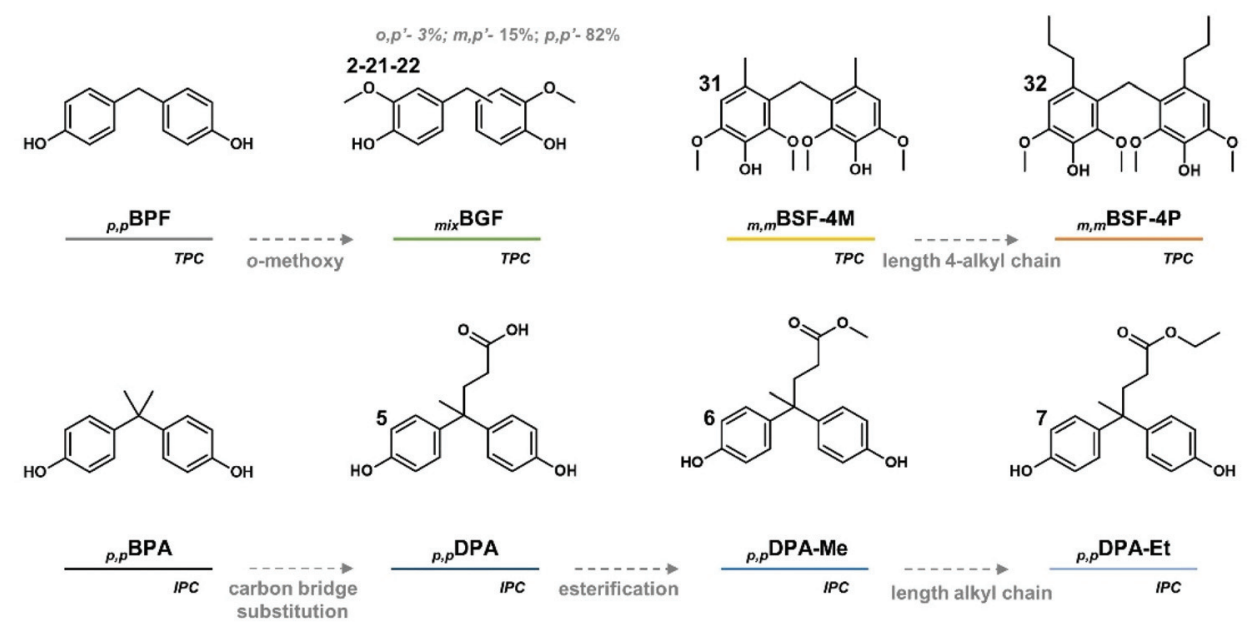

Fig. 5 Bio-bisphenols used for the synthesis of polyesters. The representation of so far reported bio-bisphenols, in addition to the petroleumbased references, used for the synthesis of (partially) bio-based polyesters using terephthaloyl chloride (TPC) and partially bio-based polyesters using isophthaloyl chloride (IPC) and their structural relations.
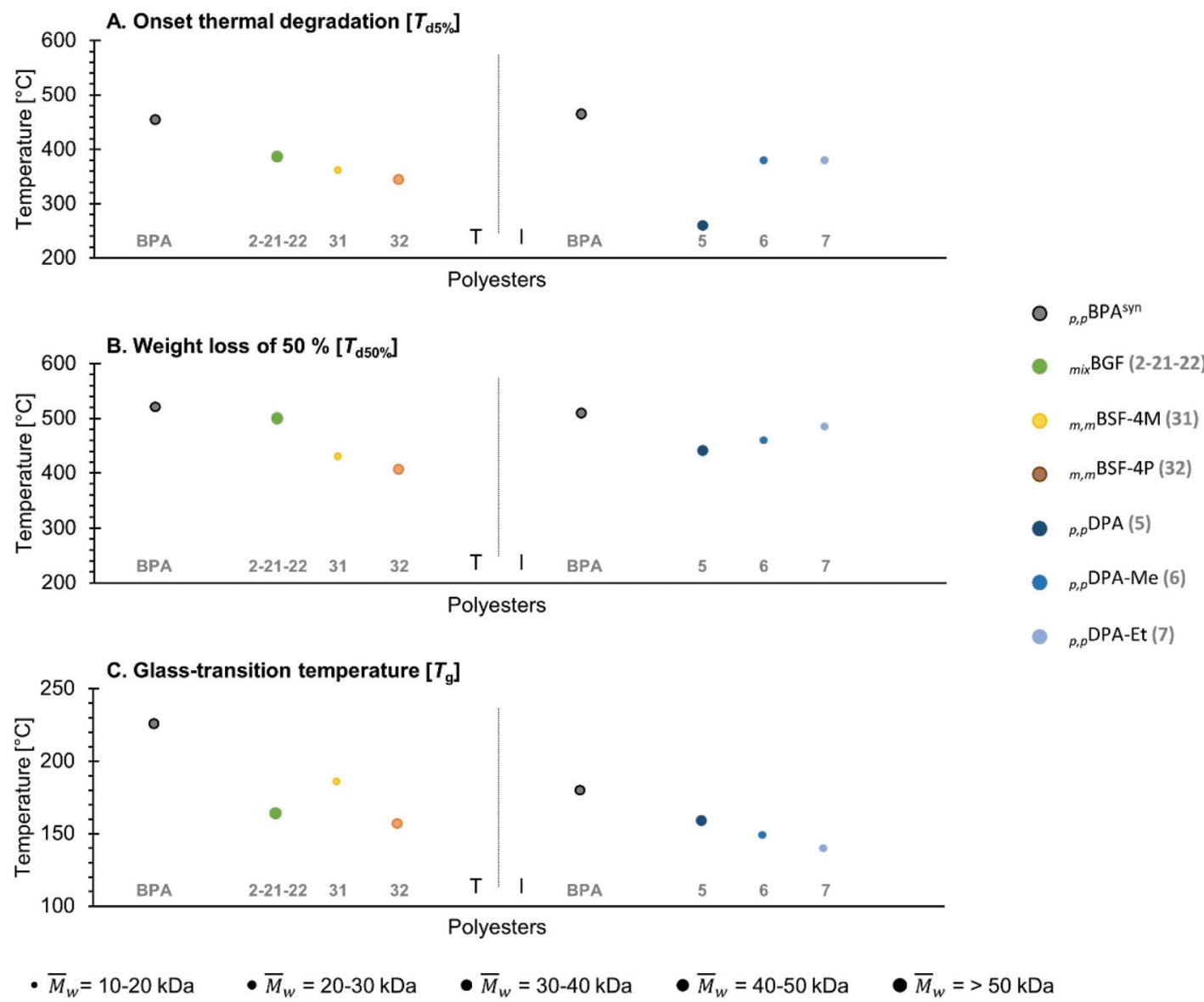

Fig. 6 Polymer properties of the bio-based and reference polyesters. Representation of $(\mathrm{A})$ the onset thermal degradation temperature, $5 \%$ weight loss temperature $\left(T_{\mathrm{d} 5 \%}\right)$ under nitrogen atmosphere (B) the temperature of $50 \%$ weight loss or $T_{\mathrm{d} 50 \%}$ under nitrogen atmosphere and (C) the glass transition temperature $\left(T_{\mathrm{g}}\right)$ of the polyesters. The area of the data points in the bubble charts are associated to the polymers average $\bar{M}_{w}$ as indicated in the legend below the set of graphics. Left: TPC-based polyesters; Right: IPC-based polyesters. 
$\mathrm{BPA} \cdot \mathrm{PAR}_{\mathrm{TPC}}$ and $p, p^{\prime}$-BPF$\cdot \mathrm{PAR}_{\mathrm{TPC}}$, these are excellent polymer properties suitable for high-performance applications. ${ }^{78}$ Koelewijn et al. $(2018)^{55}$ synthesized PARs from $m, m^{\prime}$-bissyringols: $m, m^{\prime}$-BSF-4M (31) and $m, m^{\prime}$-BSF-4P (32) using TPC. Similar to the polycarbonates of $m, m^{\prime}$-isomers, the $m, m^{\prime}$ BSF-4M-PAR ${ }_{\mathrm{TPC}}(\underline{31})$ and $m, m^{\prime}$-BSF-4P-PAR ${ }_{\mathrm{TPC}}(32)$ showed high $\bar{M}_{w}$, but also a bimodal $\bar{M}_{w}$ distribution indicating the presence of macrocycle polymer chains. However, amorphous PARs with high $T_{\mathrm{g}}$ (157-186 $\left.{ }^{\circ} \mathrm{C}\right)$, and good thermal stability, with $T_{\mathrm{d} 5 \%} \geq 345{ }^{\circ} \mathrm{C}$ and $T_{\mathrm{d} 50 \%} \geq 407{ }^{\circ} \mathrm{C}$ (Table 5, Fig. 6) were obtained. $^{55}$ Moreover, mix'-BGF.PAR ${ }_{\mathrm{TPC}}$ (2-21-22), $m, m^{\prime}$ BSF-4M-PAR ${ }_{\mathrm{TPC}}(31)$ and $m, m^{\prime}-\mathrm{BSF}-4 \mathrm{P} \cdot \mathrm{PAR}_{\mathrm{TPC}}(\underline{32})$ showed to be soluble in common organic solvents, advancing its usefulness and processability (e.g., coating, casting, spinning). ${ }^{78}$

The PAR synthesized from $p, p^{\prime}$-DPA (5) and IPC, $p, p^{\prime}$ DPA.PAR ${ }_{\text {IPC }}(5)$, showed $T_{\mathrm{g}}$ of $159{ }^{\circ} \mathrm{C}$, only $20{ }^{\circ} \mathrm{C}$ lower than that of $p, p^{\prime}$-BPA.PAR ${ }_{\mathrm{IPC}}$. However, similar to the polycarbonate from $p, p^{\prime}$-DPA, $p, p^{\prime}$-DPA.PAR IPC $_{\text {was }}$ characterised by a lower thermal stability, showing $T_{\mathrm{d} 5 \%}$ of $260{ }^{\circ} \mathrm{C}$ and $T_{\mathrm{d} 50 \%}$ of $441{ }^{\circ} \mathrm{C} .{ }^{85}$ To enhance the thermal stability, Ping et al. $(2009)^{79}$ used methyl and ethyl esters (6-7) for the synthesis of PARs.

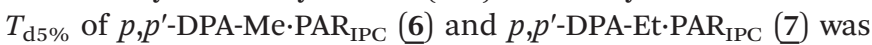
found to be $120{ }^{\circ} \mathrm{C}$ higher than that of $p, p^{\prime}-\mathrm{DPA} \mathrm{PAR}_{\mathrm{IPC}}(\mathbf{5})$, suggesting a significant increase of the thermal stability through the use of $p, p^{\prime}$-DPA-esters. $T_{\mathrm{g}}$ lowered upon esterification and with the elongation of the alkyl chain, being $149{ }^{\circ} \mathrm{C}$ and $140{ }^{\circ} \mathrm{C}$ for $p, p^{\prime}$-DPA-Me.PAR ${ }_{\text {IPC }}(6)$ and $p, p^{\prime}$-DPA-Et-PAR ${ }_{\mathrm{IPC}}$ (7), respectively (Table 3, Fig. 6). ${ }^{79}$

The three main parameters controlling gas permeation in PARs are packing density, chain rigidity and molecular mobility. Hence, substitution on the DPM bisphenol core structure directly influences gas permeability and selectivity of the polymer matrix. ${ }^{81}$ In this regard, Charati et al. (1992) ${ }^{86}$ and Kharul et al. (1998) ${ }^{81}$ showed that the permeability and selectivity of the polymer matrix can be modified and improved by (i) bulkier alkyl substituents on the bisphenols carbon bridge ${ }^{86}$ and (ii) $o$-methylation of bisphenol. ${ }^{81}$ Although not studied yet, this indicates high potential features of the here presented new bio-based PARs.

In order to prepare entirely renewable PARs, the fossilbased TPC and IPC might be substituted by the acyl dichloride of 2,5-furandicarboxylic acid (FDCA) (Fig. S2b, ESI $\dagger$ ). ${ }^{87}$ FDCA is derived from a first generation furan derivative, HMF, which is synthesized from mono- and polysaccharides. ${ }^{88}$ In this regard, Curia et al. (2018) ${ }^{78}$ synthesized a fully bio-based polyester from mix'-BGF (2-21-22) and the dichloride of FDCA, mix'BGF.PAR ${ }_{\text {FDCA }}$ (2-21-22). The use of the dichloride of FDCA instead of TPC, lowered $T_{\mathrm{g}}$ by $7{ }^{\circ} \mathrm{C}, T_{\mathrm{d} 5 \%}$ by $41{ }^{\circ} \mathrm{C}$ and $T_{\mathrm{d} 50 \%}$ by $100{ }^{\circ} \mathrm{C}$. With $T_{\mathrm{g}}$ of $157^{\circ} \mathrm{C}, T_{\mathrm{d} 5 \%}$ of $346^{\circ} \mathrm{C}$ and $T_{\mathrm{d} 50 \%}$ of $400{ }^{\circ} \mathrm{C}$, this polymer still shows excellent polymer properties for valuable engineering applications. ${ }^{78}$

Similar to the PC, the PAR of $p, p^{\prime}$-DPA (5), $p, p^{\prime}$-DPA.PAR ${ }_{\mathrm{IPC}}$ (5), could reach a $T_{\mathrm{g}}$ the closest to the BPA-based reference, being only $20{ }^{\circ} \mathrm{C}$ lower than the $T_{\mathrm{g}}$ of $p, p^{\prime}$-BPA.PAR $\mathrm{IPC}_{\text {I }}$. In addition, $T_{\mathrm{g}}$ of the PARs lowered by (i) the presence of $o$-methoxy moieties and/or (ii) the use of $m, m^{\prime}$-bisphenol isomers and/or (iii) the presence of 4-alkyl chains and (iv) the incorporation of ester functional groups $\left(c f . p, p^{\prime}\right.$-DPA.PAR ${ }_{\text {IPC }}$ (5)). The thermal stability of the bio-based PARs was the lowest for $p, p^{\prime}$-DPA.PAR ${ }_{\mathrm{IPC}}(5)$ with $T_{\mathrm{d} 5 \%}$ of $260{ }^{\circ} \mathrm{C}$ and $T_{\mathrm{d} 50 \%}$ of $447{ }^{\circ} \mathrm{C}$ and the highest for $m i x^{\prime}$-BGF.PAR ${ }_{\mathrm{TPC}}$ (2-21-22) with $T_{\mathrm{d} 5 \%}$ of $387{ }^{\circ} \mathrm{C}$ and $T_{\mathrm{d} 50 \%}$ of $500{ }^{\circ} \mathrm{C}$. Moreover, the bio-based polyesters, viz. $m i x^{\prime}-\mathrm{BGF} \cdot \mathrm{PAR}_{\mathrm{TPC}}$ (2-21-22), $m, m^{\prime}$-BSF-4M-PAR ${ }_{\mathrm{TPC}}$ (31) and $m, m^{\prime}$-BSF-4P.PAR ${ }_{\text {TPC }}$ (32), showed to be soluble in common organic solvents. This is in contrast to the current petroleum-based PARs, for which poor solubility and elevated $T_{\mathrm{g}}$ 's $\left(>200^{\circ} \mathrm{C}\right)$ hamper polymer processing. This emphasizes the potential of the current, and future bio-bisphenol alternatives, yielding polyesters with lower, but still remarkably high, $T_{\mathrm{g}}$ 's (i.e., $\geq 157^{\circ} \mathrm{C}$ ) combined with good solvent solubility.

\subsection{Epoxy resins}

Since 1946, Bisphenol A diglycidyl ether or BADGE is commercially manufactured through the coupling of BPA and epichlorohydrin in the caustic coupling or the phase-transfer catalyst process (Fig. S2c, ESI $\dagger$ ). Over time, the market of epoxy resins (ERs) has been growing continuously. Using different formulations, composites or derivatives of ERs (e.g., vinyl ester resins), a plethora of materials with diverse properties has been developed to answer specific needs in upcoming industries (e.g., electronic industry, wireless phones, waterborne coatings, windmill blades). ${ }^{3,77,89}$ Today, ERs are an important class of industrial polymers, from which $75 \%$ is derived of BADGE. ${ }^{3}$ Pure BADGE is a white solid with a melting point of $43^{\circ} \mathrm{C}$ and it has an epoxide equivalent weight (EEW) of $170 \mathrm{~g}$ eq. ${ }^{-1}$ EEW is defined by the molecular weight of the resin for one equivalent of epoxide, glycidyl ether. Hence, EEW of an epoxy resin (ER) increases if a resin contains dimers, trimers or oligomers. The deviation of EEW from the theoretical EEW (i.e. EEW of the pure diglycidyl monomer) is indicated by the degree of polymerization $(n){ }^{3}$ Most commercial BADGE resins show higher EEW; for instance Epon 828 is a liquid resin with $190 \mathrm{~g} \mathrm{eq}^{-1}$ EEW and $n$ equal to $0.14 .^{58}$

A hardener or curing agent is added to the epoxy resin to cross-link the resin yielding a resilient thermosetting polymer or thermoset. A variety of curing reagents can be used to target specific polymer properties. In general, the most important group of curing agents contains active hydrogen atoms (e.g., primary and secondary amines, phenols, carboxylic acids). Low molecular weight aliphatic amines, like diethylenetriamine (DETA), are used to obtain tightly cross-linked resins with good physical properties, chemical and solvent resistance but limited toughness and thermal stability. To improve toughness and thermal stability, cycloaliphatic amines can be used as curing agents, such commercial curing agents are isophorone diamine (IPDA) and bis(4-aminocyclohexyl)methane (PACM). Moreover, $T_{\mathrm{g}}$ of the thermoset is elevated up to $150{ }^{\circ} \mathrm{C}$ using cycloaliphatic curing agents. A further enhancement of thermal stability and chemical resistance can be acquired using aromatic amines as curing agents. For instance methylenedianiline (MDA), a widely used curing 
agent, provides in addition excellent mechanical and electrical properties to the thermoset. ${ }^{3}$

Industrially, thermoset resins, for instance formulations of the epoxy resin and curing agent (i.e., composites, if inorganic fillers are added), are cured at elevated temperatures (155-200 ${ }^{\circ} \mathrm{C}$ ) by compression or injection moulding. In the latter process the melt temperature inside the plasticizing cylinder is considered in the range of 55 to $115{ }^{\circ} \mathrm{C} .{ }^{67}$ Therefore, the phase at RT, viscosity and cure kinetics of the formulated resins are interesting parameters to evaluate the processability of the composite. Unfortunately, the phase at RT and viscosity of the formulation are rarely reported in research papers concerning new bio-based ERs, therefore, the processability of the formulation is assessed by its cure kinetics. In general, the curing reaction of a thermoset resin is exothermic. Hence, the cure kinetics might be examined by DSC. In most studies a dynamic DSC scan, with a heating ramp of $10{ }^{\circ} \mathrm{C}$ $\min ^{-1}$, is used to determine (i) the onset cure temperature $\left(T_{\mathrm{i}}\right)$, and (ii) the peak exotherm temperature $\left(T_{\mathrm{p}}\right)$, the temperature where the maximal polymerisation rate is achieved. However, more in-depth insights into the cure kinetics can be achieved by (i) isothermal and/or (ii) varying heating ramp DSC experiments. $^{90}$

BADGE is readily used in thermoset resin formulations to acquire high-performance thermosets. In general, BADGE thermosets are characterised by their mechanical strength, chemical resistance and thermal stability. ${ }^{2,3}$ Therefore, the three parameters taken into account to evaluate the potential of today's bio-based ERs are (i) the storage modulus ( $E^{\prime}$ ), (ii) $T_{\mathrm{g}}$ and (iii) thermal stability. The storage modulus $E^{\prime}$ is determined by DMA experiments and reflects the amount of stored energy in a viscoelastic material, hence, a measure of the solid character of the material. $E^{\prime}$ is strongly related to the present molecular motions, when determined at lower temperatures (i.e., $25{ }^{\circ} \mathrm{C}, 30^{\circ} \mathrm{C}$ or $45^{\circ} \mathrm{C}$ ) in the glassy state of a polymer. This parameter provides more information about chain packing and molecular interactions. ${ }^{58,91}$ Crossing the glass transition temperature upon heating, $E^{\prime}$ drops as molecular motions are induced. In general, $E^{\prime}$ determined at $30^{\circ} \mathrm{C}$ above $T_{\mathrm{g}}$ is associated to the rubbery state of the polymer, and according to the rubber elasticity theory, inversely proportional to the molecular weight between cross-links $\left(M_{\mathrm{x}}\right)$ and therefore directly proportional to the cross-link density. ${ }^{60,91}$ Noteworthy, just like the $\bar{M}_{w}$ influences thermoplastic polymer properties, the cross-link-density or degree of cross-linking influences the finalthermosetting polymer properties. As the cross-link density of the sample increases, the molecular motions in the polymer are restricted and $T_{\mathrm{g}}$ rises. ${ }^{91}$ Despite its importance, the cross-link density is seldom reported, rather, related parameters via the rubber elasticity theory are given. To include this aspect in the analysis, these parameters were summarized in Table 5. As the degree of cross-linking rises, strength and rigidity increases, whereas elongation capacity decreases. ${ }^{66}$

It is clear that different aspects (e.g., formulation, cure protocol) influence the processability and the final polymer properties. Consequently, the extraction of relevant structure- property relations is limited to similar formulations and crosslink density. The bio-bisphenols used for the syntheses of ERs and their mutual structural relations are shown in Fig. 7. All collected data concerning the uncured and cured ERs are summarized in Tables 4, 5 and Fig. 8.

In addition to BPA, BPF is used to manufacture BFDGE, showing a slightly higher reactivity and lower viscosity than BADGE commercial resins. ${ }^{3}$ This BFDGE often exists as a mixture of regioisomers, mix'-BPF-DGE, with $o, p^{\prime}$-BPF-DGE as the dominant isomer. ${ }^{92}$ Hence, the lower viscosity of a commercial BFDGE resin is conveyed by (i) the methylene bridge and/or (ii) the presence of ortho-regioisomers. ${ }^{42}$ In this regard, Hernandez et al. (2016) ${ }^{58}$ synthesized the epoxy resin (ER), or diglycidyl ether (DGE), of mix'-BGF (2-21-22), abbreviated as mix'-BGF-DGE. This highly pure resin $(n=0.04)$ was obtained as a white solid with $112-114{ }^{\circ} \mathrm{C}$ m.p. $m i x^{\prime}$-BGF-DGE (2-21-22) showed to be miscible with PACM and was found highly reactive yielding a high degree of cure $(>99 \%) . T_{\mathrm{g}}$ of the mix'BGF.DGE ${ }_{\text {PACM }}(\underline{2-21-22})$ thermoset $\left(111^{\circ} \mathrm{C}\right)$ showed to be lower than $T_{\mathrm{g}}$ 's observed for the commercial reference thermosets $\mathrm{BADGE}_{\mathrm{PACM}}$ (i.e., Epon $828_{\mathrm{PACM}}$ ) and $\mathrm{BFDGE}_{\mathrm{PACM}}$ (i.e., Epon $862_{\text {PACM }}$ ) with $158{ }^{\circ} \mathrm{C}$ and $138{ }^{\circ} \mathrm{C} T_{\mathrm{g}}$, respectively (Table 5, Fig. 8). This decrease in $T_{\mathrm{g}}$ can be ascribed to an increase of the degree of rotational freedom caused by (i) the methylene bridge and (ii) the $o$-methoxy groups. The $m i x^{\prime}$-BGF-DGE ${ }_{\mathrm{PACM}}$ (2-21-22) thermoset showed a good thermal stability with $T_{\mathrm{d} 5 \%}$ of $363{ }^{\circ} \mathrm{C}$ and $T_{\max }$ of $376{ }^{\circ} \mathrm{C}$, both being only $16^{\circ} \mathrm{C}$ lower than the $\mathrm{BADGE}_{\mathrm{PACM}}$ reference. Interestingly, the $m i x^{\prime}$-BGF.DGE $\mathrm{PACM}_{\mathrm{PAC}}$ (2-21-22) thermoset showed a higher storage modulus at $25{ }^{\circ} \mathrm{C}$ $\left(E_{25}^{\prime}\right)$ and glassy modulus than the reference $\mathrm{BADGE} \mathrm{PACM}_{\mathrm{P}}$ (Epon 828 PACM$_{\text {) }}$ and BFDGE PACM $_{\text {(Epon 862 }}$ PACM ) thermosets (Table 5, Fig. 8). The authors related this increase in $E_{25}^{\prime}$ to the presence of the $o$-methoxy groups, inducing hydrogen bonding interactions between the $o$-methoxy moieties and the hydroxyl groups formed by the epoxy-amine cure reaction. ${ }^{58}$

To attain more insight into the influence of $o$-methoxy moieties in the DPM core structure on ERs thermoset properties, Nicastro et al. $(2018)^{60}$ synthesized ERs derived from $o, p^{\prime}$-GPF (20), $p, p^{\prime}$-GPF (1), $m, p^{\prime}$-GSF (23), $p, p^{\prime}$-GSF (3), $m, p^{\prime}$-BSF (24) and $p, p^{\prime}$-BSF (4), and mixtures thereof (1-20), (3-23) and (4-24), using the aromatic diamine MDA. All ERs, except the commercial references BADGE and BFDGE and $m, p^{\prime}$-BSF-DGE (24), show a high monomer purity with a degree of polymerization ranging from 0.01 to 0.04 . A first interesting observation was made comparing the physical appearance of the different regioisomers. All ERs derived from $p, p^{\prime}$-isomers were solids with m.p. up to $115{ }^{\circ} \mathrm{C}$; the lowest m.p. was observed for $p, p^{\prime}$ GPF.DGE (1) being $52{ }^{\circ} \mathrm{C}$. Adding $o$-methoxy moieties to the bisphenol structures clearly increased the resins m.p., as $p, p^{\prime}-$ GSF.DGE (3) and $p, p^{\prime}$-BSF.DGE (4) showed m.p. of $64^{\circ} \mathrm{C}$ and $115{ }^{\circ} \mathrm{C}$, respectively (Table 4). In contrast, the ERs of the $o, p^{\prime}$ isomer and $m, p^{\prime}$-isomers were liquid at RT. This indicates that (i) the amount of $o$-methoxy moieties and (ii) isomer orientation of the bisphenol significantly influences ER's m.p. In addition to the pure ERs, ERs of the regioisomer mixtures obtained after reaction were synthesized. These ERs showed to 


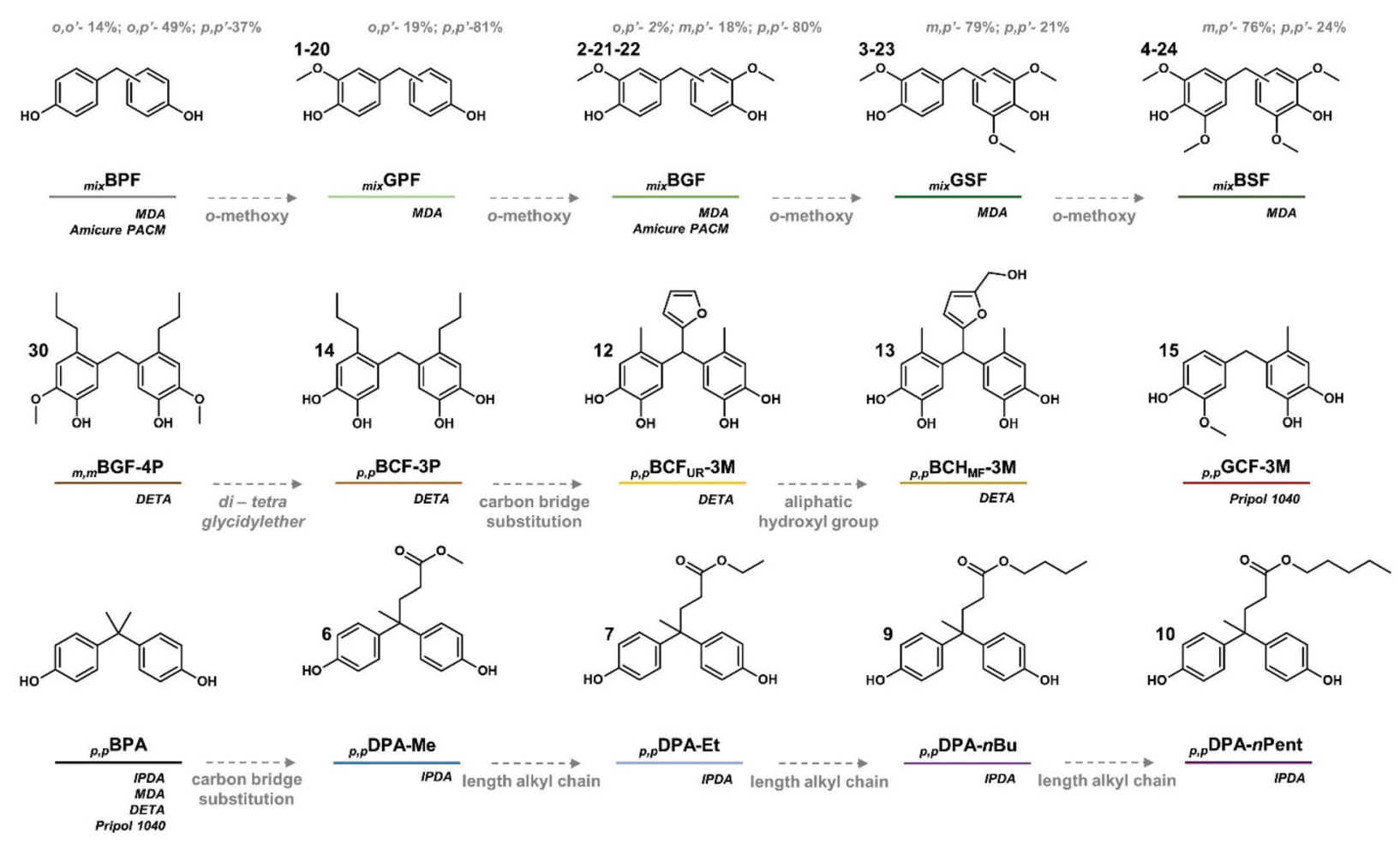

Fig. 7 Bio-bisphenols used for the synthesis of epoxy resins. The representation of so far reported bio-bisphenols, in addition to the petroleumbased references, used for the synthesis of epoxy resins and the curing agents used for formulations thereof. The curing agents are diethylenetriamine (DETA), isophorone diamine (IPDA), bis(4-aminocyclohexyl)methane (PACM), methylenedianiline (MDA) and Pripol 1040.

be solid for $m i x^{\prime}$-GPF.DGE (1-20) and $m i x^{\prime}$-BSF-DGE (4-24), liquid for $m i x^{\prime}$-GSF.DGE at RT (3-23)..$^{60}$

All ERs were miscible with MDA except for mix'-BGF-DGE (2-21-22), therefore the latter is not further discussed, the former showed full conversions after curing. Although not discussed by the authors, some additional information about the resins processability (i.e., phase at RT, m.p. of the formulation and cure kinetics) can be derived from a dynamic DSC cure experiment, given that the epoxy-amine curing reaction is exothermic. Firstly, all formulations of $m i x^{\prime}$-ERs were liquid at RT. Secondly, the onset cure temperature $\left(T_{\mathrm{i}}\right)$ was similar for all bio-based epoxy resins and bisphenol reference resins (i.e., 50-60 $\left.{ }^{\circ} \mathrm{C}\right)$. Thirdly, the peak exotherm temperature $\left(T_{\mathrm{p}}\right)$, showed the following order: $m i x^{\prime}-\mathrm{GPF} \cdot \mathrm{DGE}_{\mathrm{MDA}}$ (1-20) with $140{ }^{\circ} \mathrm{C}<m i x^{\prime}-\mathrm{BFDGE}_{\mathrm{MDA}}$ with $142{ }^{\circ} \mathrm{C}<p, p^{\prime}-\mathrm{BADGE}_{\mathrm{MDA}}$ with $148{ }^{\circ} \mathrm{C}<m i x^{\prime}$-GSF.DGE ${ }_{\mathrm{MDA}}(\mathbf{3 - 2 3})$ with $150{ }^{\circ} \mathrm{C}<m i x^{\prime}$ BSF-DGE ${ }_{\text {MDA }}(\mathbf{4 - 2 4})$ with $152{ }^{\circ} \mathrm{C}$ (Table 4). ${ }^{60}$ Because of their different regioisomer composition, the influence of $o$-methoxy moieties on cure kinetics and reactivity cannot be determined. However, these results indicate that the processability of all $m i x^{\prime}$-ERs is similar to the references, BADGE $E_{M D A}$ and BFDGE $_{\text {MDA. }}$.

The storage moduli at $200{ }^{\circ} \mathrm{C}\left(E_{200}^{\prime}\right)$, rubbery modulus, and $T_{\mathrm{g}}$ were higher for all ERs derived from $p, p^{\prime}$-isomer bisphenol structures compared to the ERs derived from $m, p^{\prime}$ - or $o, p^{\prime}$ isomers (Table 5, Fig. 8). Hence, the ERs derived from the $p, p^{\prime}$ isomer achieve a higher cross-link density during cure, increas- ing $T_{\mathrm{g}}$ of the cured resin. The author accounts this difference to the presence of topological cyclic defects in the polymer networks derived from $o, p^{\prime}$ - and $m, p^{\prime}$-isomer ERs. ${ }^{60,93}$ In general, $T_{\mathrm{g}}$ of the thermosets decreased with increasing amount of $o$-methoxy moieties. It was hypothesized that additional $o$-methoxy groups hinder close chain packing, resulting in lower $T_{\mathrm{g}}$ 's. However, $p, p^{\prime}$-BSF.DGE (24) showed a high $T_{\mathrm{g}}$ of $141{ }^{\circ} \mathrm{C}$ comparable to $T_{\mathrm{g}}$ 's of the GPF.DGE $(\mathbf{2 0}, \underline{\mathbf{1}}, \underline{\mathbf{1 - 2 0}})$ thermosets ranging from $132{ }^{\circ} \mathrm{C}$ to $151{ }^{\circ} \mathrm{C}$, indicating that a fourth $o$-methoxy group hinders the chain mobility and increases chain packing (Fig. 8). Furthermore, there was no significant difference observed for the glassy modulus at $30^{\circ} \mathrm{C}\left(E_{30}^{\prime}\right)$ of all bio-based and reference ERs. ${ }^{60}$

Finally, it was shown that the increasing amount of $o$-methoxy groups decreases the thermal stability of the cured resin. This was expected as methoxy groups ortho to the glycidyl ether linkage reduce the thermal energy required for homolytic cleavage of the phenoxy-glycidyl bond. ${ }^{60,94}$ Even though, the thermal stability of the bio-based ERs is high enough $\left(T_{\mathrm{d} 5 \%}>344{ }^{\circ} \mathrm{C}\right)$ for applications in food can linings and structural adhesives. ${ }^{60}$

In 2016, Zhao et al. ${ }^{57}$ presented the ER of $m, m^{\prime}$-BGF-4P (30), $m, m^{\prime}$-BGF-4P-DGE (30). Using an aliphatic amine, DETA, as curing agent the thermoset $m, m^{\prime}$-BGF-4P-DGE DETA (30) was obtained. Looking into the cure kinetics, an activation energy $\left(E_{\mathrm{a}}\right)$ of cure of $46 \mathrm{~kJ} \mathrm{~mol}^{-1}$ was observed, $T_{\mathrm{i}}$ of $51^{\circ} \mathrm{C}$ and $T_{\mathrm{p}}$ of $92{ }^{\circ} \mathrm{C}$ (Table 4). The thermoset showed a cross-link density of 


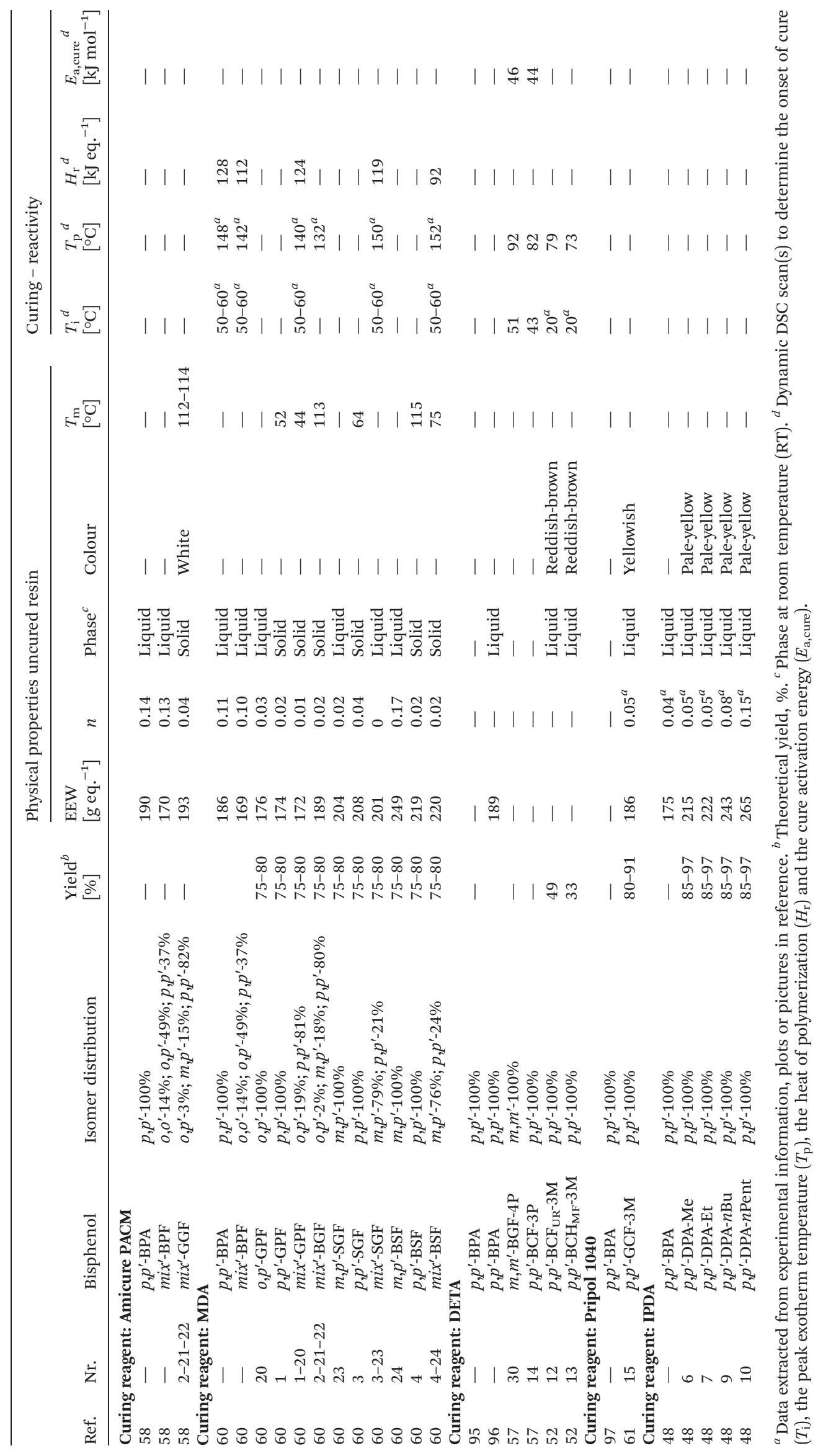




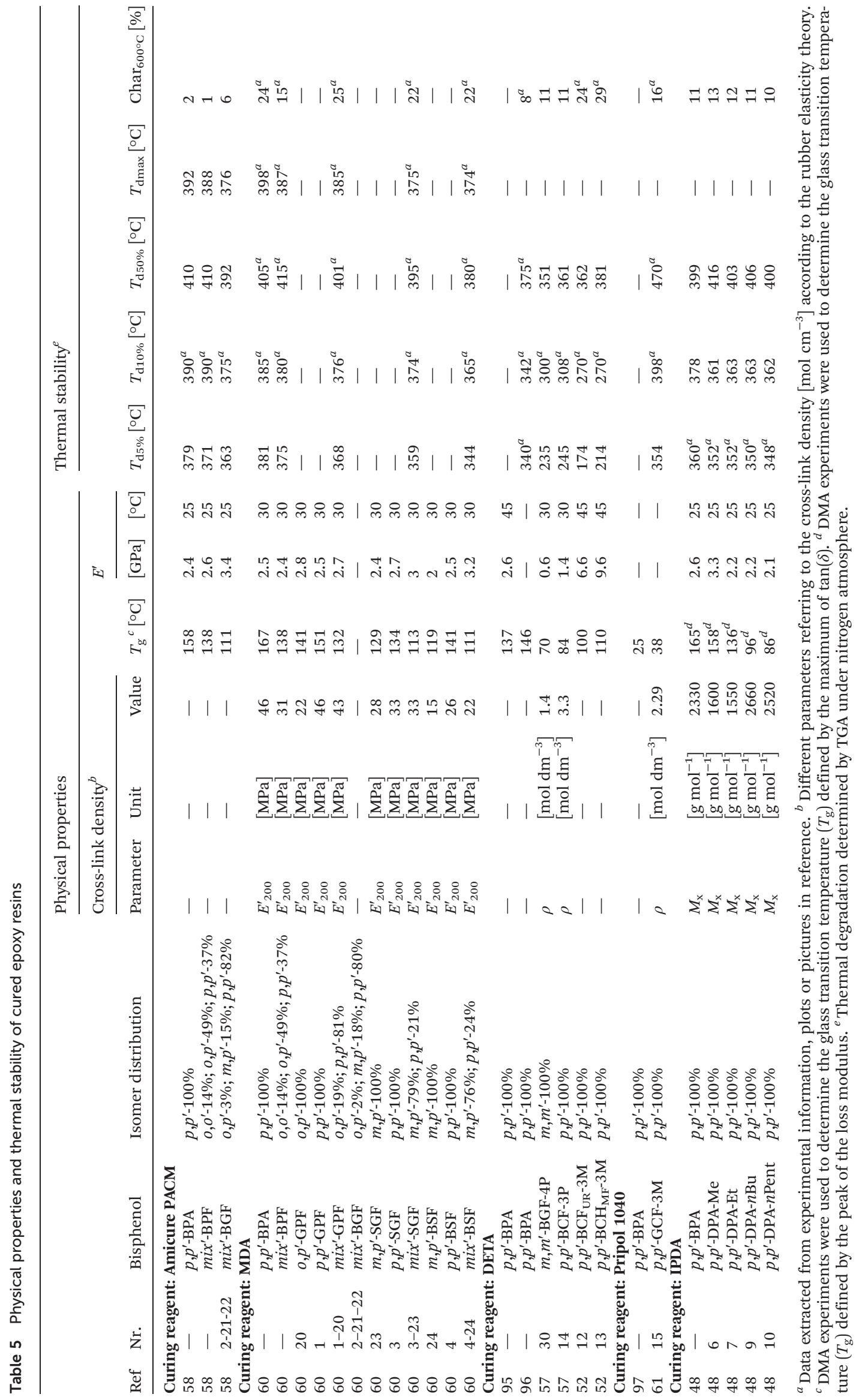




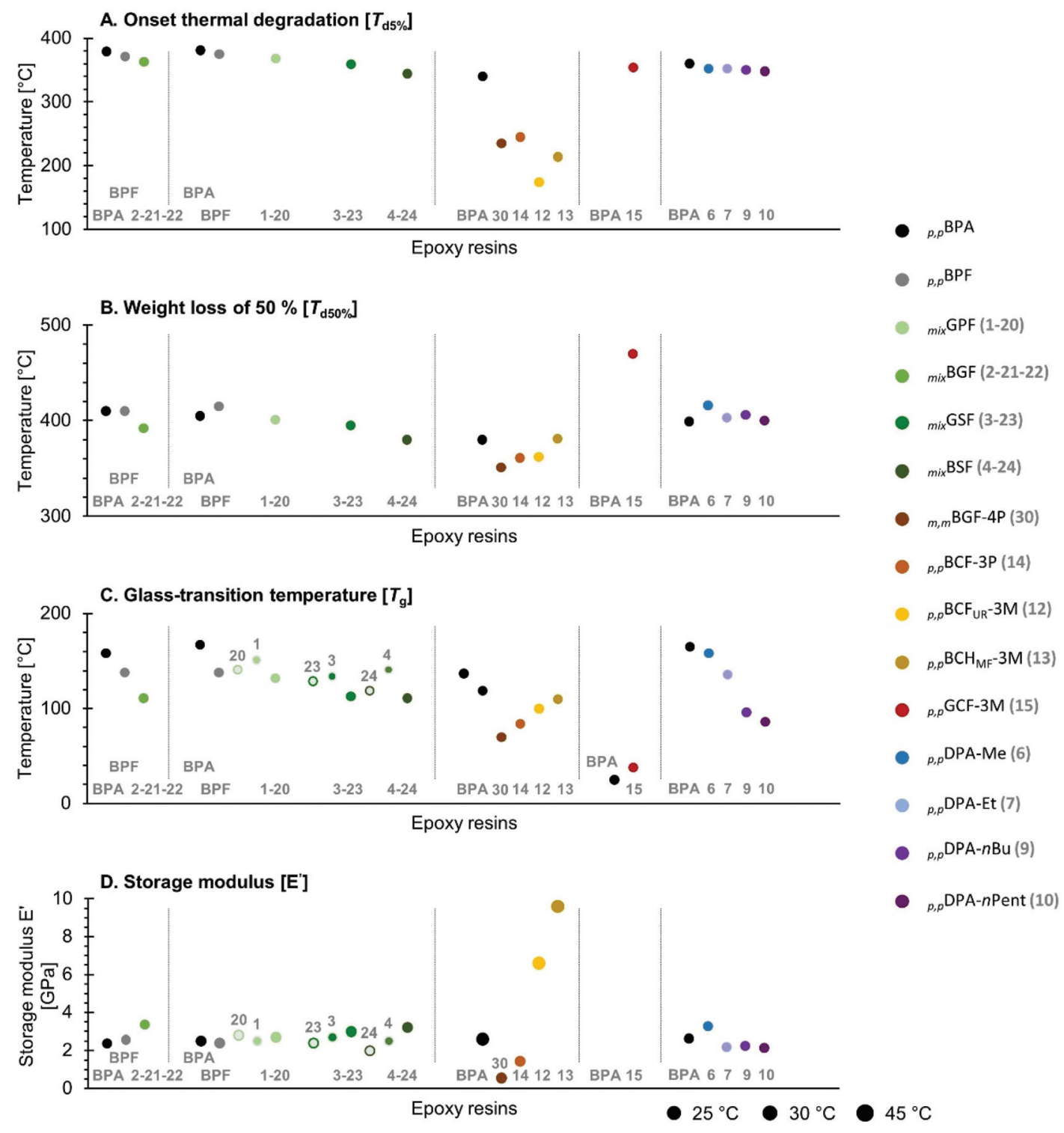

Fig. 8 Polymer properties of the bio-based and reference cured epoxy resins. Representation of (A) the onset thermal degradation temperature, 5\% weight loss temperature $\left(T_{\mathrm{d} 5 \%}\right)$ under nitrogen atmosphere (B) the temperature of $50 \%$ weight loss or $T_{\mathrm{d} 50 \%}$ under nitrogen atmosphere (C) the glass transition temperature $\left(T_{\mathrm{g}}\right)$ and $(\mathrm{D})$ Storage moduli $E^{\prime}$ at temperature $25^{\circ} \mathrm{C}-30^{\circ} \mathrm{C}-45^{\circ} \mathrm{C}$ of the cured epoxy resins. The area of the data points in the bubble chart is related to the temperature at which $E^{\prime}$ is defined. The epoxy resins are divided in sections according to the curing agent used from left to right: PACM, MDA, DETA, Pripol 1040 and IPDA.

$1.39 \mathrm{~mol} \mathrm{dm}{ }^{-1},{ }^{3}$ with $T_{\mathrm{g}}$ of $70{ }^{\circ} \mathrm{C}$, low $E_{30}^{\prime}$ of $0.6 \mathrm{GPa}$ and thermal stability showing $T_{\mathrm{d} 5 \%}$ of $235{ }^{\circ} \mathrm{C}$ and $T_{\mathrm{d} 50 \%}$ of $351{ }^{\circ} \mathrm{C}$ (Table 5). ${ }^{57}$ These lower thermomechanical properties, compared to the previously discussed ERs, were expected as an aliphatic curing agent was used. The reference resin BADGE $E_{\text {DETA }}$ shows a significant higher $T_{\mathrm{g}}$ of $137{ }^{\circ} \mathrm{C},{E^{\prime}}_{45}$ of $2.6 \mathrm{GPa}$ and thermal stability with $T_{\mathrm{d} 5 \%}$ of $340{ }^{\circ} \mathrm{C}$ and $T_{\mathrm{d} 50 \%}$ of $375{ }^{\circ} \mathrm{C} .{ }^{95}$ This might be caused by structural difference due to (i) the isomer orientation, (ii) the methylidene bridge and (iii) the 4-alkyl chain.

To further enhance the thermomechanical properties, Zhao et al. $(2016)^{57} o^{\prime}$-demethylated $m, m^{\prime}$-BGF-4P (30) to obtain a bisphenol structure characterised by four functional hydroxyl groups, $p, p^{\prime}$-BCF-3P (14) resulting in a tetra-epoxide, after glycidylation, with four epoxy groups: $p, p^{\prime}$-BCF-3P-DGE (14). However, up to $20 \mathrm{~mol} \%$ of a di-epoxy benzodioxane byproduct was observed for $p, p^{\prime}$-BCF-3P-DGE. Surprisingly, a lower $T_{\mathrm{i}}, T_{\mathrm{p}}$ and $E_{\mathrm{a}}$, compared to $m, m^{\prime}$-BGF-4P-DGE $\mathrm{DETA}_{\text {DE }}(\mathbf{3 0}$, were reported for $p, p^{\prime}$-BCF-3P-DGE ${ }_{\text {DETA }}(\mathbf{1 4})$ being $43{ }^{\circ} \mathrm{C}, 82^{\circ} \mathrm{C}$ and $44 \mathrm{~kJ} \mathrm{~mol}^{-1}$, respectively. This phenomenon is explained by the catalytic effect of the benzodioxane by-products, including a free hydroxyl group, in the epoxy-amine curing reaction. Remarkably, introducing additional epoxy groups more than doubled, even in the presence of benzodioxane by-products, the thermoset's cross-link density reaching values as high as $3.29 \mathrm{~mol} \mathrm{dm}^{-1}$. $^{3}$ This resulted in a thermoset with higher $T_{\mathrm{g}}$ of 
$84{ }^{\circ} \mathrm{C}$, an $E_{30}^{\prime}(1.4 \mathrm{GPa})$ and thermal stability with $T_{\mathrm{d} 5 \%}$ of $245^{\circ} \mathrm{C}$ and $T_{\mathrm{d} 50 \%}$ of $361{ }^{\circ} \mathrm{C} .^{57}$

Using biscatechols, which have four function hydroxyl groups, Jiang et al. (2018) ${ }^{52}$ synthesized $p, p^{\prime}-\mathrm{BCF}_{\mathrm{UR}}-3 \mathrm{M} \cdot \mathrm{DGE}$ (12) and $p, p^{\prime}-\mathrm{BCH}_{\mathrm{MF}}-3 \mathrm{M} \cdot \mathrm{DGE}$ (13). Similar to $p, p^{\prime}$-BCF-3P-DGE (14), di-epoxy benzodioxane by-products were obtained in the synthesis of these ERs. The ratio of di- to tetra-epoxy resins in the reaction mixture was found to be 1 to 1.9 and 1 to 1.2 for $p, p^{\prime}-\mathrm{BCF}_{\mathrm{UR}}-3 \mathrm{M} \cdot \mathrm{DGE}(\underline{\mathbf{1 2}})$ and $p, p^{\prime}-\mathrm{BCH}_{\mathrm{MF}}-3 \mathrm{M} \cdot \mathrm{DGE}(\underline{\mathbf{1 3}})$, respectively. Using DETA as curing agents, similar cure exotherms were observed for both resins, indicating a similar reactivity. The slightly lower $T_{\mathrm{p}}$, about $6{ }^{\circ} \mathrm{C}$, of $p, p^{\prime}-\mathrm{BCH}_{\mathrm{MF}}-3 \mathrm{M} \cdot \mathrm{DGE} \mathrm{E}_{\mathrm{DETA}}$ (13) can be attributed to presence of an additional hydroxyl group, accelerating the curing reaction (Table 4). $T_{\mathrm{g}}$ and $E_{45}^{\prime}$ were found higher for $p, p^{\prime}-\mathrm{BCH}_{\mathrm{MF}^{-}} 3 \mathrm{M} \cdot \mathrm{DGE} \mathrm{DETA}_{\text {(13), being }}$ $110{ }^{\circ} \mathrm{C}$ and $9.6 \mathrm{GPa}$ than for $p, p^{\prime}-\mathrm{BCF}_{\mathrm{UR}}-3 \mathrm{M} \cdot \mathrm{DGE} \mathrm{DETA}_{\mathrm{DA}}$ (12), being $100{ }^{\circ} \mathrm{C}$ and $6.6 \mathrm{GPa}$. The author attributes this difference to the presence of the hydroxymethyl group $(i)$ inducing stronger inter chain hydrogen bonding and (ii) less free space, limiting the rotational freedom of the polymer chain. ${ }^{52}$ Compared to the BPA-reference BADGE $_{\text {DETA }}$ the obtained epoxy resins showed a $27{ }^{\circ} \mathrm{C}$ to $37^{\circ} \mathrm{C}$ lower $T_{\mathrm{g}}$, but a, strikingly, 4 GPa to 7 GPa higher $E_{45}^{\prime}$ (Table 5). This may be explained by the higher rigidity of the thermoset resins. At least, the thermal stability of both thermosets was reported to be lower than that of BADGE $_{\text {DETA }}$ for temperatures under $340{ }^{\circ} \mathrm{C}$, but comparable above this temperature. Moreover, the thermosets showed a higher char yield ( $c f$. BPADGE $\mathrm{DETA}_{\mathrm{DE}}+8 \%$ ) above $24 \%$ at $600{ }^{\circ} \mathrm{C}$ (Table 5). ${ }^{52,96}$

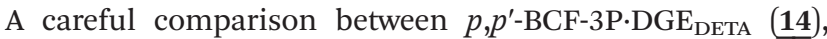
$p, p^{\prime}-\mathrm{BCF}_{\mathrm{UR}}-3 \mathrm{M} \cdot \mathrm{DGE}_{\mathrm{DETA}}(\underline{\mathbf{1 2}})$ and $p, p^{\prime}-\mathrm{BCH}_{\mathrm{MF}}-3 \mathrm{M} \cdot \mathrm{DGE}_{\mathrm{DETA}}(\mathbf{1 3})$ indicates that the embedding bulky, aromatic and/or polar groups on the bisphenol carbon bridge may be an effective way to enhance the thermomechanical properties of an epoxy thermoset resin.

Thus, Maiorana et al. $(2015)^{48}$ reported the synthesis of ERs from DPA-esters: $p, p^{\prime}$-DPA-Me-DGE (6), $p, p^{\prime}$-DPA-Et-DGE (7), $p, p^{\prime}$-DPA- $n \mathrm{Bu} \cdot \mathrm{DGE}(\underline{\mathbf{9}})$ and $p, p^{\prime}$-DPA- $n$ Pent-DGE (10). All resins were liquid at RT with $n$-values ranging from 0.05 to 0.15 and it was shown that the resin's viscosity decreased with elongation of the $n$-alkyl ester. The ERs were cured using isophorone diamine (IPDA), obtaining fully cured thermosets. Based on the average molecular weight between cross-links $\left(M_{\mathrm{x}}\right)$, it was concluded that $n$-alkyl side chains did not hinder network formation. All thermosets showed similar storage moduli to BADGE $_{\mathrm{IPDA}}$ and $T_{\mathrm{g}}$ in the range of $86{ }^{\circ} \mathrm{C}$ to $158{ }^{\circ} \mathrm{C}$ (Table 5 , Fig. 8). Compared to $\mathrm{BADGE}_{\mathrm{IPDA}}, p, p^{\prime}$-DPA-Me-DGE $\mathrm{IPDA}_{\mathrm{IPD}}$ showed a $0.7 \mathrm{GPa}$ higher storage modulus and $T_{\mathrm{g}}$ only $7{ }^{\circ} \mathrm{C}$ lower, this result is attributed to the presence of $6 \mathrm{~mol} \%$ of a tri-epoxy by-product inducing a higher cross-link density. $T_{\mathrm{g}}$ of the thermosets decreased with elongation of the $n$-alkyl ester. It is stated that the ester moieties function as internal plasticizers increasing chain mobility. Furthermore, all bio-based resins show a high thermal stability with $T_{\mathrm{d} 5 \%} \geq 348{ }^{\circ} \mathrm{C}$ and $T_{\mathrm{d} 50 \%} \geq 400{ }^{\circ} \mathrm{C}$, comparable to BADGE ${ }_{\mathrm{IPDA}}$ with $T_{\mathrm{d} 5 \%}$ of $360{ }^{\circ} \mathrm{C}$ and $T_{\mathrm{d} 50 \%}$ of $399^{\circ} \mathrm{C}$ (Table 5 , Fig. 8.). ${ }^{48}$
In 2019, Zhao et $a l .{ }^{61}$ presented the ER, $p, p^{\prime}$-GCF-3M-DGE (15), from the asymmetric bisphenol $p, p^{\prime}$-GCF-3M (15). Similar to the other catecholic ERs, a benzodioxane by-product was obtained. The ratio of the by-product (i.e., mono-epoxide) to the ER (i.e., tri-epoxide) could be tuned by controlling the reaction time. The ER containing 36\% mono- and 64\% tri-epoxide was cured with Pripol 1040, a mixture of tricarboxylic (77 wt\%) and dicarboxylic (23 wt\%) fatty acids, in the presence of $\mathrm{Zn}$ (acac) $)_{2}$ as catalyst. The obtained $p, p^{\prime}$-GCF-3M-DGE PRIPOL thermoset showed good mechanical strength, good solvent resistance, $T_{\mathrm{g}}$ of $38{ }^{\circ} \mathrm{C}$ (i.e., $13{ }^{\circ} \mathrm{C}$ higher than BADGE $\left.{ }_{\text {PRIPOL }}\right)^{97}$ and high thermal stability with $T_{\mathrm{d} 5 \%}$ of $354{ }^{\circ} \mathrm{C}$ and $T_{\mathrm{d} 50 \%}$ of $470{ }^{\circ} \mathrm{C}$. Noteworthy, $p, p^{\prime}$-GCF-3M as well as the fatty acids can be obtained from renewable compounds, enhancing the overall bio-based content of this thermoset.

The bio-based content of ERs can be further enhanced by (i) the use of epichlorohydrin manufactured from glycerol (i.e. GTE-process ${ }^{98}$ ), commercially available under the tradename Epicerol ${ }^{99}$ and (ii) the use of a renewable curing agent (e.g. fatty acids, anhydrides, furan amines). ${ }^{100}$

In general, it was shown that the m.p. of ERs depends on the bisphenol isomer orientation and increases by the introduction of $o$-methoxy groups in the bisphenol DPM core scaffold. $T_{\mathrm{g}}$ increased using $p, p^{\prime}$-derived epoxy resins reaching a higher cross-link density and was lowered (i) by the presence of $o$-methoxy moieties and (ii) upon elongation of the ester alkyl chain for ERs derived from $p, p^{\prime}$-DPA-esters. The thermal stability of the thermosets decreased by the introduction of (additional) $o$-methoxy moieties, reducing the thermal energy required for homolytic cleavage of the phenoxy-glycidyl bond. ${ }^{60,94}$ Interestingly, an increase of the glassy modulus (i.e., storage modulus at $25^{\circ} \mathrm{C}, 30^{\circ} \mathrm{C}$ or $45^{\circ} \mathrm{C}$ ) was attributed to (i) the presence of $o$-methoxy moieties, (ii) rigid groups on the carbon bridge and (iii) the presence of polar functional groups (e.g., free hydroxyl groups), limiting the rotational freedom of the polymer chain by, for instance, hydrogen bonding interactions. To conclude, ERs with varying m.p. and colour were obtained using bio-bisphenol precursors, yielding bio-based thermosets with a thermal stability and $T_{\mathrm{g}}$ comparable to, but glassy storage moduli $\left(E^{\prime}\right)$ surpassing, fossil-based thermosets.

\subsection{Cyanate ester resins}

The first syntheses of cyanate esters were reported in the early 1960 's. A relevant cyanate ester is BADCy, produced by the reaction of BPA with cyanogen chloride in the presence of a tertiary amine (Fig. S2d, ESI $\dagger$ ). Upon heating above $150{ }^{\circ} \mathrm{C}$, these cyanate esters polymerize by cyclotrimerization to form triazine rings, yielding polycyanurates, i.e., cyanate ester resins (CERs). ${ }^{77,101}$ A metal catalyst might be added to lower the cure onset temperature $\left(T_{\mathrm{i}}\right)$, albeit compromising its thermal properties. ${ }^{102}$ CER thermosets show comparable application potential to epoxy resin thermosets, but they reach even higher thermomechanical properties (e.g., $\left.T_{\mathrm{g}}>200^{\circ} \mathrm{C}\right)$ and show high stability in demanding environments (e.g., elevated and cryogenic temperatures, exposure to vacuum, high-energy radiation). Therefore, CERs are mainly used as high-performance 
materials for specialized applications (e.g., rocket and spacecraft structures, thermonuclear fusion reactors). ${ }^{102,103}$ Another important cyanate ester, commercially available next to BADCy, is LECy prepared from $p, p^{\prime}$-BPE. While BADCy is a white solid at RT with a m.p. of $79-82{ }^{\circ} \mathrm{C}$, LECy is a supercooled liquid at RT with a m.p. of $29{ }^{\circ} \mathrm{C}$, facilitating its processing. ${ }^{101,102,104}$

Like mentioned in the previous section, the phase at RT, m.p., viscosity and cure kinetics of thermoset resins are useful parameters to assess the resin's processability. In general, CERs are characterised by a processing window, i.e., the difference between m.p. of the pure cyanate ester and the onset of the cure $\left(T_{\mathrm{i}}\right)$.

Despite their high thermomechanical stability, CERs are prone to hydrolysis when exposed to hot and wet conditions. ${ }^{105,106}$ The hydrolytic stability of CERs has been studied since the 1980 's, investigating the influence of cure conversion and structural modifications on the hydrolytic stability of the ester bonds. In particular, it was shown that (i) a higher conversion, leads to a more 'open' structure, more free volume, enhancing the accessibility of the polar cyanurate oxygens and (ii) the presence of a methyl group in ortho to the cyanate group (i.e., o-methyl group) moderately enhanced the hydrolytic stability by sterically hindering the cyanurate oxygen, thus, the absorption of water. ${ }^{101,103,106}$ To assess the performance after exposure to wet and hot conditions, $T_{\mathrm{g}}$ of CERs is, generally, determined before and after immersion in water for 96 hours at $85{ }^{\circ} \mathrm{C}$ (i.e., the dry $T_{\mathrm{g}}$ and wet $T_{\mathrm{g}}$ ). The water uptake and difference between both $T_{\mathrm{g}}$ 's, also called the wet $T_{\mathrm{g}}$ knockdown, are taken as measure for hydrolytic stability. ${ }^{103}$

Most cyanate esters are cured using the following cure protocol: 1 hour at $150{ }^{\circ} \mathrm{C}, 24$ hours at $210{ }^{\circ} \mathrm{C}$ with a $5{ }^{\circ} \mathrm{C} \mathrm{min}{ }^{-1}$ heating ramp, yielding 'as-cured' resins. Although most ascured resins reach a complete cure, a post-cure at elevated temperature, up to $350^{\circ} \mathrm{C}$, is frequently added to attain a fullycured resin. Decomposition of the CERs during this additional post-cure may occur, resulting in fully-cured resin with lower thermomechanical properties than the as-cured resins. This aspect complicates the interpretation of the data and extraction of structure-property relations. Therefore, this review reports the data of as-cured resins if: (i) a complete cure was achieved and (ii) the as-cured resin was fully characterised. All bio-bisphenols, interesting petroleum-based references and their structural relations are presented in Fig. 9. Details and collected data of the uncured and cured cyanate esters are summarized in Tables 6, 7 and represented in Fig. 10.

In 2015 Harvey et al. ${ }^{56}$ presented cyanate esters derived from meta-methyl alkylated bisphenols: $p, p^{\prime}$-BPF-3M (17), $p, p^{\prime}$ BPE-3M (18) and $p, p^{\prime}-\mathrm{BPP}-3 \mathrm{M}$ (19) yielding the following CERs: $p, p^{\prime}$-BPF-3M-Cy (17), $p, p^{\prime}$-BPE-3M-Cy (18) and $p, p^{\prime}$-BPP-3M-Cy (19). All resins, except $p, p^{\prime}$-BPP-3M-Cy (19) which was liquid at RT, were obtained as white solids with m.p. of $88{ }^{\circ} \mathrm{C}$ and $105{ }^{\circ} \mathrm{C}$ for $p, p^{\prime}-\mathrm{BPF}-3 \mathrm{M} \cdot \mathrm{Cy}\left(\mathbf{1 7}^{2}\right)$ and $p, p^{\prime}$-BPE-3M-Cy (18), respectively (Table 6, Fig. 10). A complete cure was achieved in a dynamic DSC scan, showing $T_{\mathrm{i}} \geq 200^{\circ} \mathrm{C}, T_{\mathrm{p}} \geq 245^{\circ} \mathrm{C}$ and processing windows above $120{ }^{\circ} \mathrm{C}$ (Table 6). Unclear complications during cure caused voids in the $p, p^{\prime}$-BPF-3M-Cy (17) resin limiting its characterisation. All as-cured resins showed similar thermal stability, comparable to the bisphenol reference resins with $T_{\mathrm{d} 5 \%} \geq 410{ }^{\circ} \mathrm{C}, T_{\mathrm{d} 50 \%}>500{ }^{\circ} \mathrm{C}$ and high char yield at $600{ }^{\circ} \mathrm{C}$ above $50 \%$ (Table 7). $T_{\mathrm{g}}$ reported for the ascured resins was $271{ }^{\circ} \mathrm{C}$ and $256{ }^{\circ} \mathrm{C}$ for $p, p^{\prime}$-BPE-3M-Cy (18) and $p, p^{\prime}$-BPP-3M-Cy (19), respectively. This indicated that the alkyl chain elongation lowers the resins $T_{\mathrm{g}}$ (Fig. 10). Furthermore, $p, p^{\prime}$-BPE-3M-Cy (18) and $p, p^{\prime}$-BPP-3M-Cy (19) showed a water uptake of $2.11 \%$ and $1.84 \%$ and wet $T_{\mathrm{g}}$ knockdown of $64{ }^{\circ} \mathrm{C}$ and $58{ }^{\circ} \mathrm{C}$, respectively. These values are comparable to the commercial bisphenol references (Table 7), and show that the presence of meta-methyl groups, in contrast to ortho-methyl groups, does not improve the hydrolytic stability. ${ }^{56}$ Noteworthy, the thermal stability of $m$-methylated $p, p^{\prime}$ BPE-3M.Cy (18) is slightly higher than the $o$-methylated $p, p^{\prime}$ BPE-2M.Cy, showing an increase of $10{ }^{\circ} \mathrm{C}$ for $T_{\mathrm{d} 5 \%}$ and a $10 \%$ higher char yield at $600{ }^{\circ} \mathrm{C}$ (Table 7). ${ }^{56}$

Subsequently, Harvey et al. $(2016)^{50}$ presented $p, p^{\prime}$ BPF-3iP-6M.Cy (16), a cyanate ester resin synthesized from a carvacrol based bisphenol, characterised by ortho-methyl and meta-isopropyl substituents. $p, p^{\prime}$-BPF-3iP-6M.Cy (16) was obtained as a white solid with $117{ }^{\circ} \mathrm{C}$ m.p. A complete cure was achieved upon heating in a dynamic DSC scan, showing $T_{\mathrm{i}}$ of $194{ }^{\circ} \mathrm{C}, T_{\mathrm{p}}$ of $275^{\circ} \mathrm{C}$ and processing window of $77^{\circ} \mathrm{C}$. The resin showed excellent thermal stability with $T_{\mathrm{d} 5 \%}$ of $390{ }^{\circ} \mathrm{C}$, only $10{ }^{\circ} \mathrm{C}$ lower than the commercial bisphenol references and high char yield at $600{ }^{\circ} \mathrm{C}$ (i.e. $32 \%$ ). Besides, at temperatures above $400{ }^{\circ} \mathrm{C}$ the reference resins showed significant higher thermal stability (Table 7, Fig. 10). Comparing $p, p^{\prime}$ BPF-3iP-6M-Cy (16) with $p, p^{\prime}$-BPE-2M-Cy, showed that the thermal stability at elevated temperature was lowered by the presence of the isopropyl substituents. Interestingly, the resin showed high $T_{\mathrm{g}}$ of $224{ }^{\circ} \mathrm{C}$, a remarkably low water uptake of $0.7 \%$ and wet $T_{\mathrm{g}}$ knockdown of only $3{ }^{\circ} \mathrm{C}$. These results showed that, in addition to the beneficial impact of $o$-methyl groups, the hydrolytic stability might be further enhanced by additional hydrophobic substituents, like the isopropyl groups in meta position. ${ }^{50}$

In 2013, Meylemans et al. ${ }^{107}$ presented cyanate ester resins based on bisphenol structures preserving similar alkylation substituents ortho to and on the carbon bridge, but characterised by the $m, m^{\prime}$-isomer orientation and the presence of $o$-methoxy groups. The presented cyanate esters, viz. $m, m^{\prime}$ BGF-4M.Cy (26)， $m, m^{\prime}$-BGE-4M-Cy (27) and $m, m^{\prime}$-BGP-4M-Cy (28), were all solid at RT showing m.p. of $125{ }^{\circ} \mathrm{C}, 91^{\circ} \mathrm{C}$ and $120{ }^{\circ} \mathrm{C}$, respectively. The differences in m.p. were attributed to the space group symmetry, thus $m, m^{\prime}-\mathrm{BGF}-4 \mathrm{M} \cdot \mathrm{Cy}(\mathbf{2 6})$ and $m, m^{\prime}$-BGP-4M-Cy (28) showed to crystallize in the monoclinic space group, whereas $m, m^{\prime}$-BGE-4M.Cy (27) crystallized in the triclinic space group. Compared to the reported m.p. of their analogous $p, p^{\prime}$-isomer lacking o-methoxy moieties (i.e., $p, p^{\prime}$ BPF-3M-Cy (17), $p, p^{\prime}$-BPE-3M-Cy (18) and $p, p^{\prime}$-BPP-3M-Cy (19), Harvey et al. $(2015)^{56}$ showed that the presence of the $o$-methoxy groups and/or the $m, m^{\prime}$-isomer orientation signifi- 


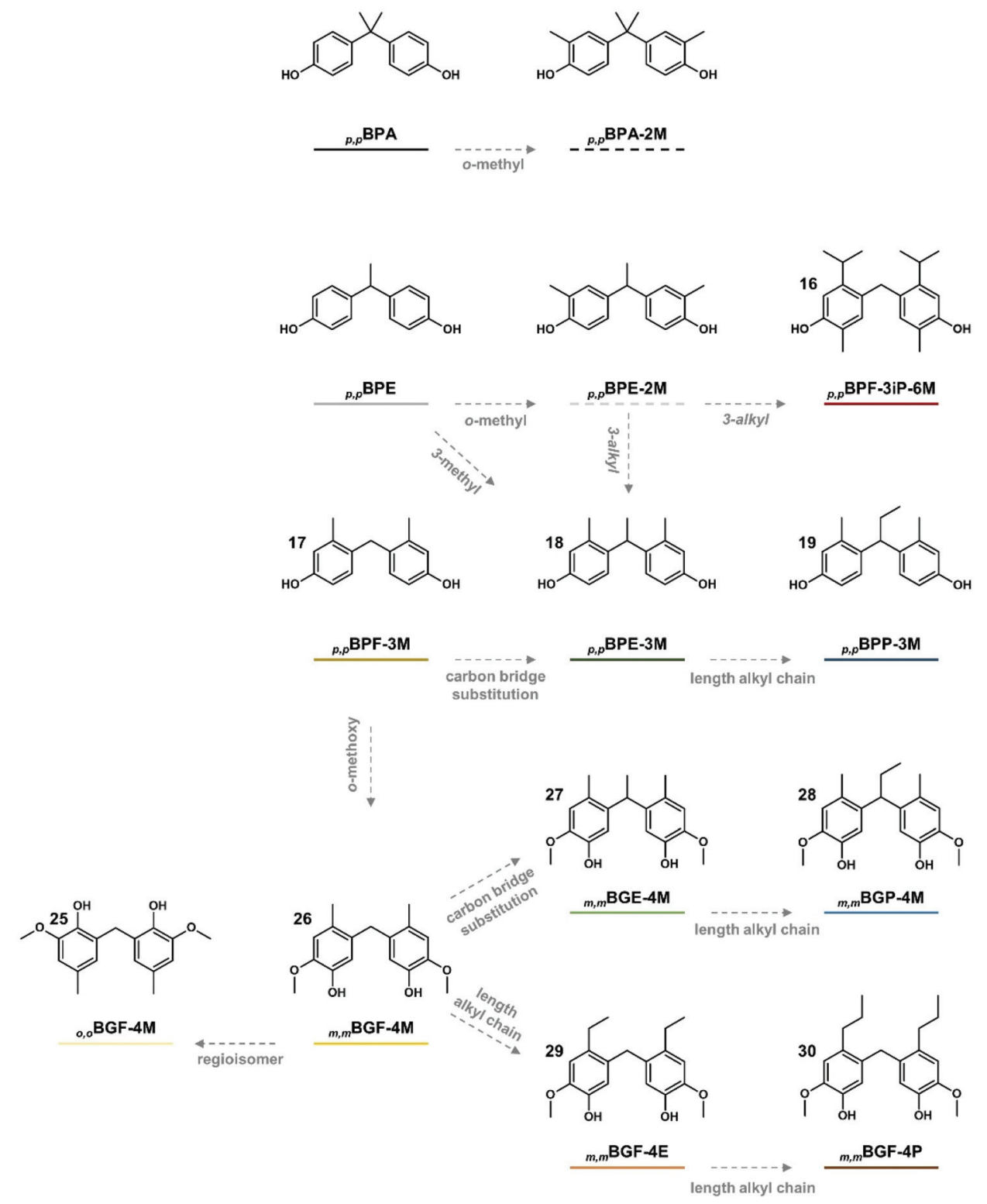

Fig. 9 Bio-bisphenols used for the synthesis of cyanate ester resins. The representation of so far reported bio-bisphenols, in addition to the petroleum-based references, used for the synthesis of cyanate ester resins and their structural relations.

cantly increased m.p. for $m, m^{\prime}$-BGF-4M-Cy (26) and $m, m^{\prime}$ BGP-4M·Cy (28), not for $m, m^{\prime}$-BGE-4M·Cy (27) (Table 6). Furthermore, a complete cure was reached for all resins in a dynamic DSC experiment. Unlike $m, m^{\prime}$-BGF-4M-Cy (26) which showed a processing window of only $20^{\circ} \mathrm{C}, m, m^{\prime}$-BGE-4M.Cy (27) and $m, m^{\prime}$-BGP-4M.Cy (28) both showed a wider processing window of $120{ }^{\circ} \mathrm{C}$. $T_{\mathrm{g}}$ 's of all as-cured CERs were equal to $257{ }^{\circ} \mathrm{C}$, this is, respectively, $20{ }^{\circ} \mathrm{C}$ lower or equal to the analogous $p, p^{\prime}$-isomers $p, p^{\prime}$-BPE-3M-Cy (18) and $p, p^{\prime}$-BPP-3M-Cy (19). The thermal stability of the CERs was found significantly lower than that of the $p, p^{\prime}$-isomer analogous and the bisphenol reference samples, showing $T_{\mathrm{d} 5 \%} \geq 330{ }^{\circ} \mathrm{C}, T_{\mathrm{d} 50 \%} \geq 375{ }^{\circ} \mathrm{C}$ and char yield $\geq 27 \% .{ }^{107}$ According to Harvey et al. (2015), ${ }^{56}$ this decrease in thermal stability is caused by the presence of the o-methoxy groups, which decreased the stability of the aliphatic bridging group by electron donation into the aromatic rings. ${ }^{56}$ In addition, the presence of the $o$-methoxy groups strikingly affected the hydrolytic stability, increasing the water uptake for $m, m^{\prime}$-BGE-4M-Cy (27) and $m, m^{\prime}$-BGP-4M-Cy (28) by $19 \%$ and $43 \%$, respectively. These results show that, in contrast to the $o$-methyl substituent, the $o$-methoxy substituents enhance the absorption of water through hydrogen bonding. Surprisingly, the water uptake and wet $T_{\mathrm{g}}$ knockdown increased with elongation of the carbon bridge alkyl chain. According to the author this was caused by increasing void space in the cured resin network. ${ }^{107}$

In 2017, Koelewijn et al. ${ }^{54}$ synthesized cyanate esters from $m, m^{\prime}$-isomer bisguaiacols characterised by an 4 -alkyl substitu- 
Table 6 Physical properties of uncured cyanate esters and curing reactivity

\begin{tabular}{|c|c|c|c|c|c|c|c|c|c|c|}
\hline \multirow[b]{2}{*}{ Ref } & \multirow[b]{2}{*}{ Nr. } & \multirow[b]{2}{*}{ Bisphenol } & \multirow[b]{2}{*}{ Yield $^{b}[\mathrm{~mol} \%]$} & \multicolumn{3}{|c|}{$\begin{array}{l}\text { Physical properties } \\
\text { uncured resin }\end{array}$} & \multicolumn{4}{|c|}{ Curing - reactivity } \\
\hline & & & & Phase $^{c}$ & Colour & $T_{\mathrm{m}}\left[{ }^{\circ} \mathrm{C}\right]$ & $T_{\mathrm{i}}^{d}\left[{ }^{\circ} \mathrm{C}\right]$ & $T_{\mathrm{p}}{ }^{d}\left[{ }^{\circ} \mathrm{C}\right]$ & $H_{\mathrm{r}}^{d}\left[\mathrm{~kJ} \mathrm{eq} \cdot{ }^{-1}\right]$ & Processing window $\left[{ }^{\circ} \mathrm{C}\right]$ \\
\hline \multicolumn{11}{|c|}{ Commercial and synthesized cyanate ester resin references } \\
\hline 102 & - & $p, p^{\prime}-\mathrm{BPA}$ & - & Solid & White & 82 & 270 & 330 & 108 & $188^{a}$ \\
\hline 102 & - & $p, p^{\prime}-\mathrm{BPE}$ & - & Liquid & White & - & 180 & 260 & 103 & $180^{a}$ \\
\hline 103 & - & $p, p^{\prime}-\mathrm{BPE}-2 \mathrm{M}$ & $48^{a}$ & Solid & White & 73 & 219 & 327 & 101 & $146^{a}$ \\
\hline 103 & - & $p, p^{\prime}-\mathrm{BPA}-2 \mathrm{M}$ & $79^{a}$ & Solid & White & 82 & 211 & 315 & 112 & $129^{a}$ \\
\hline \multicolumn{11}{|c|}{ Cyanate ester resins from bio-based bisphenols } \\
\hline 50 & 16 & $p, p^{\prime}-\mathrm{BPF}-3 \mathrm{iP}-6 \mathrm{M}$ & 91 & Solid & White & 117 & 194 & 275 & 112 & $77^{a}$ \\
\hline 56 & 17 & $p, p^{\prime}-\mathrm{BPF}-3 \mathrm{M}$ & 81 & Solid & White & 88 & $210^{a}$ & $245^{a}$ & $109-117$ & $122^{a}$ \\
\hline 56 & 18 & $p, p^{\prime}-\mathrm{BPE}-3 \mathrm{M}$ & 80 & Solid & White & 105 & $225^{a}$ & $300^{a}$ & $109-117$ & $120^{a}$ \\
\hline 56 & 19 & $p, p^{\prime}-\mathrm{BPP}-3 \mathrm{M}$ & 96 & Liquid & White & - & $200^{a}$ & $300^{a}$ & $109-117$ & $>180^{a}$ \\
\hline 54 & 26 & $m, m^{\prime}$-BGF-4M & 98 & Solid & - & 125 & 200 & 272 & 88 & 75 \\
\hline 107 & 26 & $m, m^{\prime}$-BGF-4M & 96 & Solid & White & 125 & $146^{a}$ & 216 & 106 & 20 \\
\hline 107 & 27 & $m, m^{\prime}$-BGE-4M & 88 & Solid & White & 91 & $211^{a}$ & 283 & 104 & 120 \\
\hline 107 & 28 & $m, m^{\prime}-\mathrm{BGP}-4 \mathrm{M}$ & 46 & Solid & White & 120 & $180^{a}$ & 285 & 99 & 60 \\
\hline 54 & 29 & $m, m^{\prime}-\mathrm{BGF}-4 \mathrm{E}$ & 98 & Solid & - & 108 & 223 & 309 & 61 & 115 \\
\hline 54 & 30 & $m, m^{\prime}-\mathrm{BGF}-4 \mathrm{P}$ & 97 & Solid & - & 109 & 219 & 309 & 65 & 110 \\
\hline 107 & 25 & $o, o^{\prime}-\mathrm{BGF}-4 \mathrm{M}$ & 96 & Solid & White & 151 & $151^{a}$ & 226 & 59 & $0^{a}$ \\
\hline
\end{tabular}

${ }^{a}$ Data extracted from experimental information, plots or pictures in reference. ${ }^{b}$ Theoretical yield. ${ }^{c}$ Phase at room temperature (RT). ${ }^{d}$ Dynamic DSC $\operatorname{scan}(\mathrm{s}) 10^{\circ} \mathrm{C} \mathrm{min}^{-1}$ to determine the onset of cure $\left(T_{\mathrm{i}}\right)$, the peak exotherm temperature $\left(T_{\mathrm{p}}\right)$, the heat of polymerization $\left(\mathrm{H}_{\mathrm{r}}\right)$ and processing window.

Table 7 Physical properties and thermal stability of cured cyanate ester resins. curing protocol $1 \mathrm{~h}-150^{\circ} \mathrm{C}, 24 \mathrm{~h}-210^{\circ} \mathrm{C}$ ramp $5^{\circ} \mathrm{C}$ min ${ }^{-1}$ for all references except 54 here the data corresponds to resins cured following the protocol $1 \mathrm{~h}-150^{\circ} \mathrm{C}, 24 \mathrm{~h}-210^{\circ} \mathrm{C}, 4 \mathrm{~h}-280^{\circ} \mathrm{C}$ ramp $5^{\circ} \mathrm{C}$ min ${ }^{-1}$

\begin{tabular}{|c|c|c|c|c|c|c|c|c|c|c|c|c|c|}
\hline \multirow[b]{2}{*}{ Ref } & \multirow[b]{2}{*}{ Nr. } & \multirow[b]{2}{*}{ Bisphenol } & \multicolumn{6}{|c|}{ Physical properties cured resin } & \multicolumn{5}{|c|}{ Thermal stability $^{e}$} \\
\hline & & & $\begin{array}{l}\text { Degree of } \\
\text { cure }^{b}[\%]\end{array}$ & $\begin{array}{l}\text { Cross-link } \\
\text { density } \\
{\left[\mathrm{mmol} \mathrm{cm}^{-3}\right]}\end{array}$ & $\begin{array}{l}\text { Density } \\
{\left[\mathrm{g} \mathrm{cm}^{-3}\right]}\end{array}$ & $\begin{array}{l}T_{\mathrm{g}}{ }^{c} \\
{\left[{ }^{\circ} \mathrm{C}\right]}\end{array}$ & $\begin{array}{l}\text { Water } \\
\text { uptake } \\
\text { [wt\%] }\end{array}$ & $\begin{array}{l}\text { Wet } T_{\mathrm{g}} \\
{\left[{ }^{\circ} \mathrm{C}\right]}\end{array}$ & $\begin{array}{l}T_{\mathrm{d} 5 \%} \\
{\left[{ }^{\circ} \mathrm{C}\right]}\end{array}$ & $\begin{array}{l}T_{\mathrm{d} 10 \%} \\
{\left[{ }^{\circ} \mathrm{C}\right]}\end{array}$ & $\begin{array}{l}T_{\mathrm{d} 50 \%} \\
{\left[{ }^{\circ} \mathrm{C}\right]}\end{array}$ & $\begin{array}{l}T_{\mathrm{dmax}} \\
{\left[{ }^{\circ} \mathrm{C}\right]}\end{array}$ & $\begin{array}{l}\mathrm{Char}_{600^{\circ} \mathrm{C}} \\
{[\%]}\end{array}$ \\
\hline \multicolumn{14}{|c|}{ Commercial and synthesized cyanate ester resin references } \\
\hline 102 & - & $p, p^{\prime}$-BPA & - & 2.9 & 1.21 & 275 & 1.34 & 240 & $402^{a}$ & $412^{a}$ & $555^{a}$ & - & $48^{a}$ \\
\hline 102 & - & $p, p^{\prime}-\mathrm{BPE}$ & - & 3.1 & 1.23 & 291 & 1.75 & 239 & $402^{a}$ & $412^{a}$ & $>600^{a}$ & - & $55^{a}$ \\
\hline 103 & - & $p, p^{\prime}-\mathrm{BPE}-2 \mathrm{M}$ & 99 & - & 1.14 & $246^{d}$ & 1.21 & 240 & 401 & $405^{a}$ & $560^{a}$ & 405 & 48 \\
\hline 103 & - & $p, p^{\prime}$-BPA-2M & 98 & - & 1.16 & $247^{d}$ & 1.05 & 222 & 401 & $405^{a}$ & $500^{a}$ & 405 & 43 \\
\hline \multicolumn{14}{|c|}{ Cyanate ester resins from bio-based bisphenols } \\
\hline 50 & 16 & $p, p^{\prime}$-BPF-3іP-6M & Complete & - & 1.06 & $224^{d}$ & 0.70 & 221 & 390 & $400^{a}$ & $427^{a}$ & - & $32^{a}$ \\
\hline 56 & 17 & $p, p^{\prime}-\mathrm{BPF}-3 \mathrm{M}$ & Complete & - & - & - & - & - & $410^{a}$ & $420^{a}$ & $>500^{a}$ & - & $59^{e}$ \\
\hline 56 & 18 & $p, p^{\prime}-\mathrm{BPE}-3 \mathrm{M}$ & Complete & - & 1.19 & 271 & 2.11 & 207 & $412^{a}$ & $420^{a}$ & $>500^{a}$ & - & $57^{e}$ \\
\hline 56 & 19 & $p, p^{\prime}-\mathrm{BPP}-3 \mathrm{M}$ & Complete & - & 1.16 & 256 & 1.84 & 198 & $412^{a}$ & $422^{a}$ & $>500^{a}$ & - & $52^{e}$ \\
\hline 54 & 26 & $m, m^{\prime}$-BGF-4M & Complete & - & - & 231 & 1.75 & - & 375 & 383 & $404^{a}$ & 396 & $34^{a}$ \\
\hline 107 & 26 & $m, m^{\prime}$-BGF-4M & Complete & 2.6 & 1.22 & 257 & 2.05 & 193 & 360 & 366 & $380^{a}$ & - & 35 \\
\hline 107 & 27 & $m, m^{\prime}-\mathrm{BGE}-4 \mathrm{M}$ & Complete & 2.4 & 1.20 & 257 & 2.61 & 185 & 330 & 344 & $375^{a}$ & - & 28 \\
\hline 107 & 28 & $m, m^{\prime}-\mathrm{BGP}-4 \mathrm{M}$ & Complete & 2.3 & 1.19 & 257 & 3.21 & 161 & 329 & 345 & $380^{a}$ & - & 27 \\
\hline 54 & 29 & $m, m^{\prime}$-BGF-4E & Complete & - & - & 231 & 1.36 & - & 389 & 392 & $407^{a}$ & 401 & $33^{a}$ \\
\hline 54 & 30 & $m, m^{\prime}$-BGF-4P & Complete & - & - & 193 & 1.18 & - & 389 & 393 & $415^{a}$ & 411 & $27^{a}$ \\
\hline 107 & 25 & $o, o^{\prime}$-BGF-4M & $<60$ & 2.6 & 1.24 & 181 & 2.05 & - & 317 & 326 & $370^{a}$ & - & 33 \\
\hline
\end{tabular}

${ }^{a}$ Data extracted from experimental information, plots or pictures in reference. ${ }^{b}$ Degree of cure defined by author after curing protocol -not after dynamic DSC scan-. ${ }^{c}$ DMA experiments were used to determine the glass transition temperature $\left(T_{\mathrm{g}}\right)$ defined by the maximum of tan $(\delta)$ or for ${ }^{d}$ the peak of the loss modulus. ${ }^{e}$ Thermal degradation determined by TGA under nitrogen atmosphere.

ent next to the carbon bridge. $m, m^{\prime}$-BGF-4M-Cy (26), $m, m^{\prime}$ BGF-4E.Cy (29) and $m, m^{\prime}$-BGF-4P.Cy (30) were obtained as solid resins with m.p. of $125^{\circ} \mathrm{C}, 108^{\circ} \mathrm{C}$ and $109^{\circ} \mathrm{C}$, respectively. In a dynamic DSC scan the resins did not reach complete cure. In general, the chain elongation broadens the processing window but slows down the cure of the resin. Therefore, the authors added a post cure of 4 hours at $280{ }^{\circ} \mathrm{C}$ to the curing protocol to achieve fully cured, void free resin pucks. ${ }^{54}$ Noteworthy, the processing window observed by Meylemans et al. (2013) ${ }^{107}$ for $m, m^{\prime}$-BGF-4M-Cy (26) was much smaller than the one reported by Koelewijn et al. (2017). ${ }^{54}$ This confirms that the presence of trace impurities significantly affects the curing reaction. ${ }^{104} T_{\mathrm{g}}$ of $m, m^{\prime}-\mathrm{BGF}-4 \mathrm{M} \cdot \mathrm{Cy}(26)$ and $m, m^{\prime}$ $\mathrm{BGF}-4 \mathrm{E} \cdot \mathrm{Cy}(29)$ is equal to $231^{\circ} \mathrm{C}$ and lowered upon further 

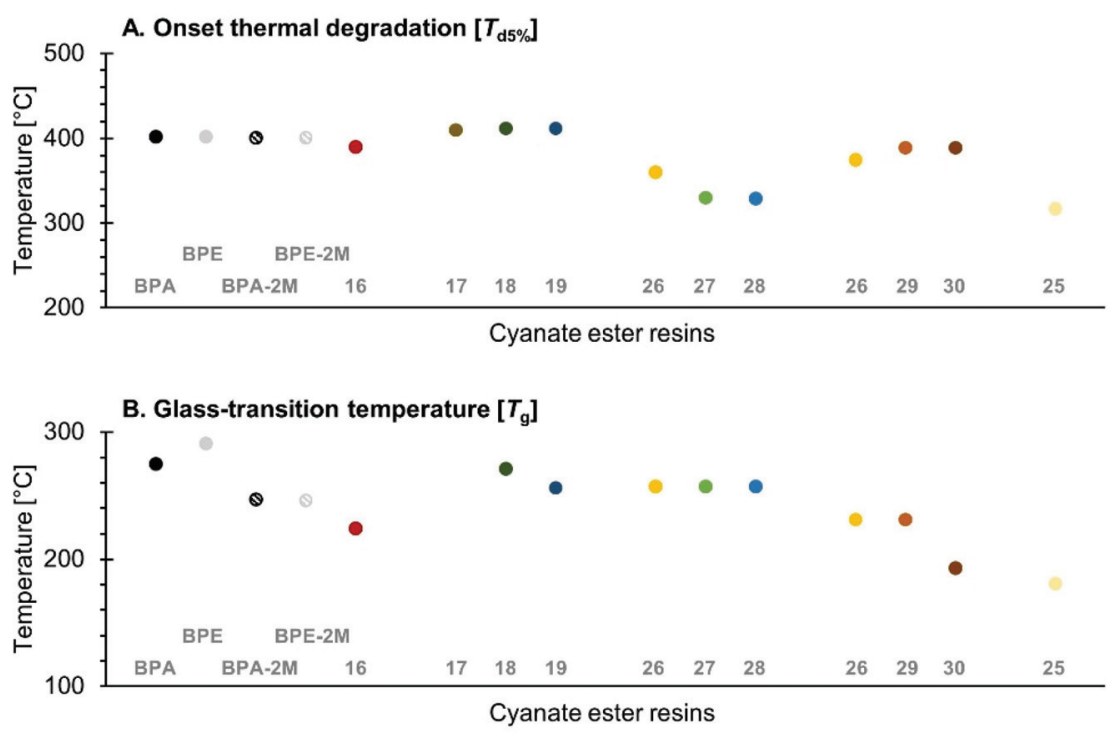

- $p, p$ BPA

- $p, p$ BPE

(2) $p, P$ BPA-2M

Q ${ }_{p, p} \mathrm{BPE}-2 \mathrm{M}$

- ${ }_{p, p}$ BPF-3iP-6M(16)

- $p, p$ BPF-3M (17)

- ${ }_{p, p} \mathrm{BPE}-3 \mathrm{M}(18)$

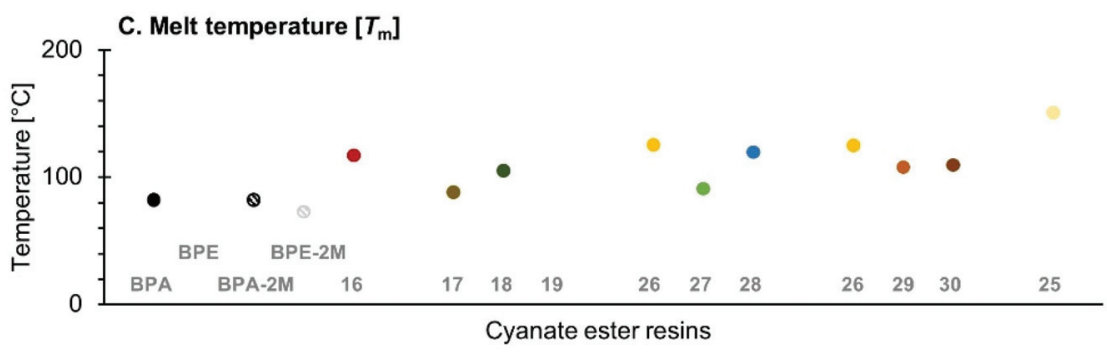

- $p, p$ BPP-3M (19)

$m, m B G F-4 M(26)$

$m_{m}$ BGE-4M (27)

- $m, m$ BGP-4M (28)

- $m_{m, m}$ BGF-4E (29)

- $m, m$ BGF-4P (30)

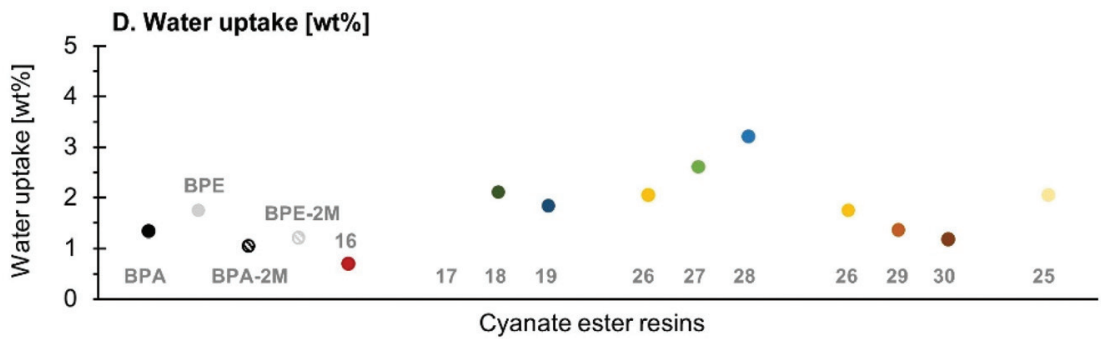

0,0 BGF-4M (25)

Fig. 10 Polymer properties of the bio-based and reference cyanate ester resins. Representation of (A) the onset thermal degradation temperature, $5 \%$ weight loss temperature $\left(T_{\mathrm{d} 5 \%}\right)$ of the cured CERs under nitrogen atmosphere (B) the glass transition temperature $\left(T_{\mathrm{g}}\right)$ of the cured CERs $(\mathrm{C})$ the melt temperature $\left(T_{m}\right)$ of the uncured CERs and (D) the water uptake in wt\% of the cured CERs after immersion in water $96 \mathrm{~h}$ at $85^{\circ} \mathrm{C}$.

elongation of the 4-alkyl chain, showing $T_{\mathrm{g}}$ of $193{ }^{\circ} \mathrm{C}$ for $m, m^{\prime}-$ BGF-4P.Cy (30) (Fig. 10). Moreover, the water uptake is lowered with alkyl chain elongation, showing a water uptake of $1.75 \%$, $1.36 \%$ and $1.18 \%$ for $m, m^{\prime}$-BGF-4M-Cy (26) $, m, m^{\prime}$-BGF-4E-Cy (29) and $m, m^{\prime}$-BGF-4P.Cy (30), respectively. This indicated that the hydrophobicity of the 4-alkyl chains had a favourable impact on the hydrophobicity of the final thermosetting polymer. The thermal stability was similar for all resins, showing $T_{\mathrm{d} 5 \%} \geq 375^{\circ} \mathrm{C}, T_{\mathrm{d} 50 \%} \geq 404{ }^{\circ} \mathrm{C}$ and char yield $\geq 27 \%$. In contrast to all other reported CERs, a similar char yield at $600{ }^{\circ} \mathrm{C}$ was observed under nitrogen and air atmosphere. ${ }^{54}$

Careful comparison of $m, m^{\prime}$-BGP-4M-Cy (28) and $m, m^{\prime}$ BGF-4P.Cy (30), highlights the importance of the alkyl chain position to beneficially influence water uptake. For the alkyl chain next to the carbon bridge, the water uptake decreases with elongation, for an alkyl chain on the carbon bridge, the water uptake increases with elongation.

Finally, the cyanate ester of an $o, o^{\prime}$-isomer is reported by Meylemans et al. (2013). ${ }^{107} o, o^{\prime}$-BGF-4M-Cy (25) is obtained as a solid with m.p. of $151{ }^{\circ} \mathrm{C}$. Hence, the $o, o^{\prime}$-isomer orientation increased the m.p. of the resin with $26^{\circ} \mathrm{C}$ compared to the analogous $m, m^{\prime}$-isomer, $m, m^{\prime}$-BGF-4M-Cy (26). The cure onset immediately followed the resin melt in a dynamic DSC scan and an incomplete cure was achieved. Hence, a post cure of 4 hours at $250{ }^{\circ} \mathrm{C}$ was added to achieve a complete cured resin puck, reaching a dry $T_{\mathrm{g}}$ of $238{ }^{\circ} \mathrm{C} .{ }^{107}$ Unfortunately all other parameters like water uptake, wet $T_{\mathrm{g}}$ and thermal stability were not reported for this fully-cured resin. To avoid any confusion, the reported data for the as-cured (i.e. incomplete cured) resin will not be further discussed, but it is shown in Table 7 . 
In general, m.p. of the cyanate esters is influenced by (i) the isomer orientation and (ii) the presence of $o$-methoxy groups. $T_{\mathrm{g}}$ of CERs is lowered upon elongation of the 4-alkyl chain on the bisphenol. Furthermore, the thermoset's thermal stability decreased by the presence of $o$-methoxy moieties. Whereas the presence of $o$-methoxy groups increased the CERs water uptake, the presence of $o$-methyl decreased the CERs water uptake. Moreover, the introduction of hydrophobic alkyl chains ortho to the carbon bridge significantly lowered water uptake. Combining both favourable structural features, the $p, p^{\prime}$-BPF-3iP-6M-Cy (16) showed the highest hydrolytic stability with a low water uptake of only $0.7 \%$ and wet $T_{\mathrm{g}}$ knockdown of only $3{ }^{\circ} \mathrm{C}$. To conclude, the current bio-based CERs show $T_{\mathrm{g}}$ 's ranging from $193{ }^{\circ} \mathrm{C}$ to $271{ }^{\circ} \mathrm{C}$ and thermal stability with $T_{\mathrm{d} 5 \%}$ $\geq 329{ }^{\circ} \mathrm{C}, T_{\mathrm{d} 50 \%} \geq 375{ }^{\circ} \mathrm{C}$ and char yield $\geq 27 \%$, and thus reaching the performance of the fossil-based bisphenol CERs. Moreover, through the use of bio-bisphenols characterized by hydrophobic alkyl chains ortho to the carbon bridge, hydrolytically stable CERs were obtained surpassing the stability of the current bisphenol references.

\subsection{Benzoxazine resins}

The formation of heterocyclic compounds as benzoxazine resins (Bzs), through the Mannich reaction of phenols, primary amines and formaldehyde is known since 1944. In an attempt to improve the material functionality, Ning X. and Ishida $\mathrm{H}$. presented the first bifunctional benzoxazine resin (Bz) from $p, p^{\prime}$-BPA, methylamine and formaldehyde in $1994{ }^{108}$ Nowadays, BPA is still an important precursor for the synthesis of benzoxazines (Fig. S2e, ESI $\dagger$ ). ${ }^{109}$ The benzoxazines cure upon heating by a ring-opening polymerization reaction yielding a polybenzoxazine network (PBz). Usage of bifunctional monomers results in a cross-linked network. This polymerization is initiated by phenols with a free ortho-position, in situ added or produced by self-dissociation of the $\mathrm{Bz}$ monomer upon heating. In addition, the polymerization reaction can be accelerated by the addition of a Lewis acid catalyst. ${ }^{108}$ During the last two decades, the synthesis of diverse PBz attracted great interest as they combine the thermal flame retardant of phenolic resins and the design flexibility of epoxy resins. ${ }^{110}$ Showing a low water adsorption, low flammability, zero volume shrinkage upon curing, low dielectric constant and high $T_{\mathrm{g}}, \mathrm{PBz}$ are used in diverse applications, such as aerospace materials and anticorrosive coatings. ${ }^{109,110}$ All Bz monomers synthesized from bio-bisphenols, related petroleumbased references and their structural relations are presented in Fig. 11. Details and collected data of the uncured and cured Bzs are summarized in Tables 8, 9 and represented in Fig. 12.

In 2016, Periyasamy et al. ${ }^{62}$ presented the $\mathrm{Bz}$ monomer derived from mix'-BGF, isomer distribution not mentioned by author, using stearylamine, yielding mix'-BGF·SBz (2-21-22). In this abbreviation 'SBz' stands for a stearylamine (S) based benzoxazine monomer $(\mathrm{Bz})$. This monomer was obtained as a solid at RT, showing m.p. of $94{ }^{\circ} \mathrm{C}$. The BPF reference SBz, mix'-BPF.SBz was recently reported by Manoj et al. $(2020)^{109}$ and showed to be liquid at RT. ${ }^{109}$ This implies that the presence of (i) the $o$-methoxy groups and/or (ii) other isomer orientations increased m.p. of the Bz monomer. Upon heating in a

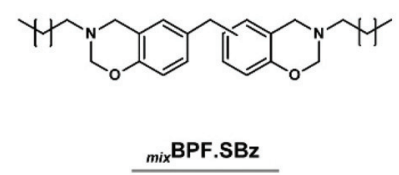
$\stackrel{-m e t h o x y}{\longrightarrow-m}$

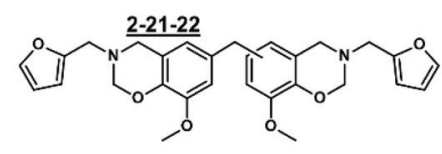

${ }_{m i x} B G F . F B z$

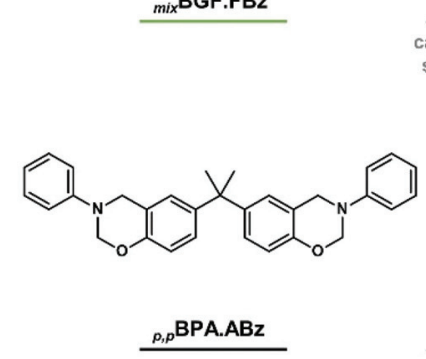

carbon bridg substitution

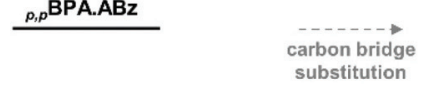
substitution
${ }_{\text {mix }}$ BPF.SBz

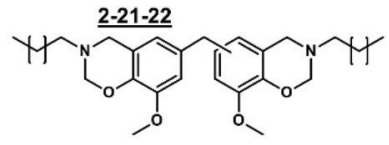

mix BGF.SBz

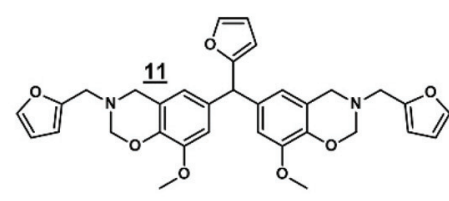

${ }_{p, p} \mathrm{BGF}_{\mathrm{UR}} \cdot \mathrm{FBz}$
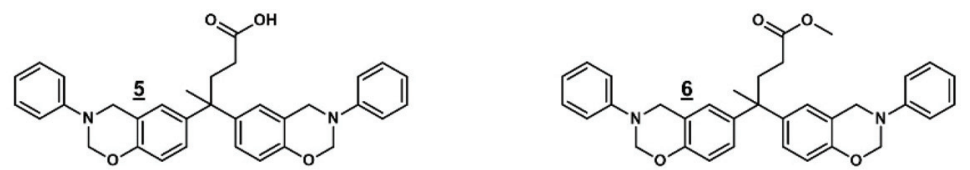

$\underline{p, p \text { DPA.ABz }}$

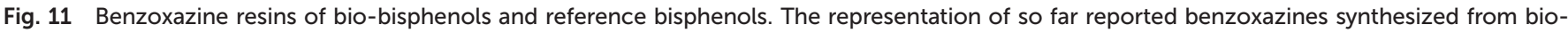
bisphenols, in addition to the petroleum-based references, and their structural relations. 
Table 8 Physical properties of uncured benzoxazine resins and curing reactivity

\begin{tabular}{|c|c|c|c|c|c|c|c|c|c|c|}
\hline \multirow[b]{2}{*}{ Ref. } & \multirow[b]{2}{*}{ Nr. } & \multirow[b]{2}{*}{ Bisphenol } & \multirow[b]{2}{*}{ Yield $^{b}[\mathrm{~mol} \%]$} & \multicolumn{3}{|c|}{$\begin{array}{l}\text { Physical properties uncured } \\
\text { resin }\end{array}$} & \multicolumn{4}{|c|}{ Curing - reactivity } \\
\hline & & & & Phase $^{c}$ & Colour & $T_{\mathrm{m}}\left[{ }^{\circ} \mathrm{C}\right]$ & $T_{\mathrm{i}}{ }^{d}\left[{ }^{\circ} \mathrm{C}\right]$ & $T_{\mathrm{p}}{ }^{d}\left[{ }^{\circ} \mathrm{C}\right]$ & $\mathrm{H}_{\mathrm{r}}{ }^{d}\left[\mathrm{~kJ}\right.$ eq. $\left.{ }^{-1}\right]$ & Processing window $\left[{ }^{\circ} \mathrm{C}\right]$ \\
\hline \multicolumn{11}{|c|}{ Reagent: stearylamine } \\
\hline 109 & - & $m i x^{\prime}-\mathrm{BPF}$ & - & - & - & - & 209 & 239 & - & $>189^{a}$ \\
\hline 62 & $2-21-22$ & $m i x^{\prime}-\mathrm{BGF}$ & 89 & Solid & Pale-yellow & 94 & 216 & 238 & - & 122 \\
\hline \multicolumn{11}{|c|}{ Reagent: furfurylamine } \\
\hline $112^{\circ}$ & - & $p, p^{\prime}-\mathrm{BPA}$ & 57 & Solid & - & 105 & 233 & $245^{a}$ & $266^{a}$ & 142 \\
\hline 62 & $2-21-22$ & $m i x^{\prime}-\mathrm{BGF}$ & 91 & Solid & Pale-yellow & 117 & 194 & 224 & - & 77 \\
\hline 51 & 11 & $p, p^{\prime}-\mathrm{BGF}_{\mathrm{UR}}$ & 76 & Solid & White & $126 ; 153$ & 204 & 242 & $204^{a}$ & 51 \\
\hline 113 & 5 & $p, p^{\prime}$-DPA & 86 & Solid & Brown-yellow & - & 150 & 185 & - & - \\
\hline \multicolumn{11}{|c|}{ Reagent: 1,3,5-triphenylhexahydro,1,3,5-triazine } \\
\hline 114 & - & $p, p^{\prime}$-BPA & 一 & - & - & - & 210 & 256 & - & - \\
\hline 113 & - & $p, p^{\prime}$-BPA & - & - & - & - & 223 & 234 & - & - \\
\hline 114 & 5 & $p, p^{\prime}$-DPA & 95 & Solid & Yellowish & - & 150 & 192 & - & - \\
\hline 47 & 5 & $p, p^{\prime}-\mathrm{DPA}$ & 95 & Solid & Yellowish & - & 152 & 189 & $311^{a}$ & - \\
\hline 114 & 6 & $p, p^{\prime}$-DPA-Me & 93 & Solid & Pale-yellow & - & 210 & 261 & - & - \\
\hline 47 & 6 & $p, p^{\prime}$-DPA-Me & 92 & Solid & Yellowish & - & 167 & 231 & $331^{a}$ & - \\
\hline
\end{tabular}

Table 9 Physical properties and thermal stability of cured benzoxazine resins

\begin{tabular}{|c|c|c|c|c|c|c|c|c|c|c|}
\hline \multirow[b]{2}{*}{ Ref. } & \multirow[b]{2}{*}{ Nr. } & \multirow[b]{2}{*}{ Bisphenol } & \multirow[b]{2}{*}{ Cure protocol } & \multicolumn{7}{|c|}{ Thermal stability $^{d}$} \\
\hline & & & & $\begin{array}{l}T_{\mathrm{g}}{ }^{b} \\
{\left[{ }^{\circ} \mathrm{C}\right]}\end{array}$ & $\mathrm{LOI}^{c}$ & $\begin{array}{l}T_{\mathrm{d} 5 \%} \\
{\left[{ }^{\circ} \mathrm{C}\right]}\end{array}$ & $\begin{array}{l}T_{\mathrm{d} 10 \%} \\
{\left[{ }^{\circ} \mathrm{C}\right]}\end{array}$ & $\begin{array}{l}T_{\mathrm{d} 50 \%} \\
{\left[{ }^{\circ} \mathrm{C}\right]}\end{array}$ & $\begin{array}{l}T_{\mathrm{dmax}} \\
{\left[{ }^{\circ} \mathrm{C}\right]}\end{array}$ & $\begin{array}{l}\mathrm{Char}_{800^{\circ} \mathrm{C}}{ }^{d} \\
{[\%]}\end{array}$ \\
\hline \multicolumn{11}{|c|}{ Reagent: stearylamine } \\
\hline $109^{\circ}$ & - & $m i x^{\prime}-\mathrm{BPF}$ & $5 \mathrm{~h}-250^{\circ} \mathrm{C}$ & - & 29.1 & 391 & 414 & $530^{a}$ & 461 & $29^{a}$ \\
\hline 62 & $2-21-22$ & $m i x^{\prime}-\mathrm{BGF}$ & $1 \mathrm{~h}-100^{\circ} \mathrm{C} ; 150^{\circ} \mathrm{C}, 200^{\circ} \mathrm{C}, 250^{\circ} \mathrm{C}$ & 124 & 32.8 & 349 & 381 & $525^{a}$ & - & 38 \\
\hline \multicolumn{11}{|c|}{ Reagent: furfurylamine } \\
\hline $112^{\circ}$ & - & $p, p^{\prime}-\mathrm{BPA}$ & $1 \mathrm{~h}-160^{\circ} \mathrm{C} ; 2 \mathrm{~h}-200^{\circ} \mathrm{C}, 2 \mathrm{~h}-240^{\circ} \mathrm{C}$ & 308 & 36.7 & 347 & 391 & $750^{a}$ & - & $48^{a}$ \\
\hline 62 & $2-21-22$ & $m i x^{\prime}-\mathrm{BGF}$ & $1 \mathrm{~h}-100^{\circ} \mathrm{C} ; 150^{\circ} \mathrm{C}, 200^{\circ} \mathrm{C}, 250^{\circ} \mathrm{C}$ & 147 & 38.5 & 382 & 417 & $>800$ & - & 52 \\
\hline 51 & 11 & $p, p^{\prime}-\mathrm{BGF}_{\mathrm{UR}}$ & $1 \mathrm{~h}-140^{\circ} \mathrm{C} ; 160^{\circ} \mathrm{C}, 180^{\circ} \mathrm{C}, 200^{\circ} \mathrm{C}, 220^{\circ} \mathrm{C}, 240^{\circ} \mathrm{C}$ & 290 & 42.3 & 340 & 375 & $>800^{a}$ & - & 62 \\
\hline 113 & 5 & $p, p^{\prime}$-DPA & $1 \mathrm{~h}-140^{\circ} \mathrm{C} ; 170^{\circ} \mathrm{C}, 190^{\circ} \mathrm{C}, 210^{\circ} \mathrm{C}, 240^{\circ} \mathrm{C}$ & - & $37.6^{a}$ & 340 & $380^{a}$ & $800^{a}$ & 449 & 50 \\
\hline \multicolumn{11}{|c|}{ Reagent: 1,3,5-triphenylhexahydro,1,3,5-triazine } \\
\hline 114 & - & $p, p^{\prime}-\mathrm{BPA}$ & $2 \mathrm{~h}-140^{\circ} \mathrm{C} ; 215^{\circ} \mathrm{C}, 235^{\circ} \mathrm{C}, 260^{\circ} \mathrm{C}$ & 172 & $31.1^{a}$ & $310^{a}$ & 366 & $490^{a}$ & 427 & 34 \\
\hline 113 & - & $p, p^{\prime}-\mathrm{BPA}$ & $1 \mathrm{~h}-210^{\circ} \mathrm{C} ; 2 \mathrm{~h}-220^{\circ} \mathrm{C} ; 230^{\circ} \mathrm{C}, 1 \mathrm{~h}-240^{\circ} \mathrm{C}$ & - & $29.7^{a}$ & 331 & $380^{a}$ & $470^{a}$ & 406 & 31 \\
\hline 114 & 5 & $p, p^{\prime}$-DPA & $2 \mathrm{~h}-140^{\circ} \mathrm{C} ; 160^{\circ} \mathrm{C}, 180^{\circ} \mathrm{C}, 190^{\circ} \mathrm{C}$ & 206 & $30.3^{a}$ & $310^{a}$ & 348 & $450^{a}$ & 425 & 32 \\
\hline 47 & 5 & $p, p^{\prime}$-DPA & $1 \mathrm{~h}-140{ }^{\circ} \mathrm{C} ; 160^{\circ} \mathrm{C}, 180^{\circ} \mathrm{C}, 200^{\circ} \mathrm{C}, 220^{\circ} \mathrm{C}, 240^{\circ} \mathrm{C}$ & - & 32.7 & 344 & 377 & 501 & 442 & 38 \\
\hline 114 & 6 & $p, p^{\prime}$-DPA-Me & $2 \mathrm{~h}-140{ }^{\circ} \mathrm{C} ; 215^{\circ} \mathrm{C}, 235^{\circ} \mathrm{C}, 260^{\circ} \mathrm{C}$ & 270 & $29.9^{a}$ & $360^{a}$ & 379 & $450^{a}$ & 420 & 31 \\
\hline 47 & 6 & $p, p^{\prime}$-DPA-Me & $1 \mathrm{~h}-140^{\circ} \mathrm{C} ; 160^{\circ} \mathrm{C}, 180^{\circ} \mathrm{C}, 200^{\circ} \mathrm{C}, 220^{\circ} \mathrm{C}, 240^{\circ} \mathrm{C}$ & - & 30.5 & 335 & 361 & 479 & 448 & 33 \\
\hline
\end{tabular}

${ }^{a}$ Data extracted from experimental information, plots or pictures in reference. ${ }^{b}$ DMA experiments were used to determine the glass transition temperature $\left(T_{\mathrm{g}}\right)$ defined by the maximum of $\tan (\delta) .{ }^{c}$ LOI following the Van Krevelen and Hoftyzer relation. ${ }^{d}$ Thermal degradation determined by TGA under nitrogen atmosphere.

dynamic DSC scan, mix'-BGF.SBz (2-21-22) and $m i x^{\prime}-\mathrm{BPF} \cdot \mathrm{SBz}$ show similar $T_{\mathrm{i}}$ and $T_{\mathrm{p}}$ of the cure reactions, resulting in wide processing windows of $122{ }^{\circ} \mathrm{C}$ and $>189{ }^{\circ} \mathrm{C}$ for the resins, respectively (Table 8). Surprisingly, this indicates that, despite the occupied ortho-position, the presence of the o-methoxy groups does not influence the reactivity for the ring-opening polymerization. $T_{\mathrm{g}}$ of the mix'-BGF·SBz (2-21-22) thermoset was found $124{ }^{\circ} \mathrm{C}$. Although $T_{\mathrm{d} 5 \%} 42{ }^{\circ} \mathrm{C}$ lower than the mix'$\mathrm{BPF} \cdot \mathrm{SBz}$ thermoset reference, the mix'-BGF.SBz (2-21-22) thermoset showed similar $T_{\mathrm{d} 50 \%}$ and even a $9 \%$ higher char yield at $800^{\circ} \mathrm{C}$. This resulted in a higher limiting oxygen index (LOI) for the $m i x^{\prime}$-BGF·SBz (2-21-22) thermoset (cfr. $m i x^{\prime}$-BPF-SBz thermoset), derived by the Van Krevelen and Hoftyzer relation between char yield and the LOI index (Table 9). ${ }^{62,111}$

The introduction of furanic groups in $\mathrm{Bz}$ monomers showed to enhance $T_{\mathrm{g}}$, storage moduli and thermal stability of the cured resin. This is mostly attributed to the active role of the furanic groups during the ring-opening polymerization, yielding di-substituted furanic groups and highly cross-linked resins. In addition, the presence of furanic groups in the resins network enhances hydrogen bond formation limiting molecular mobility in the cured network, increasing $T_{\mathrm{g}}{ }^{112} \mathrm{In}$ this regard, Periyasamy et al. (2016) $)^{62}$ and Yang et al. $(2020)^{51}$ presented the Bzs of the bisguaiacols mix'-BGF (2-21-22) and 
$p, p^{\prime}-\mathrm{BGF}_{\mathrm{UR}}$ (11) and furfurylamine yielding mix'-BGF.FBz (2-21-22) and $p, p^{\prime}-\mathrm{BGF}_{\mathrm{UR}} \cdot \mathrm{FBz}$ (11), respectively. Both BzS were obtained as solids, with m.p. of $117^{\circ} \mathrm{C}$ for mix'-BGF·FBz (2-21-22) and two observed melting points of $126{ }^{\circ} \mathrm{C}$ and $153{ }^{\circ} \mathrm{C}$ for $p, p^{\prime}-\mathrm{BGF}_{\mathrm{UR}} \cdot \mathrm{FBz}(\mathbf{1 1}) . T_{\mathrm{i}}$ of both resins was around $200{ }^{\circ} \mathrm{C}$ in a dynamic DSC scan, but $T_{\mathrm{p}}$ was found $18{ }^{\circ} \mathrm{C}$ lower for $m i x^{\prime}$-BGF·FBz (2-21-22), indicating slightly lower reactivity of the $p, p^{\prime}-\mathrm{BGF}_{\mathrm{UR}} \cdot \mathrm{FBz}(\mathbf{1 1})$. In addition, a lower cure enthalpy was observed for $p, p^{\prime}-\mathrm{BGF}_{\mathrm{UR}} \cdot \mathrm{FBz}(\underline{\mathbf{1 1}})\left(204 \mathrm{~kJ}\right.$ eq. $\left.{ }^{-1}\right)$ compared to the commercial BPA-based $\mathrm{Bz}, p, p^{\prime}-\mathrm{BPA} \cdot \mathrm{FBz}(266 \mathrm{~kJ}$ eq. $\left.{ }^{-1}\right) .{ }^{112}$ According to Yang et al. $(2020)^{51}$ this showed that the polymerization reaction of $p, p^{\prime}-\mathrm{BGF}_{\mathrm{UR}} \cdot \mathrm{FBz}(\mathbf{1 1})$ was impeded by the presence of ortho-methoxy groups, occupying one of the favourable substitution positions for the ring-opening polymerization. ${ }^{51}$ For the $m i x^{\prime}-\mathrm{BGF} \cdot \mathrm{FBz}(\underline{\mathbf{2 - 2 1 - 2 2}})$ thermoset $T_{\mathrm{g}}$ of $147^{\circ} \mathrm{C}$ was observed. This is more than $150{ }^{\circ} \mathrm{C}$ lower than the commercial $p, p^{\prime}$-BPA.FBz thermoset, showing the impact of the $o$-methoxy groups and/or the methylene bridge on $T_{\mathrm{g}}$, i.e., providing a higher rotational degree to the resin's network. The former aspect was tackled by incorporation of an additional furan on the bisguaiacol carbon bridge showing $T_{\mathrm{g}}$ of $290{ }^{\circ} \mathrm{C}$ for the $p, p^{\prime}-\mathrm{BGF}_{\mathrm{UR}} \cdot \mathrm{FBz}(\mathbf{1 1})$ thermoset (Table 9, Fig. 12). Moreover, it was shown by Yang et al. $(2020)^{51}$ that at elevated temperatures, residual furanic groups further polymerize yielding an (even) higher cross-linked resin. This feature has a beneficial impact on the thermoset's thermal stability, showing a char yield at $800{ }^{\circ} \mathrm{C}$ of $62 \%$ and LOI of 42.3. ${ }^{51}$ Noteworthy, the mix'-BGF.FBz (2-21-22) thermoset showed excellent thermal stability too, with $T_{\mathrm{d} 5 \%}$ of $382{ }^{\circ} \mathrm{C}$, $T_{\mathrm{d} 50 \%}$ above $800{ }^{\circ} \mathrm{C}$, char yield at $800{ }^{\circ} \mathrm{C}$ of $52 \%$ and LOI of 38.5. ${ }^{62}$ This shows that bio-based PBzs are reaching and/or surpassing the thermal stability of the conventional BPA-based PBz, showing $T_{\mathrm{d} 5 \%}$ of $347{ }^{\circ} \mathrm{C}, T_{\mathrm{d} 50 \%}$ of $750{ }^{\circ} \mathrm{C}$, char yield at $800{ }^{\circ} \mathrm{C}$ of $48 \%$ and LOI of 36.7 (Table 9).

In addition, Zhan et al. $(2020)^{113}$ presented the $\mathrm{Bz}$ monomer derived from $p, p^{\prime}$-DPA (5) and furfurylamine, $p, p^{\prime}$ DPA.FBz (5). Interestingly, the $T_{\mathrm{i}}$ was found more than $80^{\circ} \mathrm{C}$ lower than $p, p^{\prime}$-BPA.FBz (Table 8 ). This was attributed to the presence of the carboxyl group, which is able to catalyse the ring-opening polymerization reaction, hence, lower the cure onset temperature $\left(T_{\mathrm{i}}\right)$. Moreover, the thermal stability of the $p, p^{\prime}$-DPA.FBz (5) thermoset, with $T_{\mathrm{d} 5 \%}$ of $340{ }^{\circ} \mathrm{C}, T_{\mathrm{d} 50 \%}$ of $800{ }^{\circ} \mathrm{C}$, char yield at $800{ }^{\circ} \mathrm{C}$ of $50 \%$ and LOI of 37.6 , was comparable to the BPA reference. ${ }^{113}$

Looking into the potential of $p, p^{\prime}$-DPA and $p, p^{\prime}$-DPA-esters, like $p, p^{\prime}$-DPA-Me (6), Zúñiga et al. $(2011)^{114}$ and Yan et al. $(2016)^{47}$ synthesized $p, p^{\prime}-\mathrm{DPA} \cdot \mathrm{ABz}(\underline{\mathbf{5}})$ and $p, p^{\prime}-\mathrm{DPA}-\mathrm{Me} \cdot \mathrm{ABz}(\underline{\mathbf{6}})$ using 1,3,5-triphenylhexahydro-1,3,5-triazine as amine precursor. These $\mathrm{Bz}$ monomers are characterised by the presence of aryl structures that can participate in the polymerization reaction. Comparing the exotherm cure events of $p, p^{\prime}-\mathrm{DPA} \cdot \mathrm{ABz}(\mathbf{5})$ and $p, p^{\prime}$-DPA-Me.ABz (6) in a dynamic DSC scan, both authors observed a lower $T_{\mathrm{i}}$ for $p, p^{\prime}-\mathrm{DPA} \cdot \mathrm{ABz}(5)$ around $150{ }^{\circ} \mathrm{C}$, attributed to the presence of carboxylic groups (Table 8). The cure exotherm of $p, p^{\prime}$-DPA-Me.ABz (6) was comparable to the BPA reference, $p, p^{\prime}$-BPA-ABz. Moreover, it was shown that, in addition to the ring-opening polymerization, esterification or transesterification of the acidic groups and the free hydroxyl groups (i.e., phenolic $\mathrm{OH}$ formed during ring opening of oxazines) in $p, p^{\prime}$-DPA-ABz (5) and $p, p^{\prime}$-DPA-Me·ABz (6) increased the cross-link density in the cured network. The thermosets showed $T_{\mathrm{g}}$ of $206{ }^{\circ} \mathrm{C}$ and $270{ }^{\circ} \mathrm{C}$ for $p, p^{\prime}$-DPA.ABz (5) and $p, p^{\prime}-$ $\mathrm{DPA}-\mathrm{Me} \cdot \mathrm{ABz}(6)$, respectively, surpassing that of the reference $p, p^{\prime}$-BPA.ABz $\left(172{ }^{\circ} \mathrm{C}\right)$. With $T_{\mathrm{d} 5 \%} \geq 310{ }^{\circ} \mathrm{C}, T_{\mathrm{d} 50 \%} \geq 450{ }^{\circ} \mathrm{C}$, char yield at $800{ }^{\circ} \mathrm{C} \geq 31 \%$ and LOI above 30 , the thermal stability of thermosets showed to be comparable to the reference $p, p^{\prime}$-BPA·ABz thermosets, showing $T_{\mathrm{d} 5 \%} \geq 310{ }^{\circ} \mathrm{C}, T_{\mathrm{d} 50 \%} \geq$ $470{ }^{\circ} \mathrm{C}$, char yield at $800{ }^{\circ} \mathrm{C}$ above $\geq 31 \%$ and LOI above $30 .{ }^{114}$

In general, it is shown that (i) the bisphenol isomer orientation and/or (ii) the presence of $o$-methoxy groups influenced the $\mathrm{Bz}$ monomer melting point. $T_{\mathrm{g}}$ of the thermoset is lowered by the presence of $o$-methoxy moieties but increased through the incorporation of a furanic group on the carbon bridge, impacting the polymer rigidity and reaching a higher crosslink density. A $T_{\mathrm{g}}$ surpassing the BPA reference $\mathrm{PBz}$, was found for the PBz of $p, p^{\prime}$-DPA (5) and $p, p^{\prime}$-DPA-Me (6) with $T_{\mathrm{g}}$ of $206{ }^{\circ} \mathrm{C}$ and $270{ }^{\circ} \mathrm{C}$, respectively. This was attributed to the acidic group on the carbon bridge, increasing the cross-link density through esterification and transesterification reactions with the free hydroxyl groups formed during the conventional ring-opening polymerization of the oxazines. Moreover, the presence of free carboxyl groups showed to catalyse the curing reaction, resulting in a lower cure onset temperature. In addition, the thermal stability and LOI of all bio-based PBz was found comparable or even higher than the BPA-references, highlighting the potential of bio-based bisphenols for the synthesis of high-performance benzoxazine resins.

\section{In vitro oestrogenic activity: structure-toxicity}

The adverse health effects (e.g., cancer, ${ }^{11,12}$ reproductive issues, ${ }^{13,14}$ obesity ${ }^{15}$ ) linked to human BPA exposure originate from its ability to interfere with the endocrine system. In this regard, BPA is recognized as a synthetic xenoestrogen; a synthetic chemical structure that can mimic the natural oestrogen hormones, such as $17 \beta$-oestradiol (E2). ${ }^{115}$ Moreover, a metabolite of BPA, viz. 4-methyl-2,4-bis(4-hydroxyphenyl)pent-1-ene (MBP), showed a 1000-fold higher oestrogenic activity (EA) compared to BPA. ${ }^{116}$ Hence, the pharmacophore of E2 provides valuable information to understand how BPA as well as its metabolites interact with the oestrogen receptors $\alpha(\mathrm{ER} \alpha)$ and/or $\beta(\operatorname{ER} \beta)$ and how EA can be designed out of the next generation of BPA molecules. ${ }^{117}$ In general, the pharmacophore of E2 is described as two hydroxyl groups separated by a hydrophobic spacer which includes an aromatic ring. Fig. 13 presents the molecular structures of E2, BPA and MBP. Overall, the key feature for oestrogen receptor binding affinity is the hydroxyl group on the aromatic A-ring (i.e., 3-OH) which binds with the receptor via hydrogen bonding (i.e., H-bond donor or acceptor). ${ }^{118}$ Therefore, additional substituents on the A-ring 

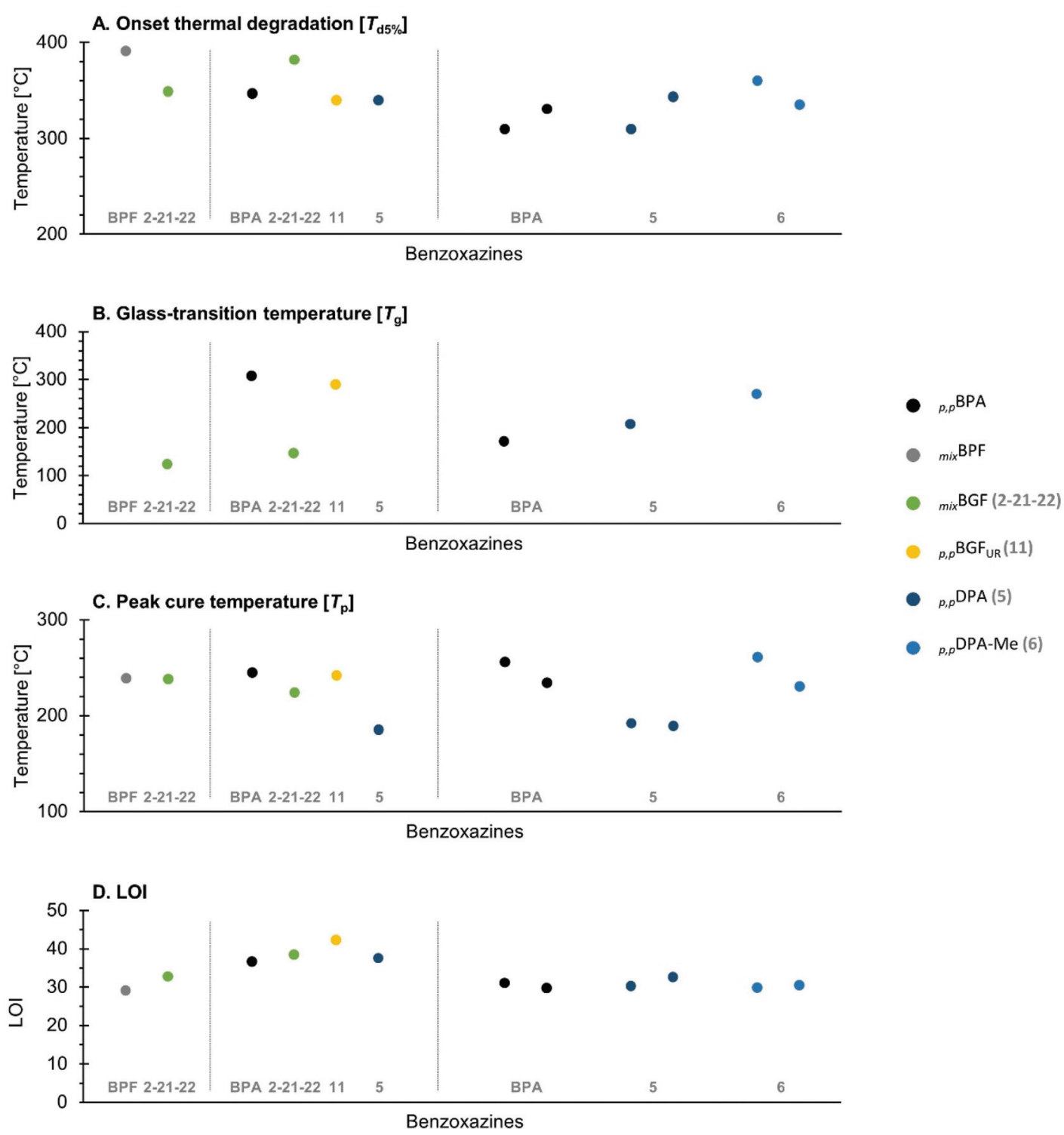

Fig. 12 Curing and polymer properties of the benzoxazine resins. Representation of (A) the onset thermal degradation temperature, $5 \%$ weight loss temperature $\left(T_{\mathrm{d} 5 \%}\right)$ of the cured Bzs under nitrogen atmosphere $(\mathrm{B})$ the glass transition temperature $\left(T_{\mathrm{g}}\right)$ of the cured Bzs (C) the cure peak temperature $\left(T_{\mathrm{p}}\right)$ determined during a dynamic DSC scan, heating ramp $10^{\circ} \mathrm{C} \mathrm{min}^{-1}$ and (D) the LOI index of the cured Bzs. The benzoxazines are divided in sections according to the amine reagent used from left to right: stearylamine, furfurylamine and 1,3,5-triphenylhexahydro,1,3,5,-triazine.

impact the EA either by (i) altering the acidity of the phenolic 3-OH, (ii) competitive intramolecular H-bonding sites and/or (iii) steric interference. In addition, some other structural alterations to E2's molecular structure are not well tolerated and significantly lower the EA binding affinity: (i) substituents incorporated at position 6 and/or (ii) polar substituents incorporated at position 11 (Fig. 13). ${ }^{118}$

In general, the molecular structures of the presented biobased bisphenols (Fig. 1) differ in four structural aspects: (i) isomer orientation, (ii) aromatic $o$-substituents (i.e., hydroxyl, methyl, methoxy), (iii) carbon bridge substituents, and (iv) aromatic $m$ - or $p$-substituents (i.e., alkyl).

Hence, to avoid the synthesis of regrettable BPA alternatives, the impact of these four structural features on the bisphenol's EA will be discussed in this section. More specifically, the following results and trends were shown by in vitro oestrogen receptor transactivation or binding assays providing a reliable assessment of the compounds oestrogen activity, expressed as potency and efficacy (vide infra) or binding affinity (RBA) for ER $\alpha$ and/or ER $\beta$. However, to assess the integral endocrine disruptive character of the compounds additional in vitro assays evaluating the affinity for other receptors belonging to the steroid/thyroid nuclear hormone receptor superfamily should be performed as well, followed by in vivo screenings, evaluating the compound's and its metabolites EA in living organisms. ${ }^{17,119}$

Moreover, computational modelling (i.e., in silico) is an emerging method to predict compounds' toxicity. Herein, 

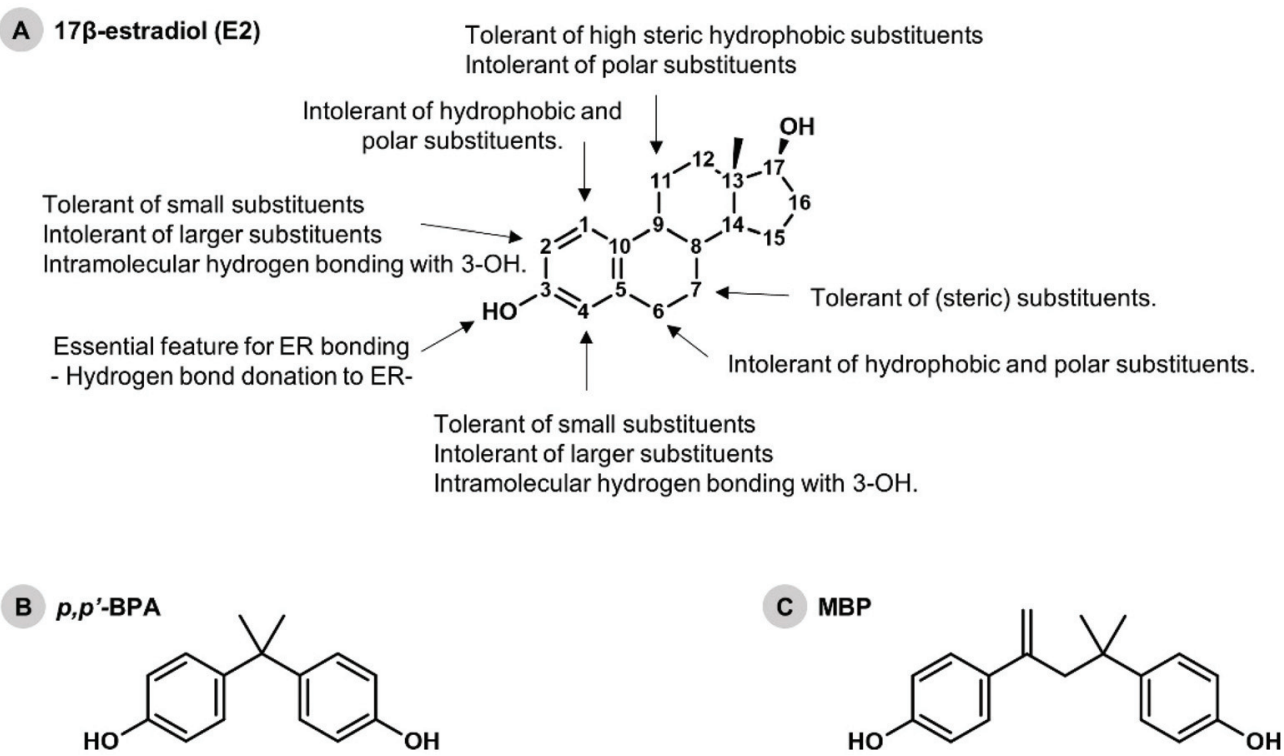

Fig. 13 Molecular structure of $17 \beta$-oestradiol, BPA and MBP. Representation of the molecular structure of (A) 17 $\beta$-Oestradiol (E2), (B) $p, p^{\prime}-\mathrm{BPA}$ and (C) MBP. In addition, an overview of structural modifications (in)tolerated by the $\alpha$-estrogen receptor (ER- $\alpha$ ) based on ref. Anstead et al. (1997). ${ }^{118}$

molecular docking software is used to compute the nuclear receptor binding affinity for multiple nuclear receptors (e.g., the oestrogenic receptor ER $\alpha) .{ }^{120}$ When correlated to experimental toxicity data (e.g., results of in vitro and/or in vivo experiments) a powerful predictive tool might be developed. ${ }^{121,122}$ Being time, labour and money efficient, it is believed that in silico screenings will become an important predictive feature in future bisphenol design, in particular helpful in preliminary screenings. ${ }^{123}$ However, there are still disadvantages (e.g., insufficient data, complex mechanism) ${ }^{123}$ impacting the accuracy of in silico results and the structure-toxicity relationships derived thereof. ${ }^{121}$ Hence, while recognizing the importance and complementary value of in silico, in vitro and in vivo data, only in vitro assays are discussed in this study.

Screening of the EA by in vitro oestrogen receptor transactivation assays induces a dose-dependent signal upon interaction of a compound with the oestrogen receptor at varying concentrations. Literature data are discussed in terms of potency and efficacy. Potency is mostly expressed by the halfmaximal effective concentration $\left(\mathrm{EC}_{50}\right)$. Accordingly, the higher the $\mathrm{EC}_{50}$, the lower the potency of the compound. Efficacy is the maximum effect induced for a given compound, and mostly expressed as $E_{\max }$ relative to the E2 reference. For in vitro oestrogen receptor binding assays, the potency is typically expressed by the half-maximal inhibitory concentration $\left(\mathrm{IC}_{50}\right)$, i.e., the concentration required to displace $50 \%$ of a bound radioligand. This is, mostly, expressed relative to the $\mathrm{IC}_{50}$ concentration of $\mathrm{E} 2$ and defined as the relative binding affinity (RBA).

\subsection{Isomer orientations}

In 2003, Coleman et al. ${ }^{124}$ showed a two-fold lower potency for $o, p^{\prime}$-BPA compared to $p, p^{\prime}$-BPA. ${ }^{124}$ At a test concentration of
$5 \mu \mathrm{M}$ (in terms of efficacy) Szafran et al. $(2017)^{125}$ found $E_{\max }$ values, of $57 \%$ and $19 \%$ for $p, p^{\prime}$ - and $o, o^{\prime}$-BPA isomers (relative to $\mathrm{E} 2=100 \%$ ), respectively. ${ }^{125}$ Although differences are modest, these results clearly show that bisphenol isomer orientation impacts EA. In this regard, Koelewijn et al. (2019) ${ }^{59}$ screened the EA of the bio-based $p, p^{\prime}$ - (2) and $m, p^{\prime}$-BGF (22) isomers over a broad concentration range (up to the solubility limit, $>100 \mu \mathrm{M}$ ). In this way, a partial dose-response curve was obtained starting at $10 \mu \mathrm{M}$, allowing statistical comparison in terms of potency and efficacy. A quasi-similar potency was reported for the $p, p^{\prime}$ - and $m, p^{\prime}$-isomer, but the latter isomer showed a lower efficacy. This confirms that deviations from the ideal para-oriented position of the aromatic hydroxyl group lowers the EA of bio-based bisphenols; a trend also observed in common bisphenols and E2. ${ }^{59}$

\section{2 ortho-substituents}

The influence of $o$-hydroxy, $o$-methyl or $o$-methoxy A-ring substituents on the ER binding affinity of E2 was examined by Zhu et al. (2006). ${ }^{126}$ In terms of potency, both receptors (i.e., $\mathrm{ER} \alpha$ and ER $\beta$ ) revealed a similar trend of decreasing binding affinity: $o$-hydroxy $>o$-methyl $>o$-methoxy. In particular, the RBAs were shown to be $70 \%, 9 \%$ and $2 \%$ for ER $\alpha$ and $56 \%$, $35 \%$ and $1 \%$ for ER $\beta .^{126}$ For BPA, Kitamura et al. $(2005)^{127}$ showed a lower EA (in terms of potency) for the one $o$-hydroxylated BPA $\left(p, p^{\prime}\right.$-PCA) compared to the tetra-o-methylated BPA $\left(p, p^{\prime}\right.$-BPA-2,6M) and $p, p^{\prime}$-BPA showing $\mathrm{EC}_{50}$ values of $1.8 \mu \mathrm{M}$, $0.73 \mu \mathrm{M}$ and $0.63 \mu \mathrm{M}$, respectively. ${ }^{127}$ Furthermore, it was shown by Coleman et al. $(2003)^{124}$ that unencumbered paraphenols showed the highest EA (in terms of potency). A decrease in EA was reported for $p, p^{\prime}-\mathrm{BPA}-2,6 \mathrm{M}$, indicating that two methyl groups adjacent to the hydroxyl reduce EA. ${ }^{124}$ This was confirmed by Szafran et al. $(2017)^{125}$ investigating the 
efficacy (at $5 \mu \mu \mathrm{M})$ for tetra- $o$-methylated $p, p^{\prime}$-BPF $\left(p, p^{\prime}\right.$ $\mathrm{BPF}-2,6 \mathrm{M})$ and $o$-methoxylated $p, p^{\prime}$-BPF ( $p, p^{\prime}$-BGF (2)), observing little to no EA. $E_{\max }$ values of $2.3 \%$ and $-0.6 \%$ were reported for $p, p^{\prime}$-BPF-2,6M and $p, p^{\prime}$-BGF (2), respectively, compared to $57 \%$ for $p, p^{\prime}$-BPA. ${ }^{125}$ To further investigate the beneficial effect of the $o$-methoxy moieties inhibiting EA in $p, p^{\prime}$-BGF (2), Koelewijn et al. $(2019)^{59}$ determined the EA at concentrations up to $100 \mu \mathrm{M}$ of $p, p^{\prime}$-BGF versus $p, p^{\prime}$-BPF in the same in vitro assay, thereby preserving identical molecular structure except for the o-methoxy moieties. It was shown that the additional $o$-methoxy groups caused a significant drop in EA, reducing the potency with approximately two orders of magnitude and the efficacy with more than $50 \% .{ }^{59}$ More recently, the influence of $o$-methoxy groups on EA was also investigated by Peng et al. (2021). ${ }^{128}$ Although the compounds were only screened up to $1 \mu \mathrm{M}$, the authors reported a lower efficacy for $p, p^{\prime}$-BSF (4) compared to $p, p^{\prime}$ GSF (3). ${ }^{128}$

\subsection{Carbon bridge substituents}

It has been shown that introducing more hydrophobic substituents (e.g., alkyl chains) on the carbon bridge enhances the EA of bisphenols. ${ }^{124,127}$ Similarly, the EA of bisphenols can be lowered by introducing more polar substituents on the carbon bridge. This was shown by Kitamura et al. $(2005)^{127}$ reporting a lower EA for bisphenols with hydrophilic substituents on the carbon bridge (i.e., carboxylic acid, hydroxyl groups). ${ }^{127}$ For example, the bio-based bisphenol, $p, p^{\prime}$-DPA (5), showed a 10-fold lower RBA compared to $p, p^{\prime}$-BPA. ${ }^{129}$

\section{4 meta-, para- aromatic substituents}

In 2006, Zhu et al. ${ }^{126}$ showed that the incorporation of a methyl group meta to the hydroxyl group of the A-ring in E2 (i.e., position 1), decreased the binding affinity with $\operatorname{ER} \alpha$ and ER $\beta$ by about $90 \% .^{126}$ In 2017 , Koelewijn et al. ${ }^{54}$ examined the EA of $p, p^{\prime}-\mathrm{BGF}-5 \mathrm{M}$, for which careful comparison with $p, p^{\prime}-\mathrm{BGF}^{59}$ did not show a further decrease in EA by the meta-methyl substituents. Looking into the EA of the $m, m^{\prime}$ BGF molecules characterised by para-alkyl substituents, a strong reduction in EA was observed with elongation of the 4-alkyl chain. This is reported by a two-fold lower efficacy and 10-100 times lower potency for $m, m^{\prime}$-BGF-4E (29) and $m, m^{\prime}$-BGF-4P (30) compared to $p, p^{\prime}$-BPA. ${ }^{54}$ The same trend was recognized for $m, m^{\prime}$-BSF-4M (31) and $m, m^{\prime}$-BSF-4P (32). Both bio-based bisphenols show, respectively, a 19-45 times lower potency and $45 \%-36 \%$ lower efficacy than $p, p^{\prime}$ BPA. $^{55}$

Hence, it has been shown that some structural features characterising the bio-derived, more particular lignin-derived, phenols (e.g., o-methoxy groups, 4-alkyl chain) lower the oestrogenic activity of the resulting bisphenols significantly. Furthermore, the use of carbonyl reagents with more hydrophilic functional groups might further lower the bio-bisphenol oestrogenic activity.

\section{Conclusion}

During the last decades, extensive research concerning the valorisation of biomass led to a plethora of renewable chemical intermediates, like phenols, aldehydes and ketones, which are interesting alternative substrates for bisphenol chemistry. Accordingly, this innovation transitioned the focus from DPA and DPA-esters to the syntheses of new, more diverse bisphenol structures. In general, the existing bio-bisphenol platform contains 32 bisphenol structures varying in: (i) isomer orientation, (ii) aromatic o-substituents (i.e., hydroxyl, methyl, methoxy), (iii) carbon bridge substituents, and (iv) aromatic $m$ or $p$-substituents (i.e., alkyl). Assessing the impact of these four structural features on polymer performance and oestrogenic activity, it was shown that:

Bio-bisphenols made from lignin-derived phenols led to new $m, m^{\prime}$ - and $m, p^{\prime}$-isomer orientations as well as conventional $o, o^{\prime}$, $o, p^{\prime}$ and $p, p^{\prime}$-isomer orientations. $m, p^{\prime}$-Isomers are as reactive and functional as $p, p^{\prime}$-isomers, yielding polymers with similar polymer properties. However, the bio-bisphenol isomer orientation clearly influences the melting point, viscosity and crosslink density of corresponding epoxy and cyanate ester resins, thereby impacting the processability and thermomechanical properties of the thermosets. For the different bisphenol isomer orientations, it was shown that the oestrogenic activity of $o, p^{\prime}-$, $o, o^{\prime}$ - and $m, p^{\prime}$-isomers is lower compared to the $p, p^{\prime}$-isomers.

The $o$-substituents in bio-bisphenols not only strikingly affected the polymer properties but also the oestrogenic activity. When $o$-hydroxylated bisphenols (i.e., catechol-based) were used to synthesize epoxy resins, a benzodioxane diepoxide by-product was acquired in addition to the tetraepoxide. The benzodioxane by-product includes a free hydroxyl group, catalysing the amine-epoxide curing reaction. Thus, even with high concentrations of this by-product, highly crosslinked epoxy resins with excellent thermomechanical properties were obtained. Use of $o$-methylated bisphenols (i.e., $o$-cresol based) showed enhancement of the hydrolytic stability of cyanate ester resins, significantly lowering the water uptake and constraining the wet $T_{\mathrm{g}}$ knockdown. In general, $o$-methoxy moieties in the DPM core structure (i.e., guaiacol-, syringolbased), moderately, lowered the polymers $T_{\mathrm{g}}$ and thermal stability and increased the resins melting point. For the epoxy resins a beneficial impact on the storage modulus was reported and attributed to hydrogen bonding interactions. Regarding the endocrine disrupting character, a free hydroxyl group was reported as the key structural feature for oestrogenic activity. Hence, $o$-substituents and, moreover, $o$-substituents which induce intramolecular hydrogen bonding, showed to significantly decrease the bisphenol's oestrogenic activity. The most remarkable impact was shown for $o$-methoxylated bisphenols, typical phenolics derived from lignin. Additional $o$-methoxy groups cause a serious drop in the oestrogenic activity, reducing the potency by about two orders of magnitude and the efficacy with more than $50 \%$.

Embedding steric, aromatic and/or polar substituents on the carbon bridge showed an efficient way to enhance the ther- 
momechanical polymer properties, however, the impact differs for each polymer type. In general, imparting rigidity (e.g., the isopropylidene bridge), intermolecular hydrogen bonding (e.g., free hydroxyl groups) and reactive functional groups (e.g., furan groups, carboxyl groups) increased the polymer's glass transition temperature, storage modulus and thermal stability. For the benzoxazine resins, bio-based thermosets could even surpass the fossil-based thermoset references, showing higher $T_{\mathrm{g}}$ 's and thermal stability. Concerning oestrogenic activity, it was shown that hydrophobic substituents increase the bisphenol oestrogenic activity. Hence, the incorporation of more polar, hydrophilic substituents on the carbon bridge is most preferred in light of lowering the oestrogenic activity.

Adding para-alkyl (i.e., 4-alkyl) moieties to the DPM core structure, a typical structure moiety of phenolics derived from lignin, seemed to lower the bisphenol's melting point, as well as the tendency to crystallize in polycarbonates, upon elongation of the 4-alkyl chain. Although moderately lowering the thermal stability, the incorporation of alkyl groups increased the overall hydrophobicity of the resins, enhancing the hydrolytic stability of cyanate ester resins. Moreover, it was shown that the oestrogenic activity decreased upon elongation of the 4-alkyl chains.

Noteworthy, while compiling this systematic review, it was found that the main factor impeding the extraction of clear structure-property and structure-toxicity relationships until now, has been the lack of a consistent analysis, parameter definition and reporting. To provide more qualitative relationships and create more insight for future rational bio-bisphenol design, it is encouraged to include the following in future research presenting new safer BPA-alternatives. Firstly, a full monomer characterisation (i.e., bio-bisphenols and/or thermoset monomers) including: the phase at RT, colour, purity, viscosity, melting point and crystal structure. Secondly, a preliminary screening of endocrine activity, for example in vitro oestrogen receptor transactivation assays using compound concentrations up to the solubility limit, providing quantitative data and allowing statistical comparison between bio-bisphenol structures. Thirdly, a full polymer characterisation including: (i) the molar mass distribution, i.e., $\bar{M}_{w}$ and $\emptyset$-for the thermoplastic polymers- and the degree of cure and cross-link density (e.g., via the rubber elasticity theory) -for the thermosetting polymers-, (ii) general polymer characteristics (e.g., $T_{\mathrm{g}}$ and thermal stability) and (iii) specific polymer characteristics (e.g, crystallinity, solubility, water uptake). Moreover, incorporation of relevant bisphenol reference samples, which show a comparable monomer purity (e.g., wt $\%$, EEW, $n$ ), molar mass distribution (i.e., $\bar{M}_{w}, Ð$ ), degree of cure and/or cross-linking density (e.g., via the rubber elasticity theory), would facilitate the evaluation of the bio-bisphenol's functionality.

To conclude, this review assembled structure-property and structure-toxicity relations from the literature data to assess today's bio-based bisphenol platform and provide more insight for future rational bisphenol design towards safe, renewable and functional BPA alternatives. Hereby, highlighting the importance of a multidisciplinary approach in the design of new bisphenols providing, in addition to performance evaluation, a preliminary screening of potential hazards, such as for instance the oestrogenic activity.

\section{Author contributions}

B. S. and L. T. wrote this article with the aid of S. F. K., I. S., T. H. and P. V. P., reviewing and approving this paper.

\section{Conflicts of interest}

There are no conflicts of interest to declare.

\section{Acknowledgements}

This work was written in the framework of a project funded by the KULeuven industrial research fund (L. T. and S. F. K.) and financially supported by the Flanders Innovation \& Entrepreneurship cluster Catalisti, cSBO project - PADDLE (I. S. and T. H.).

\section{Notes and references}

1 H. Fiege, H.-W. Voges, T. Hamamoto, S. Umemura, T. Iwata, H. Miki, Y. Fujita, H.-J. Buysch, D. Garbe and W. Paulus, in Ullmann's Encyclopedia of Industrial Chemistry, Wiley-VCH Verlag GmbH \& Co. KGaA, American Cancer Society, Weinheim, Germany, 2000, pp. 559-563.

2 P. Czub, in Handbook of Engineering and Speciality Thermoplastics, ed. Sabu Thomas and P. M. Visakh, John Wiley \& Sons, Inc., Hoboken, NJ, USA, 2011, pp. 221-270.

3 H. Q. Pham and M. J. Marks, in Ullmann's Encyclopedia of Industrial Chemistry, Wiley-VCH Verlag GmbH \& Co. KGaA, American Cancer Society, Weinheim, Germany, 2005, pp. 156-238.

4 Global Bisphenol A Industry, https://www.reportlinker. com/p05818026/Global-Bisphenol-A-Industry.html?utm_ source $=\mathrm{GNW}$, (accessed June 10, 2021).

5 J.-H. Kang, K. Kito and F. Kondo, J. Food Prot., 2003, 66, 1444-1447.

6 C. Brede, P. Fjeldal, I. Skjevrak and H. Herikstad, Food Addit. Contam., 2003, 20, 684-689.

7 J. N. Hahladakis, C. A. Velis, R. Weber, E. Iacovidou and P. Purnell, J. Hazard. Mater., 2018, 344, 179-199.

8 J. Corrales, L. A. Kristofco, W. B. Steele, B. S. Yates, C. S. Breed, E. S. Williams and B. W. Brooks, DoseResponse, 2015, 13, 1-29.

9 L. N. Vandenberg, R. Hauser, M. Marcus, N. Olea and W. V. Welshons, Reprod. Toxicol., 2007, 24, 139-177.

10 F. S. vom Saal and L. N. Vandenberg, Endocrinology, 2021, 162, bqaa171. 
11 A. M. Soto, L. N. Vandenberg, M. V. Maffini and C. Sonnenschein, Basic Clin. Pharmacol., 2008, 102, 125133.

12 G. S. Prins, W.-Y. Hu, L. Xie, G.-B. Shi, D.-P. Hu, L. Birch and M. C. Bosland, Environ. Health Perspect., 2018, 126, 117001.

13 N. J. Cabaton, P. R. Wadia, B. S. Rubin, D. Zalko, C. M. Schaeberle, M. H. Askenase, J. L. Gadbois, A. P. Tharp, G. S. Whitt, C. Sonnenschein and A. M. Soto, Environ. Health Perspect., 2011, 119, 547-552.

14 F. Pallotti, M. Pelloni, D. Gianfrilli, A. Lenzi, F. Lombardo and D. Paoli, J. Clin. Med., 2020, 9, 471.

15 J. J. Heindel, R. Newbold and T. T. Schug, Nat. Rev. Endocrinol., 2015, 11, 653-661.

16 4,4'-Isopropylidenediphenol - Substance Information ECHA, https:/echa.europa.eu/nl/substance-information/-/ substanceinfo/100.001.133, (accessed June 10, 2021).

17 J. J. Heindel, S. Belcher, J. A. Flaws, G. S. Prins, S.-M. Ho, J. Mao, H. B. Patisaul, W. Ricke, C. S. Rosenfeld, A. M. Soto, F. S. vom Saal and R. T. Zoeller, Reprod. Toxicol., 2020, 98, 29-60.

18 L. N. Vandenberg, P. A. Hunt and A. C. Gore, Nat. Rev. Endocrinol., 2019, 15, 366-374.

19 S. Eladak, T. Grisin, D. Moison, M.-J. Guerquin, T. N’TumbaByn, S. Pozzi-Gaudin, A. Benachi, G. Livera, V. Rouiller-Fabre and R. Habert, Fertil. Steril., 2015, 103, 11-21.

20 E. Schirmer, S. Schuster and P. Machnik, Commun. Biol., 2021, 4, 465.

21 J. B. Zimmerman and P. T. Anastas, Science, 2015, 347, 1198-1199.

22 A. Maertens, E. Golden and T. Hartung, ACS Sustainable Chem. Eng., 2021, 9, 7749-7758.

23 Y. Geng, J. Sarkis and R. Bleischwitz, Nature, 2019, 565, 153-155.

24 Directorate-General for Research and Innovation (European Commission), A sustainable bioeconomy for Europe: strengthening the connection between economy, society and the environment: updated bioeconomy strategy, Publications Office of the European Union, Luxembourg, 2018.

25 The Bio-based Industries Consortium | Bio-Based Industries Consortium, https://biconsortium.eu/, (accessed June 11, 2021).

26 The Ellen MacArthur Foundation's Mission, https://www. ellenmacarthurfoundation.org/our-story/mission, (accessed June 11, 2021).

27 J. Spekreijse, T. Lammens, C. Parisi, T. Ronzon and M. Vis, Insights into the European market for bio-based chemicals. Analysis based on ten key product categories, Publications Office of the European Union, Luxembourg, 2019.

28 Y. Liao, S.-F. Koelewijn, G. Van den Bossche, J. Van Aelst, S. Van den Bosch, T. Renders, K. Navare, T. Nicolaï, K. Van Aelst, M. Maesen, H. Matsushima, J. M. Thevelein, K. Van Acker, B. Lagrain, D. Verboekend and B. F. Sels, Science, 2020, 367, 1385-1390.
29 W. Schutyser, T. Renders, S. V. den Bosch, S.-F. Koelewijn, G. T. Beckham and B. F. Sels, Chem. Soc. Rev., 2018, 47, 852-908.

30 Z. Sun, B. Fridrich, A. de Santi, S. Elangovan and K. Barta, Chem. Rev., 2018, 118, 614-678.

31 M. M. Abu-Omar, K. Barta, G. T. Beckham, J. S. Luterbacher, J. Ralph, R. Rinaldi, Y. Román-Leshkov, J. S. M. Samec, B. F. Sels and F. Wang, Energy Environ. Sci., 2021, 14, 262-292.

32 E. M. Anderson, M. L. Stone, M. J. Hülsey, G. T. Beckham and Y. Román-Leshkov, ACS Sustainable Chem. Eng., 2018, 6, 7951-7959.

33 Z. Sun and K. Barta, Chem. Commun., 2018, 54, 77257745 .

34 M. V. Galkin and J. S. M. Samec, ChemSusChem, 2016, 9, 1544-1558.

35 Y. M. Questell-Santiago, M. V. Galkin, K. Barta and J. S. Luterbacher, Nat. Rev. Chem., 2020, 4, 311-330.

36 P. T. Anastas, Trends Chem., 2019, 1, 145-148.

37 R. Bruckner, Organic mechanisms: reactions, stereochemistry and synthesis, Springer, 2010.

38 G. D. Yadav and N. Kirthivasan, Appl. Catal., A, 1997, 154, 29-53.

39 J. I. de Jong and F. H. D. Dethmers, Recl. Trav. Chim. PaysBas, 1965, 84, 460-464.

40 A. Gardziella, L. A. Pilato and A. Knop, Phenolic Resins: Chemistry, Applications, Standardization, Safety and Ecology, Springer Science \& Business Media, 2013.

41 S. Jana, Appl. Catal., A, 2004, 266, 245-250.

42 Phenolic Resins: A Century of Progress, ed. L. Pilato, Springer Berlin Heidelberg, Berlin, Heidelberg, 2010.

43 J. J. Bozell, L. Moens, D. C. Elliott, Y. Wang, G. G. Neuenscwander, S. W. Fitzpatrick, R. J. Bilski and J. L. Jarnefeld, Resour., Conserv. Recycl., 2000, 28, 227-239.

44 S. Van de Vyver, S. Helsen, J. Geboers, F. Yu, J. Thomas, M. Smet, W. Dehaen, Y. Román-Leshkov, I. Hermans and B. F. Sels, ACS Catal., 2012, 2, 2700-2704.

45 A. Kumar, D. Z. Shende and K. L. Wasewar, Mater. Today: Proc., 2020, 29, 790-793.

46 R. P. Fischer, G. Robert Hartranft and J. S. Heckles, J. Appl. Polym. Sci., 1966, 10, 245-252.

47 H. Yan, C. Sun, Z. Fang, X. Liu, J. Zhu and H. Wang, Polymer, 2016, 97, 418-427.

48 A. Maiorana, S. Spinella and R. A. Gross, Biomacromolecules, 2015, 16, 1021-1031.

49 J. A. Moore and T. Tannahill, High Perform. Polym., 2001, 13, S305-S316.

50 B. G. Harvey, A. J. Guenthner, T. A. Koontz, P. J. Storch, J. T. Reams and T. J. Groshens, Green Chem., 2016, 18, 2416-2423.

51 R. Yang, M. Han, B. Hao and K. Zhang, Eur. Polym. J., 2020, 131, 109706.

52 Y. Jiang, D. Ding, S. Zhao, H. Zhu, H. I. Kenttämaa and M. M. Abu-Omar, Green Chem., 2018, 20, 1131-1138.

53 H. A. Meylemans, T. J. Groshens and B. G. Harvey, ChemSusChem, 2012, 5, 206-210. 
54 S.-F. Koelewijn, S. Van den Bosch, T. Renders, W. Schutyser, B. Lagrain, M. Smet, J. Thomas, W. Dehaen, P. Van Puyvelde, H. Witters and B. F. Sels, Green Chem., 2017, 19, 2561-2570.

55 S.-F. Koelewijn, C. Cooreman, T. Renders, C. Andecochea Saiz, S. Van den Bosch, W. Schutyser, W. De Leger, M. Smet, P. Van Puyvelde, H. Witters, B. Van der Bruggen and B. F. Sels, Green Chem., 2018, 20, 1050-1058.

56 B. G. Harvey, A. J. Guenthner, W. W. Lai, H. A. Meylemans, M. C. Davis, L. R. Cambrea, J. T. Reams and K. R. Lamison, Macromolecules, 2015, 48, 3173-3179.

57 S. Zhao and M. M. Abu-Omar, ACS Sustainable Chem. Eng., 2016, 4, 6082-6089.

58 E. D. Hernandez, A. W. Bassett, J. M. Sadler, J. J. La Scala and J. F. Stanzione, ACS Sustainable Chem. Eng., 2016, 4, 4328-4339.

59 S.-F. Koelewijn, D. Ruijten, L. Trullemans, T. Renders, P. Van Puyvelde, H. Witters and B. F. Sels, Green Chem., 2019, 21, 6622-6633.

60 K. H. Nicastro, C. J. Kloxin and T. H. Epps, ACS Sustainable Chem. Eng., 2018, 6, 14812-14819.

61 S. Zhao and M. M. Abu-Omar, Macromolecules, 2019, 52, 3646-3654.

62 T. Periyasamy, S. P. Asrafali, S. Muthusamy and S.-C. Kim, New J. Chem., 2016, 40, 9313-9319.

63 T. Sakakura, J.-C. Choi and H. Yasuda, Chem. Rev., 2007, 107, 2365-2387.

64 Q. Dong, C. Gao, Y. Ding, F. Wang, B. Wen, S. Zhang, T. Wang and M. Yang, J. Appl. Polym. Sci., 2012, 123, 10851093.

65 B. N. Jang and C. A. Wilkie, Polym. Degrad. Stab., 2004, 86, 419-430.

66 Polymers - Opportunities and Risks I, ed. P. Eyerer, Springer Berlin Heidelberg, Berlin, Heidelberg, 2010, vol. 11.

67 V. Goodship, ARBURG Practical Guide to Injection Moulding, Smithers Rapra, 2017.

68 G. Abts, T. Eckel and R. Wehrmann, in Ullmann's Encyclopedia of Industrial Chemistry, Wiley-VCH Verlag $\mathrm{GmbH} \&$ Co. KGaA, American Cancer Society, Weinheim, Germany, 2014, pp. 1-18.

69 Y. Lin, E. Bilotti, C. W. M. Bastiaansen and T. Peijs, Polym. Eng. Sci., 2020, 60, 2351-2376.

70 A. Alizadeh, S. Sohn, J. Quinn, H. Marand, L. C. Shank and H. D. Iler, Macromolecules, 2001, 34, 4066-4078.

71 G. A. Adam, J. N. Hay, I. W. Parsons and R. N. Haward, Polymer, 1976, 17, 51-57.

72 A. F. Yee and S. A. Smith, Macromolecules, 1981, 14, 5564.

73 Q. Chen, W. Huang, P. Chen, C. Peng, H. Xie, Z. K. Zhao, M. Sohail and M. Bao, ChemCatChem, 2015, 7, 1083-1089.

74 R. Zhang and J. A. Moore, Macromol. Symp., 2003, 199, 375-390.

75 S. Fukuoka, M. Kawamura, K. Komiya, M. Tojo, H. Hachiya, K. Hasegawa, M. Aminaka, H. Okamoto, I. Fukawa and S. Konno, Green Chem., 2003, 5, 497-507.

76 G. Bier, Polymer, 1974, 15, 527-535.
77 High Performance Polymers: Their Origin and Development, ed. R. B. Seymour and G. S. Kirshenbaum, Springer Netherlands, Dordrecht, 1986.

78 S. Curia, A. Biundo, I. Fischer, V. Braunschmid, G. M. Gübitz and J. F. Stanzione, ChemSusChem, 2018, 11, 2529-2539.

79 Z. Ping, W. Linbo and L. Bo-Geng, Polym. Degrad. Stab., 2009, 94, 1261-1266.

80 P. Liu, L. Zeng, G. Ye and J. Xu, J. Polym. Res., 2013, 20, 279.

81 U. K. Kharul, S. S. Kulkarni, M. G. Kulkarni, A. Y. Houde, S. G. Charati and S. G. Joshi, Polymer, 1998, 39, 20112022.

82 L. A. Pessan and W. J. Koros, J. Polym. Sci., Part B: Polym. Phys., 1993, 31, 1245-1252.

83 S.-H. Hsiao and H.-W. Chiang, Eur. Polym. J., 2004, 40, 1691-1697.

84 V. V. Korshak, I. F. Manucharova, S. V. Vinogradova and V. A. Pankratov, Polym. Sci., 1965, 7, 1996-2001.

85 P. Zhang, L. Wu, Z. Bu and B.-G. Li, J. Appl. Polym. Sci., 2008, 108, 3586-3592.

86 S. G. Charati, R. Vetrivel, M. G. Kulkarni and S. S. Kulkarni, Macromolecules, 1992, 25, 2215-2220.

87 M. Gomes, A. Gandini, A. J. D. Silvestre and B. Reis, J. Polym. Sci., Part A: Polym. Chem., 2011, 49, 37593768.

88 A. Gandini, Polym. Chem., 2010, 1, 245-251.

89 R. Auvergne, S. Caillol, G. David, B. Boutevin and J.-P. Pascault, Chem. Rev., 2014, 114, 1082-1115.

90 H. Cai, P. Li, G. Sui, Y. Yu, G. Li, X. Yang and S. Ryu, Thermochim. Acta, 2008, 101-105.

91 J. M. G. Cowie and V. Arrighi, Polymers: Chemistry and Physics of Modern Materials, CRC Press, Taylor \& Francis group, NW, United states of America, 3rd edn, 2007.

92 M. Kasperkowiak, M. Beszterda, I. Bańczyk and R. Frański, Anal. Bioanal. Chem., 2021, 413, 1893-1903.

93 M. Zhong, R. Wang, K. Kawamoto, B. D. Olsen and J. A. Johnson, Science, 2016, 353, 1264-1268.

94 A. Beste and A. C. Buchanan, J. Org. Chem., 2009, 74, 2837-2841.

95 F. G. Garcia, B. G. Soares, V. J. R. R. Pita, R. Sánchez and J. Rieumont, J. Appl. Polym. Sci., 2007, 106, 2047-2055.

96 J. Hong, D. Radojčić, M. Ionescu, Z. S. Petrović and E. Eastwood, Polym. Chem., 2014, 5, 5360-5368.

97 D. Montarnal, M. Capelot, F. Tournilhac and L. Leibler, Science, 2011, 334, 965-968.

98 B. M. Bell, J. R. Briggs, R. M. Campbell, S. M. Chambers, P. D. Gaarenstroom, J. G. Hippler, B. D. Hook, K. Kearns, J. M. Kenney, W. J. Kruper, D. J. Schreck, C. N. Theriault and C. P. Wolfe, Clean, 2008, 36, 657-661.

99 Solvay Epicerol ${ }^{\circledR}$ Earns Roundtable on Sustainable Biomaterials Certification, https:/www.solvay.com/en/ press-release/solvay-epicerol-earns-roundtable-sustainablebiomaterials-certification, (accessed June 3, 2021).

100 E. A. Baroncini, S. Kumar Yadav, G. R. Palmese and J. F. Stanzione, J. Appl. Polym. Sci., 2016, 133, 44301. 
101 T. Fang and D. Shimp, Prog. Polym. Sci., 1995, 20, 61118.

102 M. C. Davis, A. J. Guenthner, T. J. Groshens, J. T. Reams and J. M. Mabry, J. Polym. Sci., Part A: Polym. Chem., 2012, 50, 4127-4136.

103 A. J. Guenthner, M. E. Wright, A. P. Chafin, J. T. Reams, K. R. Lamison, M. D. Ford, S. P. J. Kirby, J. J. Zavala and J. M. Mabry, Macromolecules, 2014, 47, 7691-7700.

104 Chemistry and Technology of Cyanate Ester Resins, ed. I. Hamerton, Springer Netherlands, Dordrecht, 1994.

105 V. V. Marella, J. A. Throckmorton and G. R. Palmese, Polym. Degrad. Stab., 2014, 104, 104-111.

106 L. J. Kasehagen, I. Haury, C. W. Macosko and D. A. Shimp, J. Appl. Polym. Sci., 1997, 64, 107-113.

107 H. A. Meylemans, B. G. Harvey, J. T. Reams, A. J. Guenthner, L. R. Cambrea, T. J. Groshens, L. C. Baldwin, M. D. Garrison and J. M. Mabry, Biomacromolecules, 2013, 14, 771-780.

108 X. Ning and H. Ishida, J. Polym. Sci., Part A: Polym. Chem., 1994, 32, 1121-1129.

109 M. Manoj, A. Kumaravel, R. Mangalam, P. Prabunathan, A. Hariharan and M. Alagar, J. Coat. Technol. Res., 2020, 17, 921-935.

110 C. Nair, Prog. Polym. Sci., 2004, 29, 401-498.

111 D. W. van Krevelen, Polymer, 1975, 16, 615-620.

112 Y.-L. Liu and C.-I. Chou, J. Polym. Sci., Part A: Polym. Chem., 2005, 43, 5267-5282.

113 Z. Zhan, H. Yan, P. Yin, J. Cheng and Z. Fang, Polym. Int., 2020, 69, 355-362.

114 C. Zúñiga, M. S. Larrechi, G. Lligadas, J. C. Ronda, M. Galià and V. Cádiz, J. Polym. Sci., Part A: Polym. Chem., 2011, 49, 1219-1227.

115 N. Ben-Jonathan and R. Steinmetz, Trends Endocrinol. Metab., 1998, 9, 124-128.
116 M. E. Baker and C. Chandsawangbhuwana, PLoS One, 2012, 7, e46078.

117 T. T. Schug, R. Abagyan, B. Blumberg, T. J. Collins, D. Crews, P. L. DeFur, S. M. Dickerson, T. M. Edwards, A. C. Gore, L. J. Guillette, T. Hayes, J. J. Heindel, A. Moores, H. B. Patisaul, T. L. Tal, K. A. Thayer, L. N. Vandenberg, J. C. Warner, C. S. Watson, F. S. vom Saal, R. T. Zoeller, K. P. O'Brien and J. P. Myers, Green Chem., 2012, 15, 181-198.

118 G. M. Anstead, K. E. Carlson and J. A. Katzenellenbogen, Steroids, 1997, 62, 268-303.

119 M. V. Maffini and R. D. Canatsey, Food Chem. Toxicol., 2020, 135, 110889.

120 O. Conroy-Ben, I. Garcia and S. S. Teske, Environ. Technol., 2018, 33, 569-578.

121 H. Hong, B. G. Harvey, G. R. Palmese, J. F. Stanzione, H. Wen Ng, S. Sakkiah, W. Tong and J. M. Sadler, Int. J. Environ. Res. Public Health, 2016, 13, 705.

122 A. Amitrano, J. S. Mahajan, L. T. J. Korley and T. H. Epps, RSC Adv., 2021, 11, 22149-22158.

123 S. Sharma, S. Ahmad, M. F. Khan, S. Parvez and S. Raisuddin, Toxicol. Mech. Methods, 2018, 28, 660-669.

124 K. Coleman, W. Toscano and T. Wiese, QSAR Comb. Sci., 2003, 22, 78-88.

125 A. T. Szafran, F. Stossi, M. G. Mancini, C. L. Walker and M. A. Mancini, PLoS One, 2017, 12, e0180141.

126 B. T. Zhu, G.-Z. Han, J.-Y. Shim, Y. Wen and X.-R. Jiang, Endocrinology, 2006, 147, 4132-4150.

127 S. Kitamura, Toxicol. Sci., 2005, 84, 249-259.

128 Y. Peng, K. H. Nicastro, T. H. Epps III and C. Wu, Food Chem., 2021, 338, 127656.

129 R. M. Blair, Toxicol. Sci., 2000, 54, 138-153.

130 C. Gioia, M. Vannini, A. Celli, M. Colonna and A. Minesso, $R S C$ Adv. , 2016, 6, 31462-31469. 